\title{
Further Extending the Dilution Range of the "water-in-DES" Regime upon the Replacement of Water by an Organic Solvent with Hydrogen Bond Capabilities 10.1021/acssuschemeng.0c03516
}

N. López-Salas, ${ }^{a,}{ }^{*}$ J. M. Vicent-Luna, ${ }^{b}$ E. Posada, ${ }^{a}$ S. Imberti, ${ }^{c}$ R. M. Madero Castro, ${ }^{b}$ S. Calero, ${ }^{b}$ C. O. Ania, ${ }^{d}$ R. J. Jiménez-Riobóo, ${ }^{a}$ M. C. Gutiérrez, ${ }^{a}$ M. L. Ferrer, ${ }^{a}$ and F. del Monte ${ }^{a, *}$

a Instituto de Ciencia de Materiales de Madrid-ICMM, Consejo Superior de Investigaciones CientíficasCSIC. Campus de Cantoblanco, 28049-Madrid (Spain) E-mail: delmonte@icmm.csic.es / marialasnieves.lopez@gmail.com

${ }^{\mathrm{b}}$ Department of Physical, Chemical, and Natural Systems, Universidad Pablo de Olavide, Ctra. Utrera km. 1, ES-41013 Seville, Spain

c STFC, Rutherford Appleton Laboratory, Didcot, UK

${ }^{d}$ CNRS-CEMHTI, Orléans, France

Keywords: deep eutectic solvents; DESs dilutions; binary liquid mixtures; H-bond complexes; neutron scattering; ${ }^{1} \mathrm{H}$ NMR spectroscopy; Brillouin spectroscopy; local structure rearrangements 


\begin{abstract}
Aqueous dilutions of deep eutectic solvents (DESs) have lately allowed exploring new and more demanding applications where neat DESs are not capable to perform well. However, the use of DES dilutions with non-aqueous $\mathrm{H}$-bond-forming solvents remains basically unexplored. It is worth noting the obvious interest of using organic solvents in those cases where any reagent or by-product is non-soluble, non-miscible or unstable in water, the presence of water might alter the reaction kinetics (for instance, when water is a by-product), or a co-solvent with low vapour pressure allows exploring reaction processes (high temperatures or solvothermal conditions, among others) not suitable for water. Herein, we investigated benzyl alcohol (BA) dilutions of DES composed of resorcinol (R), urea $(U)$ and choline chloride $(\mathrm{ChCl})$. In particular, neutron scattering, nuclear magnetic resonance and Brillouin experiments revealed how BA was accommodated within the $\mathrm{H}$-bond complex structure of the original DES for BA contents of up to $67 \mathrm{wt} \%$ whereas this $\mathrm{H}$-bond complex structure basically disappeared for higher BA contents. This behaviour somehow resembled that found in aqueous solutions, with two well differentiated regimes - e.g., the "solvent-in-DES" and the "DES-in-solvent" - depending on the DES content. However, the "solvent-in-DES" regime was preserved for much higher solvent contents of $B A$ than $\mathrm{H}_{2} \mathrm{O}-$ e.g., 60-65 versus 18-20 wt\%, respectively. Interestingly, the specific BA dilution where transition from one regime to the other occurs was particularly well suited to develop a spinodal decomposition process when used as the precursor for the preparation of polymer resins (by polycondensation between resorcinol and para-phthalaldehyde).
\end{abstract}




\section{Introduction}

With increasing pressure to improve the eco-friendly features of many chemical processes, the design (and use) of more sustainable solvents is by no means trivial. Within this context, deep eutectic solvents $(\mathrm{DESs})^{1}$ gained particular relevance as they share some interesting properties with ionic liquids (ILS) ${ }^{2}$ - e.g., low flammability, stability against air and moisture, excellent solvation potential, chemical and thermal stability, high heat capacity, density and conductivity, and low vapour pressure - whose negative environmental impact has been lately a matter of concern.

DESs are obtained by combination between a hydrogen-bond donor (HBD) and a hydrogen-bond acceptor (HBA) in a proper molar ratio., ${ }^{3,5}$ With the aim of obtaining even less-toxic and more biodegradable DESs, König's and Kroon's groups promoted the design of eutectic mixtures using either sugars ${ }^{6,7}$ or natural organic acids, ${ }^{8,9}$ whereas Choi et al. described the so-called NADESs (natural DESs) ${ }^{10}$ containing sugars, natural organic acids and/or amino acids as $\mathrm{HBDs}$ and $\mathrm{ChCl}$ (an essential nutrient extracted from biomass and often regarded as a part of the B-complex vitamins ${ }^{11}$ ) as the HBA. NADESs further improved the environmental sustainability of regular DESs, opening the path to their use in the field of green chemistry and sustainable processes. $^{12}$

It is worth noting that $\mathrm{H}$-bonds governing components interactions in most of these eutectic mixtures make them quite compatible with water. Thus, further improvement of the greenness aspects of DESs and NADESs has been achieved by dilution with water. In this regard, water addition allows decreasing the typically high viscosity of DESs/NADESs. ${ }^{13,14,15,16}$ It is worth noting that high viscosities are a serious drawback that, in many cases, has limited the ultimate performance of DESs/NADESs. ${ }^{17,18}$ Nonetheless, attention to the dilution range has to be paid so that $\mathrm{H}$-bond complexes between DES/NADES components are yet preserved, this is, within the "water-in-DES" regime. Otherwise, at pseudo-high dilutions in the so-called DES-inwater regime, a simple dilution of the individual DES/NADES components would be obtained. ${ }^{19,20,21,22,23}$

While mixing water in controlled amounts - e.g., within the so-called water-inDES regime ${ }^{24}$ - has been widely accepted as a simple and practical way of altering DES 
chemical and thermodynamic properties (with viscosity and conductivity exhibiting an exponential evolution along with water content), ${ }^{14,19,25,26,27,28,29,30,31}$ the study of DES dilutions with non-aqueous $\mathrm{H}$-bond-forming solvents remains basically unexplored. It is worth noting the obvious interest of using organic solvents in those cases where any reagent or by-product is non-soluble, non-miscible or unstable in water, $^{32,33,34,35,36}$ the presence of water might alter the reaction kinetics (for instance, when water is a by-product), 37, 38, 39, 40,41, 42 or a co-solvent with low vapour pressure allows exploring reaction processes (high temperatures or solvothermal conditions, among others) not suitable for water. ${ }^{43,44,45}$

Herein, we investigated the dilution with benzyl alcohol (BA) of a ternary DESs composed of resorcinol and urea ( $R$ and $U$, respectively, as the HBDs) and choline chloride $(\mathrm{ChCl}$, as the $\mathrm{HBA})$ in a 3:2:1 molar ratio. DES dilutions with different $\mathrm{BA}$ contents were named as RUChClnBA, with $n$ being moles of BA per mole of DES in the different samples. Brillouin and ${ }^{1} \mathrm{H}$ NMR spectroscopies, neutron scattering with isotopic substitution together with empirical potential structure refinement (NDISEPSR), and molecular dynamic (MD) simulations were used to study both the neat form of $\mathrm{RUChCl}$ and the different $\mathrm{BA}$ dilutions. $\mathrm{RUChCl}$ and aqueous dilutions thereof have been recently studied by similar means thus providing an interesting background for the discussion of the results obtained in this work. ${ }^{46}$ In this case, BA was chosen because of its natural occurrence (produced naturally by many plants and commonly found in fruits and teas, as well as in a variety of essential oils) and low acute toxicity (the median lethal dose, $L_{50}$, is $1.2 \mathrm{~g} / \mathrm{kg}$ in rats). Moreover, the aromatic nature, the polarity (the dipole moment is $1.67 \mathrm{D}$ ) and the low vapor pressure $\left(0.18 \mathrm{kPa}\right.$ at $60{ }^{\circ} \mathrm{C}$ ) of BA provide this solvent some capabilities not provided by water. ${ }^{47,48}$ Finally, we explored the suitability of RUChClnBA to obtain polymeric resins by polycondensation of $\mathrm{R}$ with para-phthalaldehyde (pPA, benzene-1,4-dicarboxaldehyde) as an alternative to DES-assisted polycondensations carried out in aqueous dilutions. ${ }^{49,50,51,52,53,54,55}$

\section{Results and Discussion}

We first studied RUChClOBA, RUChCl5.4BA, RUChCl11BA and RUChCl22BA using NDIS-EPSR (see experimental part for details and Table S1). ${ }^{56,57}$ Details of the different isotopic substituted samples measured using NDIS and the atom labels assigned to R, 
$\mathrm{U}, \mathrm{Ch}, \mathrm{Cl}$ and BA in the EPSR simulation of the diffraction data are provided in Tables S2 and S3, and Fig. 1, respectively. MD simulations were also performed with the aim of gaining further insights into the properties of these systems at a molecular level. Moreover, it is worth noting how the density of DES dilutions with different BA contents obtained by MD simulations correlated well with the experimentally data (Fig. S1).

The agreement between experimental total diffraction data and their corresponding EPSR fits (Fig. S2) revealed the goodness of this approach to investigate our samples (i.e., in all the simulations, $R$-factors were 0.001 after ca. 5000 iterations). The evolution of the solvents structure was followed by representing the total diffraction patterns of the fully deuterated samples (Fig. S3). As in previous results found in aqueous dilutions of DESs (both this one and others), $22,23,46,58$ the absence of small-angle scattering features (i.e., in the range of $Q=0.01-0.5 \AA^{-1}, d=1.2-60 \mathrm{~nm}$ ) demonstrated that RUChCInBA mixtures were not classically phase-separated. ${ }^{22,23}$ It is worth noting some minor divergences in the region $Q \leq 2 \AA^{-1}$ coming from the typical inelastic scattering corrections for ${ }^{1} \mathrm{H}$ nuclei in non-fully deuterated compounds (Fig.1). Fig. S3 also revealed a nanostructure transition on the intermolecular level from sample RUChCIOBA (i.e., with two primary scattering features at $Q=1.39$ and $2 \AA^{-1}$, the former greater than the latter) to RUChCl22BA (i.e., with just one primary scattering features at $Q=2 \AA^{-1}$ typical of BA can we say this??).

Fig. 2 and Fig. S4-S13 display both centre-of-mass to centre-of-mass radial distribution functions (RDFs) as well as partial atom-to-atom radial distribution functions (pRDFs) obtained from EPSR. Coordination numbers $\left(N_{\text {coord }}\right)$ and spatial density function (SDF) plots were also obtained by the combination of NDIS and EPSR (Table S4, Fig. S14-S17). Interestingly, the evolution of $N_{\text {coord }}$ along with BA dilution was similar to that happening along with aqueous dilution, ${ }^{46}$ although not exactly the same. As for aqueous dilution, pRDFs obtained from both NDIS-EPSR and MD simulations corroborated the capital role played by the chloride anion ( $\mathrm{Cl}$ ) in the HB interactions of the neat DES (e.g., RUChClOBA) was preserved upon the addition of $B A$ in certain contents (e.g., RUChCl5.4BA and RUChCl11BA) (Fig. 3a). Actually, the $N_{\text {coord }}$ values found for $\mathrm{HB}$ interactions established by $\mathrm{Cl}$ with $\mathrm{R}, \mathrm{U}$ and $\mathrm{Ch}$ in $\mathrm{RUChCl5.4BA}$ and RUChCl11BA just experienced a slight decrease as compared to those in 
RUChClOBA as consequence of the new $\mathrm{HB}$ interactions established by $\mathrm{Cl}$ with $\mathrm{BA}$ for the accommodation of the latter into the HB complex structure. It was only for high BA contents (e.g., RUChCl22BA) that the $\mathrm{HB}$ interaction between $\mathrm{Cl}$ and $\mathrm{Ch}$ became quite weak (e.g., $\mathrm{N}_{\text {coord }}$ of $\mathrm{Cl}-\mathrm{Hco}$ was only 0.12 in $\mathrm{RUChCl22BA}$ ) (Fig. 3a). This low value of $N_{\text {coord }}$ was indicative of the rupture of the HB complexes characteristic of DESs. For instance, in our previous work dealing with aqueous dilutions of the same DES, $N_{\text {coord }}$ of $\mathrm{Cl}-\mathrm{Hco}$ was even a bit higher (e.g., 0.19) in $\mathrm{RUChCl} 32 \mathrm{~W}$, a dilution range where the system was defined as a simple aqueous solution of the individual components $R, U$ and $\mathrm{ChCl}^{46}$ Moreover, BA was capable to self-correlate into the $\mathrm{HB}$ complex structure of RUChCl5.4BA and RUChCl11BA as water did in RUChCl11W (see Os-Hs in Fig. 3b, with " $s$ " being either W or BA). Nonetheless, it is worth noting that self-correlation in $\mathrm{RUChCl5.4BA}$ and $\mathrm{RUChCl11BA}$ experienced a dramatic decrease as compared to neat $\mathrm{BA}$ or even to RUChCl22BA, as revealed by the plot of cluster probability versus cluster size as well as the MD simulation snapshots depicted in Fig. S18.

A closer analysis of the evolution of $N_{\text {coord }}$ along with BA dilution allowed distinguishing significant differences with aqueous dilutions. Thus, the $N_{\text {coord }}$ values between $\mathrm{BA}$ and DES components other than $\mathrm{Cl}$ (e.g., $\mathrm{R}, \mathrm{U}$ and $\mathrm{Ch}$ ) in RUChCl5.4BA and RUChCl11BA were well below those found in RUChCl11W (see Ou-Hs, Oc-Hs, Or-Hs, Os-Hco and Os-Hrp in Fig. 3b). Actually, the $N_{\text {coord }}$ values found for Oc-Hb, Or-Hb, Ob$\mathrm{HcO}$ and Ob-Hrp were too low to consider the occurrence of effective HB interactions between $B A$ and both $\mathrm{R}$ and $\mathrm{Ch}$. It is worth noting that neither the size nor the aromatic nature of BA favoured strong HB interactions with all DES components as it happened with water. Moreover, the number of HBs capable to be formed by water and BA (e.g., 4 and 2, respectively) was also a limiting factor for BA (Fig. 4a, left). This is reflected in the linear fashion in which HB networks are formed in BA (Fig. 4b). Actually, despite the average number of HB per water molecule $\left(n_{H B}\right)$ decreased along with dilution for both water and BA (Fig. 4C), the plot of the percentage of solvent molecules that engage in $n$ HBs $\left(f_{i}\right)$ was just 1 in the "BA-in-DES" regime (for RUChCl5.4BA and RUChCl11BA) (Fig. 4d) whereas it was 3 in the "water-in-DES" regime (for RUChCl11W). ${ }^{46}$ Interestingly, the molar ratio of solvent to DES in the "solvent-inDES" regime was basically the same in aqueous and $\mathrm{BA}$ dilutions of $\mathrm{RUChCl}$. Nonetheless, it is worth noting that the water content in RUChCl11W was only 18-20 
wt\% whereas the BA content in RUChCl11BA was ca. 60-67 wt\%. Moreover, this extended dilution range of the "BA-in-DES" regime where BA was yet successfully accommodated into the $\mathrm{HB}$ complex structure originally formed by $\mathrm{R}, \mathrm{U}$ and $\mathrm{ChCl}$ was also reflected in the evolution of $\pi-\pi$ interactions that are characteristic in neat BA (Fig. $4 a$, right). The tendency of $\pi-\pi$ interactions changed for DES contents of ca. $35 \mathrm{wt} \%$, when transitioning from the "DES-in-BA" regime into the "BA-in-DES" regime (Fig. 4c). It seems that accommodation into the HB complex structure by HB interactions of BA with $\mathrm{Cl}$ and with $\mathrm{U}$, as well as by self-correlation between BA molecules (Fig. S13) avoided the proper emplacement between BA molecules for $\pi$ - $\pi$ interactions .

The preservation of the "solvent-in-DES" regime even at extremely low DES contents was indeed an intriguing result that merits further investigation. Unfortunately, DSC scans of BA dilutions of RUChCl displayed neither a melting point $\left(T_{m}\right)$ nor a crystallization temperature $\left(T_{c}\right)$ (Fig. S19). This behaviour is typical of noneasily crystallizable ILs and DESs ${ }^{59}$ and limits the capability of DSC to study the formation of certain eutectic mixtures. As an alternative, we have been lately using Brillouin and ${ }^{1} \mathrm{H}$ NMR spectroscopy given their capability to study different co-solvents mixtures, ${ }^{60,61,62,63,64}$ including DESs. ${ }^{24,27-29,65}$ Actually, Brillouin spectroscopy is a reliable technique to study non-ideal liquid binary mixtures. Brillouin scattering results from the inelastic interaction between light and thermal acoustic excitations in dielectric materials. Interestingly, the deviation from linearity experienced by these interactions at the eutectic composition of liquid binary mixtures where water is one of the main components allowed the certain assignment of the eutectic composition in different liquid binary mixtures ${ }^{66,67}$ including aqueous DES solutions. Actually, we have observed this deviation in the evolution along with the DES content of both the hypersonic velocity $\left(v_{H}\right)$ and the opto-acoustic dispersion function ( $D^{180}$-function). ${ }^{24,27-}$ 29, 65 In this work, we found that $v_{H}$ deviated from the linear pattern followed by the ultrasound velocity ( $v_{U}$, not accounting for acoustic dispersions) at a DES content of ca. 35 wt\% (Fig. 5a).

We also studied by ${ }^{1} \mathrm{H}$ NMR the evolution of the chemical shifts of the different DES components along with the DES content (in wt\%) (Fig. S20, Table S5). In particular, the protons at the aromatic ring of $\mathrm{R}$ experienced the most significant changes, with protons at 2-, 4- and 6-positions up-field shifting for DES contents of 40 wt\% and 
above. It is well known that hydroxyl groups of $\mathrm{R}$ donate some of its electron density into the conjugated $\pi$ system via resonance so the protons at 2-, 4- and 6-positions are upfield shifted, more so as the electron donating capability increases (Fig. 5b). This was actually our case with the hydroxyl group participating more and more actively in HB complexes as the DES content increases within the "BA-in-DES" regime.

Moreover, the self-diffusion coefficients of the different DES components $\left(D_{R}, D_{U}\right.$ and $\left.D_{C h}\right)$ as well as of deuterated BA $\left(D_{B A}\right)$ (Fig. S21, Table S6) followed the pattern observed for aqueous dilutions of $\mathrm{RUChCl}$, this is, the self-diffusion coefficient of the solvent (either water or BA) is similar to those of all DES components at high DES contents and diverge at low DES contents, mainly from the DES content at which transition occurs from the "solvent-in-DES" regime to the "DES-in-solvent" one. ${ }^{24,28,46}$ It is worth reminding the above-mentioned peculiarities of BA (molecular size and aromatic nature) to understand why the self-diffusion coefficient of water diverged further than that of BA in the "DES-in-solvent" regime. Interestingly, self-diffusion coefficients obtained from MD simulations agreed with those obtained experimentally (Fig. S21). Actually, previous works using MD simulations in heterogeneous liquid mixtures correlated changes in the slope of the diffusion-concentration plot to local structure rearrangements. ${ }^{68}$

Finally, we also investigated the relaxation dynamics in BA dilutions of $\mathrm{RUChCl}$ by the determination of the spin-lattice relaxation time, $T_{1} . T_{1}$ for $\mathrm{R}, \mathrm{U}$ and $\mathrm{ChCl}$ were obtained as the averaged value from the different protons of the respective molecules (e.g., $T_{1_{-} R}, T_{1_{-} U}$, and $T_{1_{-} C h C l}$ ). The plots of $1 / T_{1_{-} R}, 1 / T_{1_{-} U}$, and $1 / T_{1_{-} C h C l}$ versus $D E S$ content and versus viscosity exhibited a deviation at a DES content of ca. 35 wt\% (Fig. $5 c$ and $5 d)$. Interestingly, the similarities between both plots pointed to the intrinsic features of "BA-in-DES" and "DES-in-BA" regimes as the origin of the observed changes in $T_{1}{ }^{24}$, 69

As mentioned in the introduction, we aimed to promote the polycondensation of resorcinol in some of the above $\mathrm{BA}$ solutions of $\mathrm{RUChCl}$ to obtain resins, the carbonization of which is one of the most common synthetic processes used for preparation of porous carbon materials. ${ }^{70,71,72}$ The polycondensation reaction is typically carried out in aqueous media, using formaldehyde as the cross-linker agent, and in the presence of either acid or basic catalysts as well as of soft or hard templates 
to finally obtain porous carbon materials. Introducing some textural properties in the resulting carbons is by no means trivial as it ultimately determines the field of application of these carbons - e.g., from water and air purification, adsorption, or catalysis, to electrodes and energy storage. ${ }^{73,74}$ Unfortunately, the design of predictable process (not based on trial and error) is difficult when playing around with so many reagents (e.g., acids, bases, templates, and solvents). Minimizing the number of reagents would indeed help to rationalize the process. Previous DES-assisted polycondensations carried out using water as co-solvent have allowed to obtain carbon materials with co-continuous porous structures without the use of templates. In order to avoid any eventual uncontrolled evaporation of water (that would make difficult to control the reaction kinetic, note water is a byproduct of the reaction), the temperature used at the initial stages of the polycondensation is typically around 60$70{ }^{\circ} \mathrm{C}$. This low temperature explains why renouncing to the use of catalysts in aqueous media is difficult.

RUChClnBA-assisted polycondensations opened interesting perspectives in this regard. As mentioned in the introduction, BA has some suitable solvent features (e.g., polarity and the low vapor pressure) to succeed as an alternative to water. Thus, polycondensation was carried out by addition of pPA to RUChCl3.6BA, RUChCl5.4BA, RUChCl8.2BA, RUChCl10BA, and RUChCl13BA with a fixed pPA to $\mathrm{R}$ molar ratio of 2 (Table S5) without the aid of any further catalyst and/or template. FTIR and solid-state ${ }^{13} \mathrm{C}$ CPMAS NMR spectroscopies revealed that the resulting resins (e.g., $R_{\text {RUChCl3.6BA, }}$

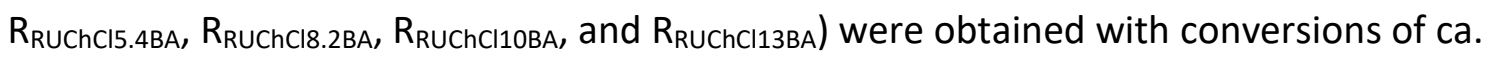
60-70\%, this is, in range to those obtained in other DES-assisted polycondensations using water as the co-solvent (Fig. S22 and S23, Table S6). FTIR and solid-state ${ }^{13} \mathrm{C}$ CPMAS NMR spectroscopies also revealed the occurrence of certain $U$ incorporation into the pPA-R network via condensation between $\mathrm{PPA}$ and $\mathrm{U} .^{49}$ The formation of networks containing both $\mathrm{R}$ and $\mathrm{U}$ linked through pPA was also confirmed by chemical analyses. The nitrogen content in every sample was ca. 4.0-4.5 wt\% (Table S6).

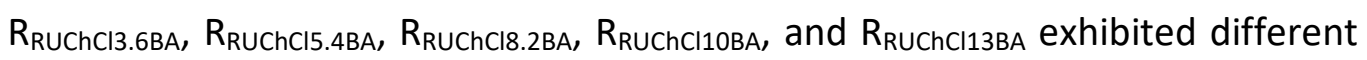
morphologies, from interconnected with either aggregate-of-particles or cocontinuous morphologies to open-cell pore morphologies. This sort of morphologies is typical of materials obtained via chemically induced phase separation $(\mathrm{CIPS})^{75,76}$ 
processes where the formation of a rich-polymer phase is accompanied by the segregation of the non-condensed matter (creating first a poor-polymer phase that, ultimately, becomes a depleted-polymer phase), the elimination of which (in our case, either before carbonization by washing or during carbonization by thermal decomposition) results in the formation of the above-mentioned porous structures. ${ }^{77}$, 78, 79, 80, 81, 82 CIPS processes can be illustrated on the phase diagram obtained by representing the reaction time versus composition with two unsymmetrical parabolic curves, an upper and a lower known respectively as the binodal and spinodal curves, meeting at the point of common curvature of both curves also known as the critical point (Fig. 6a). In particular, the spinodal curve demarcates the two-phase region into metastable and unstable regions, with the metastable region being defined between the binodal and spinodal curves, and the unstable region being defined below the spinodal curve. ${ }^{78,83,84}$ The polymerization starts in the region defined above the binodal curve where the polymer solution exists as a stable single-phase system. When reaction proceeds, transitioning into either the metastable or unstable region occurs depending on the composition of the original solution. Entering into the metastable region provides for spheroidal domains through a nucleation and growth mechanism. In these cases, polymers exhibit either an open-cell pore morphology ${ }^{75,76}$ if the spherical domains correspond to the poor-polymer phase or an interconnected structure of aggregate-of-particles ${ }^{85}$ if the spherical domains correspond to the richpolymer phase. Meanwhile, entering into the unstable region provides for cocontinuous domains through a spinodal decomposition mechanism. ${ }^{78,86}$ For this purpose, anticipating the composition that allows entering into the unstable region (e.g., that of the critical point) is by no means trivial.

In our case, morphologies were open-cell like for $\mathrm{R}_{\mathrm{RUChCl3.6BA}}$ and $\mathrm{R}_{\mathrm{RUChC15.4BA}}$ and aggregates-of-particles like for $\mathrm{R}_{\mathrm{RUChCl13BA}}$ and $\mathrm{R}_{\mathrm{RUChC122BA}}$, whereas co-continuous morphologies were found for $R_{\text {RUChC18.2BA }}$ and $R_{\text {RUChCl10BA }}$ (Fig. 6b). The composition of the starting dilutions of these latter samples seem by and large simply to correspond those in which transition from the "solvent-in-DES" regime to the "DES-in-solvent" one occurs according to all the experimental techniques and MD simulations discussed above. Interestingly, the morphologies were preserved after carbonization so that, in the particular case of $C_{R U C h C 18.2 B A}$ and $C_{R U C h C l 10 B A}$, carbon materials with a co-continuous 
porous structure were obtained (Fig. 7). In any case, all carbons exhibited a bimodal porous structure with both macropores and micropores as revealed by Hg porosimetry and $\mathrm{N}_{2}$ adsorption isotherms (Fig. S24 and S25, Table S7). The presence of micropores made these carbons suitable as $\mathrm{CO}_{2}$ absorbents (Fig. S26, Table S8).

\section{Conclusions}

The $N_{\text {coord }}$ obtained for RUChClnBA by the combination of NDIS and EPSR revealed the existence of a "BA-in-DES" regime for a dilution range of up to RUChCl11BA (DES content, 33 wt\%) where BA was successfully accommodated into the $\mathrm{HB}$ complex structure originally formed by $\mathrm{R}, \mathrm{U}$ and $\mathrm{ChCl}$. This DES content was within the 33-40-wt\%-range where the "BA-in-DES" regime transitioned into the "DES-in-BA" one according to data coming from both Brillouin $\left(v_{H}\right)$ and ${ }^{1} \mathrm{H}$ NMR (chemical shifts, self-diffusion coefficients and spin-lattice relaxation times) spectroscopies, as well as from MD simulations (self-diffusion coefficients). The presence of two well differentiated regimes - e.g., the "solvent-in-DES" and the "DES-in-solvent" depending on the DES content resembled the two well differentiated regimes observed in aqueous DES dilutions. However, it is worth noting that BA was capable to preserved the "solvent-in-DES" regime at much higher solvent contents than $\mathrm{H}_{2} \mathrm{O}-$ e.g., 60-67 versus 18-20 wt\%, respectively. Interestingly, when these BA dilutions were used as the precursor for preparation of R-based resins via polycondensation, the composition capable to provide materials with co-continuous morphologies via an spinodal decomposition process was also that in which transition from the "solvent-inDES" regime to the "DES-in-solvent" one occurs. These results revealed the capability of any of the above-mentioned techniques to anticipate the specific RUChClnBA dilution that allows entering into the unstable region (e.g., that of the critical point). This issue is by no means trivial when one desires to control the morphology of the resulting materials.

\section{Experimental Part}

Materials: Resorcinol $(\mathrm{R})$, urea $(\mathrm{U})$, choline chloride $(\mathrm{ChCl})$, benzyl alcohol $(\mathrm{BA})$, and para-phthalaldehyde (pPA) were purchased from Sigma-Aldrich. Deuterated D7-benzyl alcohol (BA-d7 98\%) and dimethylsulfoxide (DMSO-d6, 99,9\%) were acquired from 
Tracer tecnologías analíticas. All the reagents were used as received but $\mathrm{ChCl}$ that was dried at $90{ }^{\circ} \mathrm{C}$ overnight prior to its use. After drying, the water content was negligible as determined by Karl Fisher titration using a Titrando 888. Water was distilled and deionized.

DES and DES dilutions preparation: RUChCl DES was obtained by physical mixing of the individual components ( $\mathrm{R}, \mathrm{U}$ and $\mathrm{ChCl}$ in a 3:2:1 molar ratio) followed by a thermal treatment at $90{ }^{\circ} \mathrm{C}$ (see reference 37 in main text for further details). RUChClnBA dilutions ( $n=1.4,3.6,4.5,5.4,7,8,10,11,13,16,22$, and 49, for RUChCl contents of $80,60,55,50,45,40,35,33,30,20$, and $10 \mathrm{wt} \%$, respectively, Table S1) were prepared by physical mixing of the DES and the corresponding BA amount at room temperature.

Carbons preparation: Polycondensation was performed upon the addition of pPA to RUChCl3.6BA, RUChCl5.4BA, RUChCl8.2BA, RUChCl10BA, and RUChCl13BA with a fixed PPA to $\mathrm{R}$ molar ratio of 2 . The mixture was homogenized by gently stirring and, then, thermally treated for 4 days at $90{ }^{\circ} \mathrm{C}$ to obtain $R_{\text {RUChC13.6BA, }} R_{R U C h C 15.4 B A}, R_{R U C h C 18.2 B A}$, $\mathrm{R}_{\mathrm{RUChCl10BA}}$, and $\mathrm{R}_{\mathrm{RUChCl13BA}}$. The resins were submitted to pyrolysis under a nitrogen atmosphere at $800{ }^{\circ} \mathrm{C}$ for 4 hours (the heating ramp was $1.0^{\circ} \mathrm{C} / \mathrm{min}$ ) to obtain the

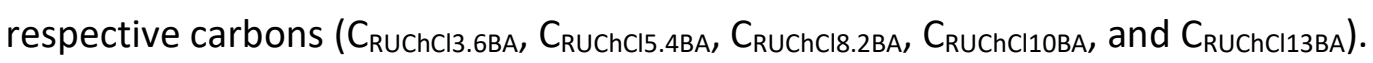

Samples characterization: Densities, viscosities and ultrasonic velocities were measured in a DSA 5000M coupled with a LOVIS 2000 ME module from Anton Paar. Differential scanning calorimetry (DSC) analyses were performed in a TA Instruments Discovery system under a $\mathrm{N}_{2}$ atmosphere. The samples were sealed in an aluminium pan and placed in the calorimeter furnace. For data acquisition, DESs were cooled from room temperature to $-90^{\circ} \mathrm{C}$ at a scan rate of $5{ }^{\circ} \mathrm{C} \mathrm{min}^{-1}$ and kept at this temperature over $10 \mathrm{~min}$ before starting the heating/cooling cycles (two additional ones), which consisted of heating the sample to $60{ }^{\circ} \mathrm{C}$ (for all the dilutions) or $90{ }^{\circ} \mathrm{C}$ (for BA and $\mathrm{RUChCl}$ ), and then cooling it again to $-90{ }^{\circ} \mathrm{C}$ at the same scan rate. Resins were studied by Fourier transform infrared (FTIR) spectroscopy (using a FTIR spectrometer a NICOLET $20 \mathrm{SXC}$ ) and by solid-state ${ }^{13}$ C-CPMAS-NMR spectroscopy (using a Bruker Model AV- 400-WB spectrometer and applying a standard cross-polarization pulse sequence). The morphology of the different resins and carbons was studied by scanning electron microscopy (SEM), using a SEM Hitachi S-3000N system. Nitrogen 
adsorption/desorption isotherms were conducted at $-196{ }^{\circ} \mathrm{C}$ using a Tristar 3020 from Micromeritics system on samples thermally treated at $100{ }^{\circ} \mathrm{C}$ for $6 \mathrm{~h}$ prior to nitrogen gas adsorption. Brunauer-Emmett-Teller (BET) theory was used to calculate the specific surface areas $\left(S_{B E T}\right)$. Pore volumes were calculated using the 2D-NLDFT method (micropore and mesopore volume) and the Dubinin Radushkevich equation (micropore volume) applied to the $\mathrm{N}_{2}$ adsorption data. $\mathrm{CO}_{2}$ adsorption-desorption isotherms were performed at 0 and $25{ }^{\circ} \mathrm{C}$ in a Micromeritics Tristar 3020 instrument in the pressure range of 0.1-900 mbar. The narrow microporosity was further evaluated from the $\mathrm{CO}_{2}$ adsorption isotherms using the Dubinin Radushkevich equation. Hg porosimetry was carried out using a Quantachrome Poremaster. Elemental analyses were carried out in a LECO CHNS-932 Analyser. The technique involved sample combustion at $1000{ }^{\circ} \mathrm{C}$ in an oxygen rich environment. The products of combustion $\left(\mathrm{CO}_{2}, \mathrm{H}_{2} \mathrm{O}\right.$ and $\left.\mathrm{N}_{2}\right)$ were carried through the system by He carrier gas. The combustion products were measured quantitatively by means of a non-dispersive IR absorption detection system, except for the $\mathrm{N}_{2}$ that was determined via a thermal conductivity detector (TC).

Brillouin spectroscopy: Brillouin spectra were recorded using a Sandercock $3+3$ Pass Tandem Fabry-Pérot interferometer as Brillouin spectrometer and the light source was a DPPS laser working at a wavelength $\left(\lambda_{0}\right)$ of $532 \mathrm{~nm} .{ }^{87}$ In this case, the liquid samples were placed in optical cuvettes (Starna) with $1 \mathrm{~mm}$ in optical path length. Experiments were performed using backscattering and $90 \mathrm{~A}$ scattering geometry, simultaneously.

The simultaneous recording of both scattering geometries required of the use of a neutral filter for the Backscattering component and we also had to reduce the intensity of the central peak. The Brillouin peaks were fitted using a Lorentzian function with an adequate background function. The constraints associated with this experimental set-up made impossible the application of a typical damped harmonic oscillator model.

The 90A scattering geometry is independent of the refractive index $(n)^{2}$ and its acoustic wave vector is: ${ }^{88}$

$$
\mathrm{q}^{90 \mathrm{~A}}=[4 \pi \sin (\pi / 4)] / \lambda_{0}
$$

The hypersonic sound propagation velocity $\left(\mathrm{v}_{\mathrm{H}}\right)$ can be obtained from the relation between the Brillouin frequency shift $\left(f^{90 A}\right)$ and $q^{90 A}$, and expressed as

$$
v_{H}{ }^{90 A}=\left(2 \pi f^{90 A}\right) / q^{90 A}
$$


Meanwhile, the acoustic wave vector for Backscattering geometries is

$$
\mathrm{q}^{180}=[4 \pi \mathrm{n}] / \lambda_{0}
$$

and hence $\mathrm{n}$-dependent. Thus, the hypersonic velocities for both geometries are:

$$
v_{H}{ }^{90 A}=f^{90 A} \lambda_{0} / v 2
$$

and

$$
\mathrm{v}_{\mathrm{H}}^{180}=\mathrm{f}^{180} \lambda_{0} / 2 \mathrm{n}
$$

${ }^{1} \boldsymbol{H}$ NMR analysis: Samples for ${ }^{1} \mathrm{H}$ NMR analyses were prepared by mixing $\mathrm{RUChCl}$ with the proper amount of BA-d7. ${ }^{1} \mathrm{H} N M R$ spectra of RUChCInBA $A_{D}$ were recorded using a Bruker Avance DRX500 spectrometer operating at $500 \mathrm{MHz}$ with a $30^{\circ}$ pulse, acquisition time of $3.1719 \mathrm{~s}$, relaxation delay of $1 \mathrm{~s}$ and 16 scans. The samples were placed in capillary tubes whereas the DMSO-d6 used as the external reference was placed in $5 \mathrm{~mm}$ NMR glass tubes with a height of 8 inches. The peaks were identified and spectra were processed using the software MestReNova. ${ }^{1} \mathrm{H}$ NMR diffusion experiments were performed using a pulsed-field gradient stimulated spin-echo (PFGSTE NMR) technique by applying a LED-bipolar gradients pulse sequence from Bruker (in particular, ledbpgp2s pulse sequence). ${ }^{89}$ The spectrometer was equipped with a broadband fluorine observe (BBFO) NMR probe capable of producing magnetic fields pulses in the z-direction. A Bruker Variable Temperature BVT 3000 was also used to set the temperature to $353 \mathrm{~K}$ for the measurements of samples.

The NMR signal attenuation $\left(I / I_{0}\right)$ is described by the equation $(6):^{90}$

$$
\mathrm{I}=\mathrm{I}_{0} e^{-D \gamma^{2} g^{2} \delta^{2}\left(\Delta-\frac{\delta}{3}\right)}
$$

Or in a simplified form (7):

$$
\mathrm{I}=\mathrm{I}_{0} e^{-D Q}
$$

where, $I$ is the observed intensity, $I_{0}$ is the intensity when the gradient strength is zero (reference intensity), D is de diffusion coefficient, $\gamma$ is the gyromagnetic ratio of the observed nuclei, $g$ is the gradient strength, $\delta$ is the duration of the gradient and $\Delta$ is the diffusion time. The gyromagnetic ratio is different for every nucleus, being $4.3 \mathrm{kHz}$ $\mathrm{G}^{-1}$ for ${ }^{1} \mathrm{H}$. The duration of the gradient and the diffusion time differ among samples. 
For the measurement of the spin-lattice relaxation time $\left(T_{1}\right)$ the standard method of inversion recovery is applied. In this method, the following equation (8) is used: ${ }^{91}$

$$
\mathrm{I}=\mathrm{I}_{0}\left[1-2 e^{\left(-\mathrm{t} / \mathrm{T}_{1}\right)}\right]
$$

The software MestReNova was used for calculation of the diffusion coefficients and $T_{1}$ by the peak integration and fitting of the exponentially decaying data based on the area.

Neutron diffraction experiments: Hydrogenated resorcinol, urea, choline chloride and deuterated BA (97\%-d7) were purchased from Tracer and used as received. d9-choline chloride $\left(\left(\mathrm{CD}_{3}\right)_{3} \mathrm{~N}\left(\mathrm{CH}_{2}\right)_{2} \mathrm{OHCl}, 98.8 \%\right.$-d9) was acquired from $\mathrm{ClL}$ laboratories. d4-urea (97.0\%-d4) and d6-resorcinol (65.0\%-d6) were prepared by ISIS Deuteration Facility. Neutron diffraction experiments were carried out on RUChClOBA, RUChCl5.4BA, RUChCl11BA, and RUChCl22BA (Table S1). Different isotopic substitution RUChCl samples were prepared by mixing the appropriate amount of the fully protonated and deuterated compounds and letting the mixture melt at $80^{\circ} \mathrm{C}$. The different isotopic contrasts are summarized in Table S2.

Neutron diffraction experiments were collected using the NIMROD diffractometer, located in Target Station 2 in the ISIS Neutron and Muon Facility, Rutherford Appleton Laboratories, Harwell Campus, UK. Neutron scattering data were recorded placing each freshly prepared solution into $1 \mathrm{~mm}$ thickness flat TiZr alloy cans. Samples were kept at $353 \mathrm{~K}$ using a circulating heater to ensure the DES remained in liquid phase during the whole data collection time.

Empirical potential structure refinement (EPSR) ${ }^{92}$ and EPSRgui ${ }^{93}$ were used to obtain computational models of the different systems. EPSR algorithm minimizes the system energy and, at the same time, builds an atomistic model that fits the collected data. Previous to be used in EPSR algorithm, neutron scattering data were treated using GudrunN in order to correct them according to detectors efficiency, subtract environment background, multiple scattering, and hydrogen inelastic scattering. ${ }^{94}$ Final datasets were then analyzed using EPSR that allowed to maximize the information obtained from them and allows comparing data with conventional simulations. The assigned bond lengths and atom types used to build the atomistic models are described in Table S3. Urea and choline chloride charges, masses and Lennard-Jones 
parameters used were the same as in reference \#46 and \#58. Resorcinol LennardJones parameters were adapted from Jorgensen ${ }^{95}$ and masses and charges extracted from Hussain et al. $^{96}$ and from reference \#46. The simulation boxes contain 7000 molecules, at the density of 0.1 atoms $/ \AA^{3}$.

Molecular dynamics (MD) simulations: MD simulations were performed to study the structural and transport properties of the DES RUChCl in presence of water. The molecular models for the molecules of urea, choline, and chloride are taken from Perkins et al. $^{97}$ In that work, the authors stated that the developed force field reproduces the physico-chemical properties of the urea/choline chloride DES, and in particular density, volume expansion coefficient, heat capacity and diffusion coefficients. We use OPLS-AA force field ${ }^{8,98}$ for resorcinol HBD, and SPC/E model for water. $^{99}$ To calculate the cross Lennard-Jones potential parameters we use standard Lorentz-Berthelot combining rules. The Lennard-Jones cut-off radius is set to $12 \AA$ and electrostatic interactions are computed using the Ewald summation technique. ${ }^{100,} 101$ We applied periodic boundary conditions in the three dimensions.

Different concentrations covering the whole range from the pure solvent to the pure $\mathrm{RUChCl}$ with eleven intermediate weight percentages of $\mathrm{RUChCl}$ were studied. The components of the mixtures were initially placed in a cubic simulation box of approximately $40 \AA$. The number of ion pairs and organic compounds of each system, as well as the total number of atoms are shown in the Table S4. The initial configurations were created by randomly placing the $\mathrm{RUChCl}$ constituents in an empty simulation box and refilled with BA molecules using the Packmol package, ${ }^{102}$ thus obtaining a homogeneous distribution of the molecules. We started the equilibration of the system by performing an energy minimization simulation employing a steepest descent algorithm. ${ }^{103}$ We continued with consecutive MD simulations in the NPT ensemble to relax the systems to their equilibrium density. This equilibrium is reached when the cell volume and the energy of the system fluctuate around an average value over time. Once the system was equilibrated we carried out MD simulations in the NVT ensemble to obtain the rest of the structural and dynamical properties of the RUChClnBA dilutions. The time step employed for the equilibration and production run simulations is 0.5 and $1 \mathrm{fs}$, respectively. The production runs consist in 50 million of MD steps giving rise to $50 \mathrm{~ns}$ of total simulation time. The pressure in the NPT 
simulations was set using the Martyna-Tuckerman-Tobias-Klein (MTTK) barostat, ${ }^{104}$ and the temperature was controlled with the Nose-Hoover thermostat. ${ }^{105,106}$ All simulations were performed using the GROMACS molecular simulation software. ${ }^{107-110}$ Self-diffusion coefficients $D_{\mathrm{MD}}$ were computed using Einstein's equation that relates $D_{\mathrm{MD}}$ with the slope of the mean square displacement in the 10-40 ns time interval. Additional details about the calculation of the transport properties of liquid systems can be found elsewhere (for further details see references ${ }^{111,112}$ and also reference 45 in main text). The calculation of hydrogen bonds we performed using the geometric criterion described by Luzar and Chandler ${ }^{113}$ over the trajectory recorded every $0.1 \mathrm{~ns}$.

\section{Acknowledgements}

This work was supported by MINECO/FEDER (Project Numbers RTI2018-097728-B-I00 and RTI2018-096918-B-C41). C.O.A. and F.d.M. acknowledge CNRS and CSIC for PICS07948 and PIC2017FR3, respectively. The Servicio Interdepartamental de Investigación (SIdl) of the Universidad Autónoma de Madrid is acknowledged for helpful assistance with NMR and DSC studies.

\section{Supporting Information}

The Supporting Information is available free of charge at https://pubs.acs.org/xxx Xxx (PDF).

\section{Conflict of Interest}

The authors declare no competing financial interest.

\section{References}

1 A. P. Abbott, G. Capper, D. L. Davies, R. K. Rasheed, V. Tambyrajah, Novel solvent properties of choline chloride/urea mixtures, Chem. Commun., 2003, 70-71. DOI: 10.1039/B210714G

2 T. Welton, Room-Temperature Ionic Liquids. Solvents for Synthesis and Catalysis, Chem. Rev., 1999, 99, 2071-2083. DOI: 10.1021/cr1003248 
3 C. Florindo, F. Lima, B. D, Ribeiro, I. M. Marrucho, Deep eutectic solvents: overcoming 21st century challenges, Current Opinion in Green and Sustainable Chemistry, 2019, 18, 31-36. DOI: 10.1016/j.cogsc.2018.12.003

4 D. A. Alonso, A. Baeza, R. Chinchilla, G. Guillena, I. M. Pastor, and D. J. Ramón, Deep Eutectic Solvents: The Organic Reaction Medium of the Century, Eur. J. Org. Chem. 2016, 4, 612-632. DOI: 10.1002/ejoc.201501197

5 J. D. Mota-Morales, R. J. Sánchez-Leija, A. Carranza, J. A. Pojman, F. del Monte, G. Luna-Bárcenas, Free-radical polymerizations of and in deep eutectic solvents: Green synthesis of functional materials, Prog. Polym. Sci., 2018, 78, 139-153. DOI: 10.1016/j.progpolymsci.2017.09.005

6 G. Imperato, E. Eibler, J. Niedermaier, B. König, Low-melting sugar-urea-salt mixtures as solvents for Diels-Alder reactions, Chem. Commun., 2005, 9, 1170-1172. DOI: $10.1039 / B 414515 A$

7 F. Ilgen, D. Ott, D. Kralisch, C. Reil, A. Palmberger, B. König, Conversion of carbohydrates into 5-hydroxymethylfurfural in highly concentrated low melting mixtures, Green Chem., 2009, 11, 1948-1954. DOI: 10.1039/B917548M

8 M. Francisco, A. van den Bruinhorst, M. C. Kroon, New natural and renewable low transition temperature mixtures (LTTMs): screening as solvents for lignocellulosic biomass processing, Green Chem., 2012, 14, 2153-2157. DOI: 10.1039/C2GC35660K

9 M. Francisco, A. van den Bruinhorst, M. C. Kroon, Low-Transition-Temperature Mixtures (LTTMs): A New Generation of Designer Solvents, Angew. Chem., 2013, 52, 3074-3085. DOI: 10.1002/anie.201207548

10 Y. H. Choi, J. van Spronsen, Y. Dai, M. Verberne, F. Hollmann, I. W. C. E. Arends, G. J. Witkamp, R. Verpoorte, Are Natural Deep Eutectic Solvents the Missing Link in Understanding Cellular Metabolism and Physiology?, Plant Physiol., 2011, 156, 1701-1705. DOI: 10.1104/pp.111.178426

${ }^{11}$ A. A. Yates, S. A. Schlicker, C. W. Suitor, Dietary Reference Intakes: The New Basis for Recommendations for Calcium and Related Nutrients, B Vitamins, and Choline, J. Am. Diet. Assoc., 1998, 98, 699-706. DOI: 10.1016/S0002-8223(98)00160-6 
12 A. Paiva, R. Craveiro, I. Aroso, M. Martins, R. L. Reis, A. R. C. Duarte, Natural deep eutectic solvents - Solvents for the 21st century, ACS Sustainable Chem. Eng., 2014, 2, 1063-1071. DOI: 10.1021/sc500096j

${ }^{13}$ S. Nardecchia, M. C. Gutiérrez, M. L. Ferrer, M. Alonso, I. M. López, J. C. RodríguezCabello, and F. del Monte, Phase Behavior of Elastin-Like Synthetic Recombinamers in Deep Eutectic Solvents, Biomacromolecules 2012, 13, 2029-2036. DOI: $10.1021 / \mathrm{bm} 300200 \mathrm{e}$

14 Y. Dai, G.-J. Witkamp, R. Verpoorte, Y. H. Choi, Tailoring properties of natural deep eutectic solvents with water to facilitate their applications, Food Chem., 2015, 187, 14-19. DOI: 10.1016/j.foodchem.2015.03.123

15 M. C. Gutiérrez, M. L. Ferrer, L. Yuste, F. Rojo, F. del Monte, Bacteria incorporation in deep-eutectic solvents through freeze-drying, Angew. Chem. Int. Ed. Engl., 2010, 49, 2158-2162. DOI: 10.1002/anie.200905212

16 Z. Maugeri, P. Domínguez De María, Whole-cell biocatalysis in deep-eutecticsolvents/aqueous mixtures, ChemCatChem, 2014, 6, 1535-1537. DOI: $10.1002 /$ cctc. 201400077

17 G. C. Dugoni, M. E. Di Pietro, M. Ferro, F. Castiglione, S. Ruellan, T. Moufawad, L. Moura, M. F. Costa Gomes, S. Fourmentin, A. Mele, Effect of Water on Deep Eutectic Solvent/ $\beta$-Cyclodextrin Systems, ACS Sustainable Chem. Eng., 2019, 7, 7277-7285. DOI: 10.1021/acssuschemeng.9b00315

${ }^{18}$ R. Esquembre, J. M. Sanz, J. G. Wall, F. del Monte, C. R. Mateo, M. L. Ferrer, Thermal unfolding and refolding of lysozyme in deep eutectic solvents and their aqueous dilutions, Phys. Chem. Chem Phys. 2013, 15, 11248-11256. DOI: $10.1039 / c 3 c p 44299 c$

19 M. C. Gutiérrez, M. L. Ferrer, C. R. Mateo, F. del Monte, Freeze-Drying of Aqueous Solutions of Deep Eutectic Solvents: A Suitable Approach to Deep Eutectic Suspensions of Self-Assembled Structures, Langmuir, 2009, 25, 5509-5515. DOI: 10.1021/la900552b

20 D. Shah, F. S. Mjalli, Effect of water on the thermo-physical properties of Reline: An experimental and molecular simulation based approach, Phys. Chem. Chem. Phys., 2014, 16, 23900-23907. DOI: 10.1039/c4cp02600d 
${ }^{21}$ H. Passos, D. J. P. Tavares, A. M. Ferreira, M. G. Freire, J. A. P. Coutinho, Are Aqueous Biphasic Systems Composed of Deep Eutectic Solvents Ternary or Quaternary Systems?, ACS Sustainable Chem. Eng., 2016, 4, 2881-2886. DOI: 10.1021/acssuschemeng.6b00485

O. S. Hammond, D. T. Bowron, K. J. Edler, The Effect of Water upon Deep Eutectic Solvent Nanostructure: An Unusual Transition from Ionic Mixture to Aqueous Solution, Angew. Chem., 2017, 56, 9782-9785. DOI: 10.1002/anie.201702486

O. S. Hammond, D. T. Bowron, A. J. Jackson, T. Arnold, A. Sanchez-Fernandez, N. Tsapatsaris, V. García Sakai, K. J. Edler, Resilience of Malic Acid Natural Deep Eutectic Solvent Nanostructure to Solidification and Hydration, J. Phys. Chem. B, 2017, 121, 7473-7483. DOI: 10.1021/acs.jpcb.7b05454

${ }^{24}$ M. J. Roldán-Ruiz, R. J. Jiménez-Riobóo, M. C. Gutiérrez, M. L. Ferrer, F. del Monte, Brillouin and NMR spectroscopic studies of aqueous dilutions of malicine: Determining the dilution range for transition from a "water-in-DES" system to a "DES-in-water" one, J. Mol. Liq., 2019, 284, 175-181. DOI: 10.1016/j.molliq.2019.03.133

25 C. D'Agostino, L. F. Gladden, M. D. Mantle, A. P. Abbott, E. I. Ahmed, A. Y. M. AlMurshedi, R. C. Harris, Molecular and ionic diffusion in aqueous - deep eutectic solvent mixtures: probing inter-molecular interactions using PFG NMR, Phys. Chem. Chem. Phys., 2015, 17, 15297-15304. DOI: 10.1039/C5CP01493J

${ }^{26}$ A. Pandey, S. Pandey, Solvatochromic probe behavior within choline chloride-based deep eutectic solvents: effect of temperature and water, J. Phys. Chem. B, 2014, 118, 14652-14661. DOI: 10.1021/jp510420h

27 E. Posada, N. López-Salas, D. Carriazo, C. Ania, R. J. Jiménez-Riobóo, M. C. Gutiérrez, M. L. Ferrer, F. del Monte, Predicting the suitability of aqueous solutions of deep eutectic solvents for preparation of bicontinuous porous carbons via spinodal decomposition processes, Carbon, 2017, 123, 536-547. DOI: 10.1016/j.carbon.2017.07.083

${ }^{28}$ E. Posada, M. J. Roldán-Ruiz, R. J. Jiménez-Riobóo, M. C. Gutiérrez, M. L. Ferrer, F. del Monte, Nanophase separation in aqueous dilutions of a ternary DES as revealed 
by Brillouin and NMR spectroscopy, J. Mol. Liq., 2019, 276, 196-203. DOI: 10.1016/j.molliq.2018.11.139

${ }^{29}$ E. Posada, N. López-Salas, R. J. Jiménez-Riobóo, M. C. Gutiérrez, M. L. Ferrer, F. del Monte, Reline aqueous solutions behaving as liquid mixtures of $\mathrm{H}$-bond cosolvents: microphase segregation and formation of co-continuous structures as indicated by Brillouin and ${ }^{1}$ H NMR spectroscopies, Phys. Chem. Chem. Phys., 2017, 19, 1710317110. DOI: $10.1039 /$ C7CP02180A

${ }^{30}$ E. O. Fetisov, D. B. Harwood, I.-F. W. Kuo, S. E. E. Warrag, M. C. Kroon, C. J. Peters, J. I. Siepmann, First-principles molecular dynamics study of a deep eutectic solvent: choline chloride/urea and its mixture with water, J. Phys. Chem. B, 2018, 122, 12451254. DOI: $10.1021 /$ acs.jpcb.7b10422

${ }^{31}$ T. Zhekenov, N. Toksanbayev, Z. Kazakbayeva, D. Shah, F. S. Mjalli, Formation of type III Deep Eutectic Solvents and effect of water on their intermolecular interactions, Fluid Phase Equilib., 2017, 441, 43-48. DOI: 10.1016/j.fluid.2017.01.022

${ }^{32}$ M. Ferreira, F. Jérôme, H. Bricout, S. Menuel, D. Landy, S. Fourmentin, S. Tilloy, E. Monflier, Rhodium catalyzed hydroformylation of 1-decene in low melting mixtures based on various cyclodextrins and N, N'-dimethylurea, Catal. Lett., 2015, 63, 62-65. DOI: 10.1016/j.catcom.2014.11.001

${ }^{33}$ C. Vidal, J. García-Alvarez, A. Hernán-Gómez, A. R. Kennedy, E. Hevia, Exploiting Deep Eutectic Solvents and Organolithium Reagent Partnerships: Chemoselective Ultrafast Addition to Imines and Quinolines Under Aerobic Ambient Temperature Conditions, Angew. Chem. Int. Ed., 2016, 55, 16145-16148. DOI: 10.1002/anie.201609929

34 A. Sánchez-Condado, G. Carriedo, A. Presa Soto, M. J. Rodríguez-Álvarez, J. GarciaAlvarez, E. Hevia, Organolithium Initiated Polymerization of Olefins in Deep Eutectic Solvents under Aerobic Conditions. Sustainable Route to Homopolymers, Random Copolymers and Block Copolymers, ChemSusChem, 2019, 12, 3134-3143. DOI: $10.1002 / \operatorname{cssc} .201900533$

${ }^{35}$ C. Florindo, L. Romero, I. Rintoul, L. C. Branco, I. M. Marrucho, From Phase Change Materials to Green Solvents: Hydrophobic Low Viscous Fatty Acid-Based Deep 
Eutectic Solvents, ACS Sustainable Chem. Eng., 2018, 6, 3888-3895. DOI: 10.1021/acssuschemeng.7b04235

${ }^{36}$ L. F. Zubeir, D. J. G. P. van Osch, M. A. A. Rocha, F. Banat, M. C. Kroon, Carbon Dioxide Solubilities in Decanoic Acid-Based Hydrophobic Deep Eutectic Solvents, J. Chem. Eng. Data, 2018, 63, 913-919, DOI: 10.1021/acs.jced.7b00534

37 M. G. Peŕez-García, M. C. Gutiérrez, J. D. Mota-Morales, G. Luna-Bárcenas, F. del Monte, Synthesis of Biodegradable Macroporous Poly(L-lactide)/Poly( $\varepsilon$ caprolactone) Blend Using Oil-in-Eutectic-Mixture High-Internal- Phase Emulsions as Template, ACS Appl. Mater. Interfaces, 2016, 8, 16939-16949, DOI: 10.1021/acsami.6b04830

38 S. García-Argüelles, C. García, M. C. Serrano, M. C. Gutiérrez, M. L. Ferrer, F. del Monte, Near-to-eutectic mixtures as bifunctional catalysts in the low-temperaturering- opening-polymerization of $\varepsilon$-caprolactone, Green Chem., 2015, 17, 3632-3643, DOI: $10.1039 / \mathrm{c5gc00348b}$

${ }^{39}$ S. García-Argüelles, M. C. Serrano, M. C. Gutiérrez, M. L. Ferrer, L. Yuste, F. Rojo, F. del Monte, Deep Eutectic Solvent-Assisted Synthesis of Biodegradable Polyesters with Antibacterial Properties, Langmuir, 2013, 29, 9525-9534, DOI: 10.1021/la401353r

${ }^{40}$ F. del Monte, D. Carriazo, M. C. Serrano, M. C. Gutiérrez, M. L. Ferrer, Deep Eutectic Solvents in Polymerizations: A Greener Alternative to Conventional Syntheses, ChemSusChem, 2014, 7, 999-1009, DOI: 10.1002/cssc.201300864

41 X. Marset, J. M. Pérez, D. J. Ramón, Cross-dehydrogenative coupling reaction using copper oxide impregnated on magnetite in deep eutectic solvents, Green Chem., 2016, 18, 826-833, DOI: 10.1002/cssc.201300864

42 F. del Monte, D. Carriazo, M. C. Serrano, M. C. Gutiérrez, M. L. Ferrer, Deep Eutectic Solvents in Polymerizations: A Greener Alternative to Conventional Syntheses, ChemSusChem, 2014, 7, 999-1009, DOI: 10.1002/cssc.201300864

43 R. C. Morales, V. Tambyrajah, P. R. Jenkins, D. L. Davies, A. P. Abbott, The regiospecific Fischer indole reaction in choline chloride. $2 \mathrm{ZnCl} 2$ with product isolation by direct sublimation from the ionic liquid, Chem. Commun., 2004, 158159. DOI: https://doi.org/10.1039/B313655H 
44 O. S. Hammond, K. J. Edler, D. T. Bowron, L. Torrente-Murciano, Deep eutecticsolvothermal synthesis of nanostructured ceria, Nature Commun., 2017, 8, Article number: 14150. DOI: 10.1038/ncomms14150

45 T. Moufawad, L. Moura, M. Ferreira, H. Bricout, S. Tilloy, E. Monflier, M. Costa Gomes, D. Landy, S. Fourmentin, First Evidence of Cyclodextrin Inclusion Complexes in a Deep Eutectic Solvent, ACS Sustainable Chem. Eng., 2019, 7, 6345-6351. DOI: 10.1021/acssuschemeng.9b00044

46 N. López-Salas, J. M. Vicent-Luna, S. Imberti, E. Posada, M. J. Roldán-Ruiz, J. A. Anta, S. R. G. Ballesta, R. M. Madero, S. Calero, R. J. Jiménez-Riobóo, M. C. Gutiérrez, M. L. Ferrer, F. del Monte, Looking at the "Water-in-Deep-Eutectic-Solvent" System: A Dilution Range for High Performance Eutectics, ACS Sustainable Chem. Eng., 2019, 7, 17565-17573. DOI: 10.1021/acssuschemeng.9b05096

47 N. Pinna, G. Neri, M. Antonietti, M. Niederberger, Nonaqueous synthesis of nanocrystalline semiconducting metal oxides for gas sensing, Angew. Chem. Int. Ed., 2004, 43, 4345-4349. DOI: 10.1002/anie.200460610

${ }^{48}$ I. Bilecka, P. Elser, M. Niederberger, Kinetic and thermodynamic aspects in the microwave-assisted synthesis of $\mathrm{ZnO}$ nanoparticles in benzyl alcohol, ACS Nano, 2009, 3, 467-477. DOI: 10.1021/nn800842b

49 D. Carriazo, M. C. Gutiérrez, M. L. Ferrer, F. del Monte, Resorcinol-Based Deep Eutectic Solvents as Both Carbonaceous Precursors and Templating Agents in the Synthesis of Hierarchical Porous Carbon Monoliths, Chem. Mater., 2010, 22, 61466152. DOI: $10.1021 / \mathrm{cm} 1019684$

50 M. C. Gutiérrez, D. Carriazo, C. O. Ania, J. B. Parra, M. L. Ferrer, F. del Monte, Deep Eutectic Solvents as Both Precursors and Structure Directing Agents in the Synthesis of Nitrogen Doped Hierarchical Carbons Highly Suitable for $\mathrm{CO}_{2}$ Capture, Energy Environ. Sci., 2011, 4, 3535-3544. DOI: https://doi.org/10.1039/C1EE01463C

${ }^{51}$ N. López-Salas, M. C. Gutiérrez, C. O. Ania, M. A. Muñoz-Márquez, M. L. Ferrer, F. del Monte, Nitrogen-Doped Carbons Prepared from Eutectic Mixtures as Metal-Free Oxygen Reduction Catalysts, J. Mater. Chem. A, 2016, 4, 478-488. DOI: https://doi.org/10.1039/C5TA08630B 
52 N. López-Salas, F. del Monte, A. Tamayo, J. L. G. Fierro, A. De Lacey, M. L. Ferrer, and M. C. Gutiérrez, Sulfur-Doped Carbons Prepared from Eutectic Mixtures Containing Hydroxymethylthiophene as Metal-Free Oxygen Reduction Catalysts, ChemSusChem, 2014, 7, 3347-3355. DOI: 10.1002/cssc.201402753

53 D. Carriazo, M. C. Gutiérrez, F. Picó, J. M. Rojo, J. L. G. Fierro, A. De Lacey, M. L. Ferrer, and F. del Monte, Phosphate-Functionalized Carbon Monoliths from Deep Eutectic Solvents and Their Use as Monolithic Electrodes in Supercapacitors, ChemSusChem, 2012, 5, 1405-1409. DOI: 10.1002/cssc.201200136

54 D. Carriazo, M. C. Serrano, M. C. Gutiérrez, M. L. Ferrer, F. del Monte, Deep-eutectic solvents playing multiple roles in the synthesis of polymers and related materials, Chem. Soc. Rev., 2012, 41, 4996. DOI: https://doi.org/10.1039/C2CS15353J

55 G. Carrasco-Huertas, R. J. Jiménez-Riobóo, M. C. Gutiérrez, M. L. Ferrer, F. del Monte, Carbon and carbon composites obtained using deep eutectic solvents and aqueous dilutions thereof, Chem. Commun., 2020, 56, 359-3604, DOI: $10.1039 / \mathrm{d} 0 \mathrm{cc} 00681 \mathrm{e}$

56 J. L. Finney, A. K. Soper, Solvent structure and perturbations in solutions of chemical and biological importance, Chem. Soc. Rev., 1994, 23, 1-10. DOI: https://doi.org/10.1039/CS9942300001

57 A.K. Soper, Empirical Potential Structure Refinement - EPSR shell: a user's guide. Version 18 - May 2011, RAL Technical Reports RAL-TR-2011-012. 2011.

58 O. S. Hammond, D. T. Bowron and K. J. Edler, Liquid Structure of the Choline Chloride-Urea Deep Eutectis Solvent (Reline) from Neutron Diffraction and Atomistic Modellin, Green Chem., 2016, 18, 2736-2744. DOI: https://doi.org/10.1039/C5GC02914G

$59 \mathrm{Xu}$, W.; Cooper, E. I.; Angell, C. A. Ionic liquids: ion mobilities, glass temperatures, and fragilities. J. Phys. Chem. B 2003, 107, 6170-6178.

${ }^{60}$ M. Casalegno, G. Raos, G. B. Appetecchi, S. Passerini, F. Castiglione, A. Mele, From Nanoscale to Microscale: Crossover in the Diffusion Dynamics within Two Pyrrolidinium-Based Ionic Liquids, J. Phys. Chem. Lett., 2017, 8, 5196-5202. DOI: 10.1021/acs.jpclett.7b02431 
${ }^{61}$ M. Mijaković, B. Kežić, L. Zoranić, F. Sokolić, A. Asenbaum, C. Pruner, E. Wilhelm, A. Perera, Ethanol-Water Mixtures: Ultrasonics, Brillouin Scattering and Molecular Dynamics, J. Mol. Liq., 2011, 164, 66-73. DOI: 10.1016/j.molliq.2011.06.009

62 L. Lupi, L. Comez, C. Masciovecchio, A. Morresi, M. Paolantoni, P. Sassi, F. Scarponi, D. Fioretto, Hydrophobic Hydration of Tert-Buthyl Alcohol Studied by Brillouin Light and Inelastic Ultraviolet Scattering, J. Chem. Phys., 2011, 134, 055104. DOI: $10.1063 / 1.3529014$

${ }^{63}$ M. Pochylski, F. Aliotta, Z. Blaszczak, J. Gapinski, Structurin Effects and Hydration Phenomena in Poly(Ethylene Glycol)/Water Mixtures Investigated by Brillouin Scattering, J. Phys. Chem. B, 2006, 110, 20533-20539. DOI: 10.1021/jp0620973

64 R. Carplo, M. Mehlclc, F. Borsay, C. Petrovic, E. Yeager, Investigation of Aqueous Calcium Nitrate, Zinc Nitrate, and Zinc Chloride Solutions Using Acoustic Velocity Measurements, J. Phys. Chem., 1982, 86, 4980-4987. DOI: 10.1021/j100222a029

65 H. Zhang, M. L. Ferrer, M. J. Roldán-Ruiz, R. J. Jiménez-Riobóo, M. C. Gutiérrez, F. del Monte, Brillouin Spectroscopy as a Suitable Technique for the Determination of the Eutectic Composition in Mixtures of Choline Chloride and Water, J. Phys. Chem. B, 2020. DOI: 10.1021/acs.jpcb.0c01919

${ }^{66}$ M. Pochylski, J. Gapinski, Brillouin Scattering Study of Polyethylene Glycol/Water System below Crystallization Temperature, J. Phys. Chem. B, 2010, 114, 2644-2649. DOI: 10.1021/jp910783j

67 M. Pochylski, F. Aliotta, Z. Blaszczak, J. Gapinski, Structuring Effects and Hydration Phenomena in Poly(Ethylene Glycol)/Water Mixtures Investigated by Brillouin Scattering, J. Phys. Chem. B, 2006, 110, 20533-20539. DOI: 10.1021/jp0620973

68 J. M. Vicent-Luna, J. M. Romero-Enrique, S. Calero, J. A. Anta, Micelle Formation in Aqueous Solutions of Room Temperature Ionic Liquids: A Molecular Dynamics Study, J. Phys. Chem. B, 2017, 121, 8348-8358. DOI: 10.1021/acs.jpcb.7b05552

69 Y. Zhao, S. Gao, J. Wang, J. Tang, Aggregation of ionic liquids [Cnmim] $\mathrm{Br}(\mathrm{n}=4,6,8$, 10, 12) in D2O: a NMR study, J. Phys. Chem. B, 2008, 112, 2031-2039. DOI: 10.1021/jp076467e

70 R. W. Pekala, Organic aerogels from the polycondensation of resorcinol with formaldehyde, J. Mater. Sci., 1989, 24, 3221-3227. DOI: 10.1007/BF01139044 
${ }^{71}$ A. Taguchi, J.-H. Smatt, M. Lindén, Carbon Monoliths Possessing a Hierarchical, Fully Interconnected Porosity, Adv. Mater., 2003, 15, 1209-1211. DOI: 10.1002/adma.200304848

72 S. A. Al-Muhtaseb, J. A. Ritter, Preparation and Properties of ResorcinolFormaldehyde Organic and Carbon Gels, Adv. Mater., 2003, 15, 101-114. DOI: 10.1002/adma.200390020

${ }^{73}$ Y. Zhai , Y. Dou , D. Zhao , P. F. Fulvio, R. T. Mayes, Sheng Dai, Carbon materials for chemical capacitive energy storage, Adv. Mater., 2011, 9, 4828-4850. DOI: 10.1002/adma.201100984

74 J. Biener, M. Stadermann, M. Suss, M. A. Worsley, M. M. Biener, K. A. Rose, T. F. Baumann, Advanced carbon aerogels for energy applications, Energy Environ. Sci., 2011, 4, 656-667. DOI: https://doi.org/10.1039/COEE00627K

75 J. Kiefer, J. G. Hilborn, J. L. Hedrick, H. J. Cha, D. Y. Yoon, J. C. Hedrick, Microporous Cyanurate Networks via Chemically Induced Phase Separation, Macromol., 1996, 29, 8546-8548. DOI: 10.1021/ma960960z

76 J. Kiefer, J. G. Hilborn, J. A. E. Manson, Y. Leterrier, J. L. Hedrick, Macroporous Epoxy Networks via Chemically Induced Phase Separation, Macromol., 1996, 29, 41584160. DOI: $10.1021 / \mathrm{ma951674a}$

77 T. Inoue, Reaction-induced phase decomposition in polymer blends, Prog. Polym. Sci., 1995, 20, 119-153. DOI: 10.1016/0079-6700(94)00032-W

${ }^{78}$ K. Nakanishi, N. Tanaka, Sol - Gel with Phase Separation. Hierarchically Porous Materials Optimized for High-Performance Liquid Chromatography Separations. Acc. Chem. Res., 2007, 40, 863-873. DOI: 10.1021/ar600034p

79 C. Triantafillidis, M. S. Elsaesser, N. Husing, Chemical Phase Separation Strategies towards Silica Monoliths with Hierarchical Porosity, Chem. Soc. Rev., 2013, 42, 3833-3846. DOI: 10.1039/C3CS35345A

${ }^{80}$ L. Li, X. Shen, S. W. Hong, R. C. Hayward, T. P. Russell, Fabrication of Co-Continuous Nanostructured and Porous Polymer Membranes: Spinodal Decomposition of Homopolymer and Random Copolymer Blends, Angew. Chem. Int. Ed., 2012, 51, 4089-4094. 10.1002/anie.201107867 
${ }^{81}$ F. Schuth, H.-J. Bongard, A.-H. Lu, Structurally designed synthesis of me- chanically stable poly(benzoxazine-co-resol)-based porous carbon monoliths and their application as high-performance $\mathrm{CO}_{2}$ capture sorbents, J. Am. Chem. Soc., 2011, 133, 11378-11388. DOI: 10.1021/ja203857g

82 G. Hasegawa, Y. Ishihara, K. Kanamori, K. Miyazaki, Y. Yamada, K. Nakanishi, T. Abe, Facile preparation of monolithic LiFePO4/carbon composites with well-defined macropores for a lithium-ion battery, Chem. Mater., 2011, 23, 5208-5216. DOI: $/ 10.1021 / \mathrm{cm} 2021438$

83 J. W. Cahn, Phase Separation by Spinodal Decomposition in Isotropic Systems, J. Chem. Phys., 1965, 42, 93-99. DOI: 10.1063/1.1695731

${ }^{84}$ Y. Gao, J. Kim, M. E. Helgeson, Microdynamics and arrest of coarsening during spinodal decomposition in thermoreversible colloidal gels, Soft Matter., 2015, 11, 6360-6370. DOI: 10.1039/C5SM00851D

${ }^{85}$ H. Kaji, K. Nakanishi, N. Soga, T. Inoue, N. Nemoto, In Situ Observation of Phase Separation Processes in Gelling Alkoxy-Derived Silica System by Light Scattering Method, J. Sol-Gel Sci. Technol., 1994, 3, 169-188. DOI: 10.1007/BF00486556

${ }^{86}$ H. Kaji, K. Nakanishi, N. Soga, T. Inoue, N. Nemoto, Phase Separation in Silica Sol-Gel System Containing Poly/ethylene oxide) II. Effects of Molecular Weight and Temperature, Bull. Chem. Soc. Jpn., 1997, 70, 587-592. DOI: 10.1246/bcsj.70.587

87 Sandercock, J. R. Trends in Brillouin scattering: studies of opaque materials, supported films, and central modes, in: M. Cardona, G. Güntherodt (Eds.), Light Scattering in Solids III: Recent Results, Springer Berlin Heidelberg, Berlin, Heidelberg 1982, pp. 173-206. DOI: xxx

${ }^{88}$ Küger, J. K. in: H. Bässler (Ed.), Optical Techniques to Characterize Polymer Systems in Studies in Polymer Science, Elsevier, Amsterdam 1989, pp. 429-5346. DOI: xxx

${ }^{89}$ See, Pulse Program Catalogue: I. 1D \& 2D NMR Experiments, Topspin v3.0 NMRGuide 2010 by Bruker BioSpin $\mathrm{GmbH}$ in http://www.biocore.pku.edu.cn/public/Uploads/file/20170901/20170901085426_5 9631.pdf 
90 Stejskal, E. O.; Tanner, J. E.; Spin Diffusion Measurements: Spin Echoes in the Presence of a Time-Dependent Field Gradient. J. Chem. Phys. 1965, 42, 288-292. DOI: $10.1063 / 1.1695690$.

91 Modern NMR techniques for chemistry research, in: A.E. Derome (Ed.), Tetrahedron Organic Chemistry Series, 6, Pergamon Press, 1987 , ISBN 978-0-08-032513-2.

92 A. K. Soper, Empirical Potential Structure Refinement - EPSRshell: a user's guide. Version 18 - May 2011, RAL Technical Reports RAL-TR-2011-012. 2011.

93 S. Callear, EPSRgui manual, RAL Technical Reports RAL-TR-2017-002. STFC, 2017.

94 A. K. Soper, GudrunN and GudrunX: programs for correcting raw neutron and X-ray diffraction data to differential scattering cross section, RAL Technical Reports RALTR-2011-013. 2011.

95 W. L. Jorgensen, D. S. Maxwell, J. Tirado-Rives, Development and testing of the OPLS all-atom force field on conformational energetics and properties of organic liquids. J. Am. Chem. Soc., 1996, 118, 11225-11236

96 M. Hussain, J. Anwar, The Riddle of Resorcinol Crystal Growth Revisited: Molecular Dynamics Simulations of $\alpha$-Resorcinol Cristal-Water Interface. J. Am. Chem. Soc., $1999,121,8583-8591$.

97 S. L. Perkins, P. Painter, C. M. Colina, Molecular Dynamic Simulations and Vibrational Analysis of an Ionic Liquid Analogue. J. Phys. Chem. B 2013, 117, 1025010260.

98 W. L. Jorgensen, N. A. McDonald, Development of an All-Atom Force Field for Heterocycles. Properties of Liquid Pyridine and Diazenes. J. Mol. Struct. 1998, 424, 145-155.

99 P. G. Kusalik, I. M. Svishchev, The Spatial Structure in Liquid Water. Science 1994, 265, 1219.

100 U. Essmann, L. Perera, M. L. Berkowitz, T. Darden, H. Lee, L. G. Pedersen, A Smooth Particle Mesh Ewald Method. J. Chem. Phys. 1995, 103, 8577-8593.

101 T. Darden, D. York, L. Pedersen, Particle Mesh Ewald - an N.Log(N) Method for Ewald Sums in Large Systems. J. Chem. Phys. 1993, 98, 10089-10092. 
102 L. Martinez, R. Andrade, E. G. Birgin, J. M. Martinez, Packmol: A Package for Building Initial Configurations for Molecular Dynamics Simulations. J. Comput. Chem. 2009, 30, 2157-2164.

M. C. Payne, M. P. Teter, D. C. Allan, T. A. Arias, J. D. Joannopoulos, Iterative Minimization Techniques for Ab Initio Total-Energy Calculations: Molecular Dynamics and Conjugate Gradients. Rev. Mod. Phys. 1992, 64, 1045-1097.

G. J. Martyna, M. E. Tuckerman, D. J. Tobias, M. L. Klein, Explicit Reversible Integrators for Extended Systems Dynamics. Mol. Phys. 1996, 87, 1117-1157.

S. Nose, A Molecular Dynamics Method for Simulations in the Canonical Ensemble (Reprinted from Molecular Physics, Vol 52, Pg 255, 1984). Mol. Phys. 2002, 100, 191-198.

W. G. Hoover, Canonical Dynamics - Equilibrium Phase-Space Distributions. Phys. Rev. A 1985, 31, 1695-1697.

S. Pronk, et al., Gromacs 4.5: A High-Throughput and Highly Parallel Open Source Molecular Simulation Toolkit. Bioinformatics 2013, 29, 845-854.

B. Hess, Gromacs 4: Algorithms for Highly Efficient, Load-Balanced, and Scalable Molecular Simulation. Abstr. of Papers of J. Am. Chem. Soc. 2009, 237, 435-447.

H. J. C. Berendsen, D. van der Spoel, R. Vandrunen, Gromacs - a Message-Passing Parallel Molecular-Dynamics Implementation. Comput. Phys. Commun. 1995, 91, 43-56.

110 D. van der Spoel, E. Lindahl, B. Hess, G. Groenhof, A. E. Mark, H. J. C. Berendsen, Gromacs: Fast, Flexible, and Free. J. Comput. Chem. 2005, 26, 1701-1718.

111 Vicent-Luna, J. M.; Azaceta, E.; Hamad, S.; Ortiz-Roldán, J. M.; Tena-Zaera, R.; Calero, S.; Anta, J. A., Molecular Dynamics Analysis of Charge Transport in IonicLiquid Electrolytes Containing Added Salt with Mono, Di, and Trivalent Metal Cations. ChemPhysChem. 2018, 19, 1665-1673.

112 Vicent-Luna, J. M.; Ortiz-Roldan, J. M.; Hamad, S.; Tena-Zaera, R.; Calero, S.; Anta, J. A., Quantum and Classical Molecular Dynamics of Ionic Liquid Electrolytes for $\mathrm{Na} /$ Li-Based Batteries: Molecular Origins of the Conductivity Behavior. ChemPhysChem 2016, 17, 2473-81. 
113 A. Luzar, D. Chandler, Structure and Hydrogen-Bond Dynamics of Water-Dimethyl Sulfoxide Mixtures by Computer-Simulations. J. Chem. Phys. 1993, 98, 8160-8173. 
Figure 7: $S E M$ micrographs of $C_{R U C h C l 3.6 B A}, C_{R U C h C l 5.4 B A}, C_{R U C h C l 8 B A}, C_{R U C h C 110 B A}, C_{R U C h C l 13 B A}$, and CRUChCl22BA.
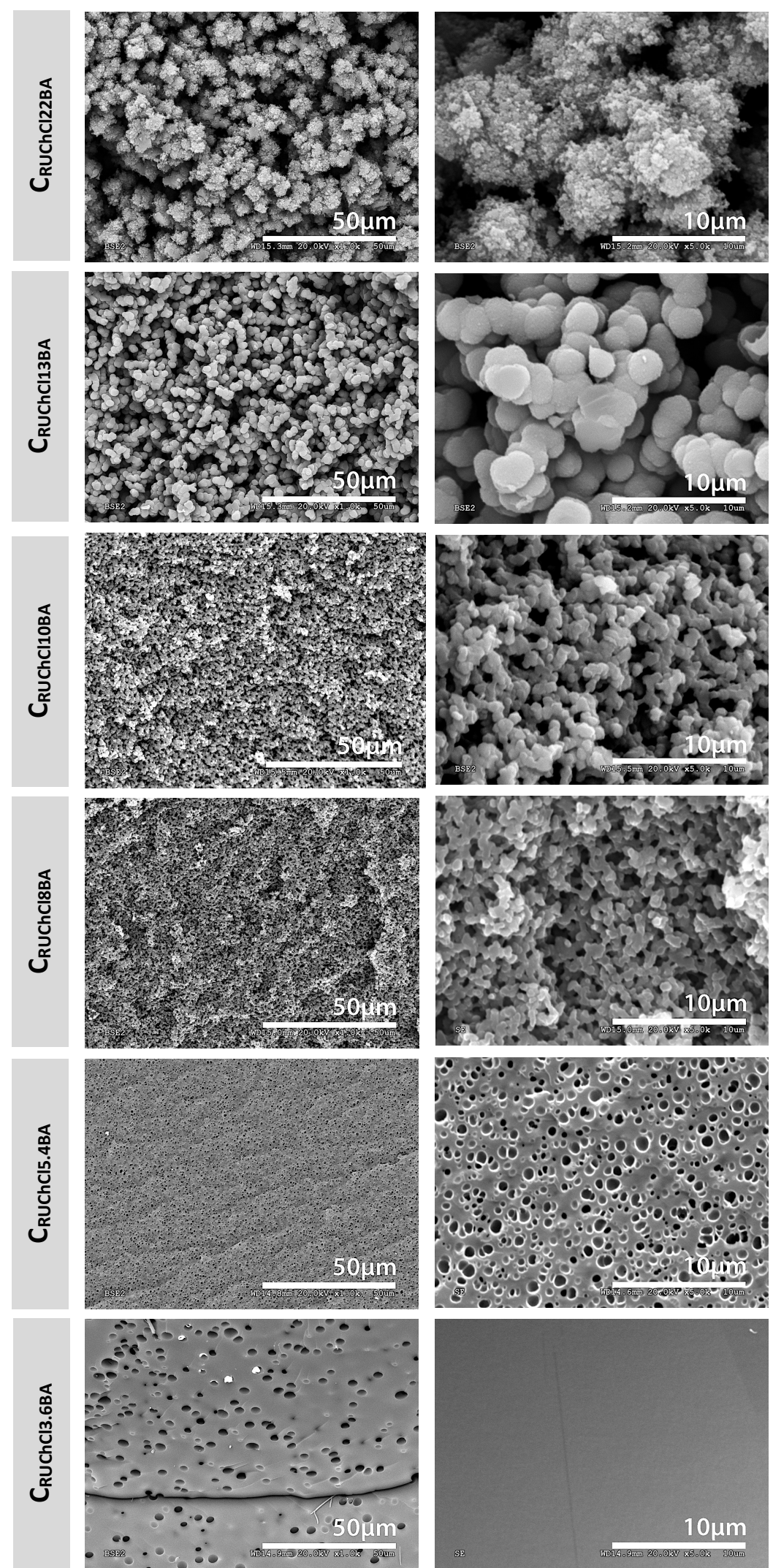
Figure 6: (a) Phase diagram of reaction time versus composition representing the binodal (red line) and spinodal curves (blue line). (b) SEM micrographs of RRUChCI5.4BA, $\mathrm{R}_{\mathrm{RUChCl} \text { BBA, }} \mathrm{R}_{\mathrm{RUChCl} 10 \mathrm{BA}}$ and $\mathrm{R}_{\mathrm{RUChCI} 2 \mathrm{BA}}$.
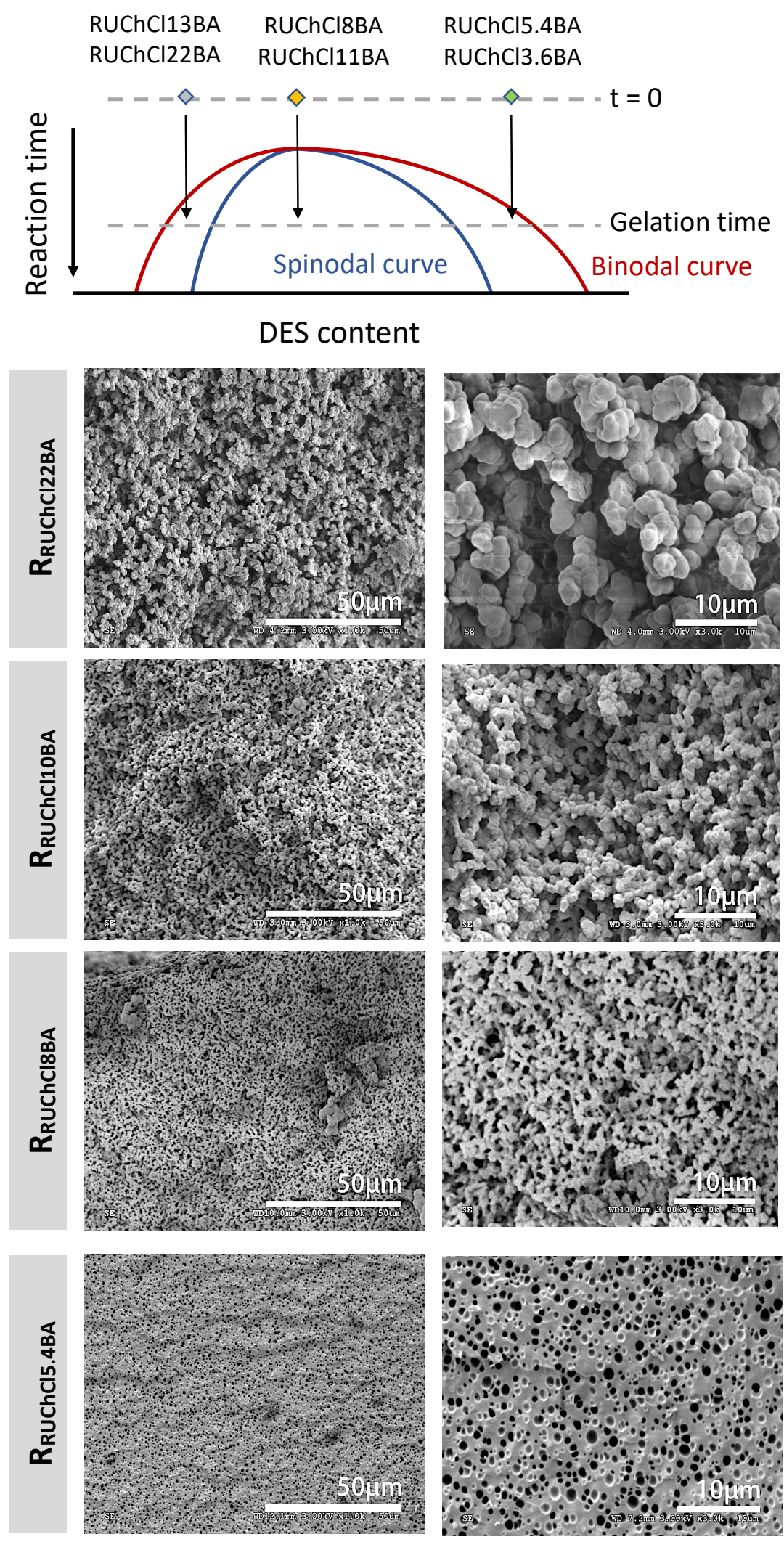
Figure 5: (a) Plot of hypersonic velocity $\left(v_{H}\right.$, blue circles) obtained from Brillouin spectroscopy versus DES content. Ultrasound velocity data ( $v_{v}$, red circles) are also included for comparison. (b) Chemical shifts obtained from ${ }^{1} \mathrm{H}$ NMR spectroscopy for protons at 2- (blue circles), 4- (orange circles) and 6- (grey circles) positions in $\mathrm{R}$ versus DES content. (c) Inverse of $T_{1}$ values obtained from ${ }^{1} \mathrm{H}$ NMR spectroscopy for $\mathrm{R}$ (red circles), $\mathrm{U}$ (purple circles) and $\mathrm{ChCl}$ (green circles) versus DES content. (d) Inverse of $T_{1}$ values obtained from ${ }^{1} \mathrm{H}$ NMR spectroscopy for $\mathrm{R}$ (red circles), $U$ (purple circles) and $\mathrm{ChCl}$ (green circles) versus viscosity of RUChClnBA with different DES contents (see Table S1b). Deviations occur within the range of 35-40 wt\% in DES content.

\section{a}

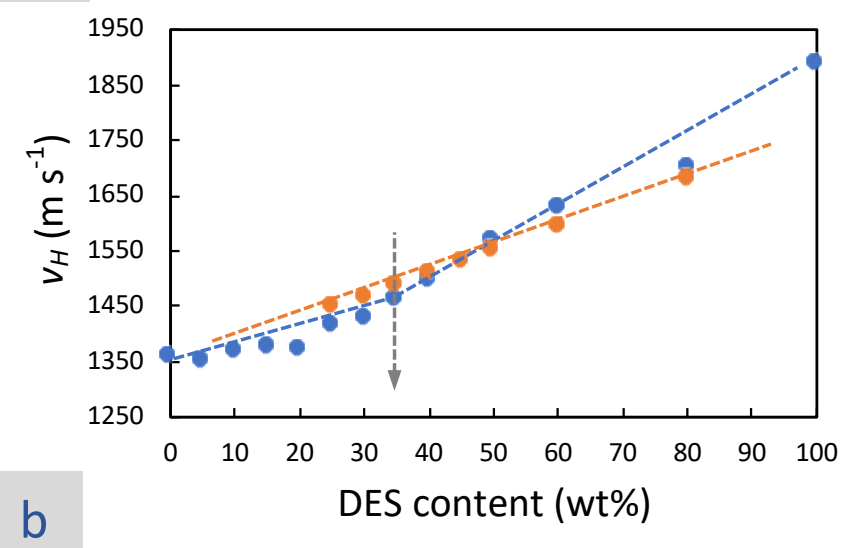

b

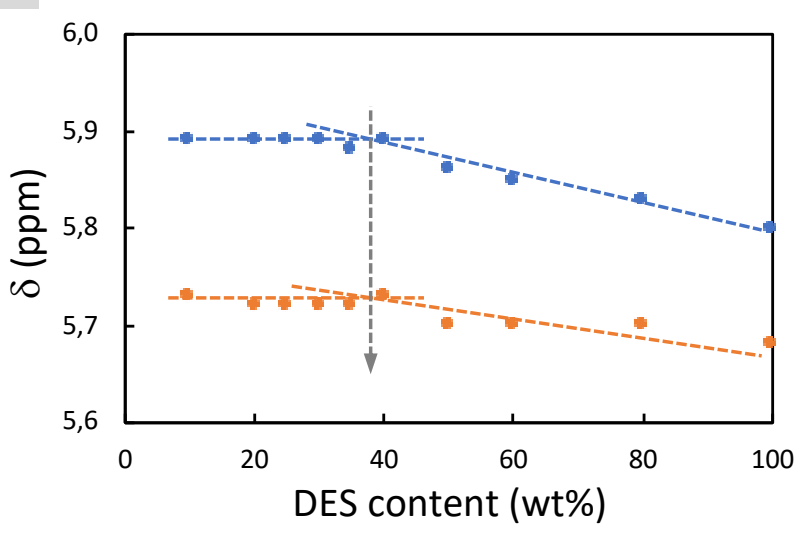

C
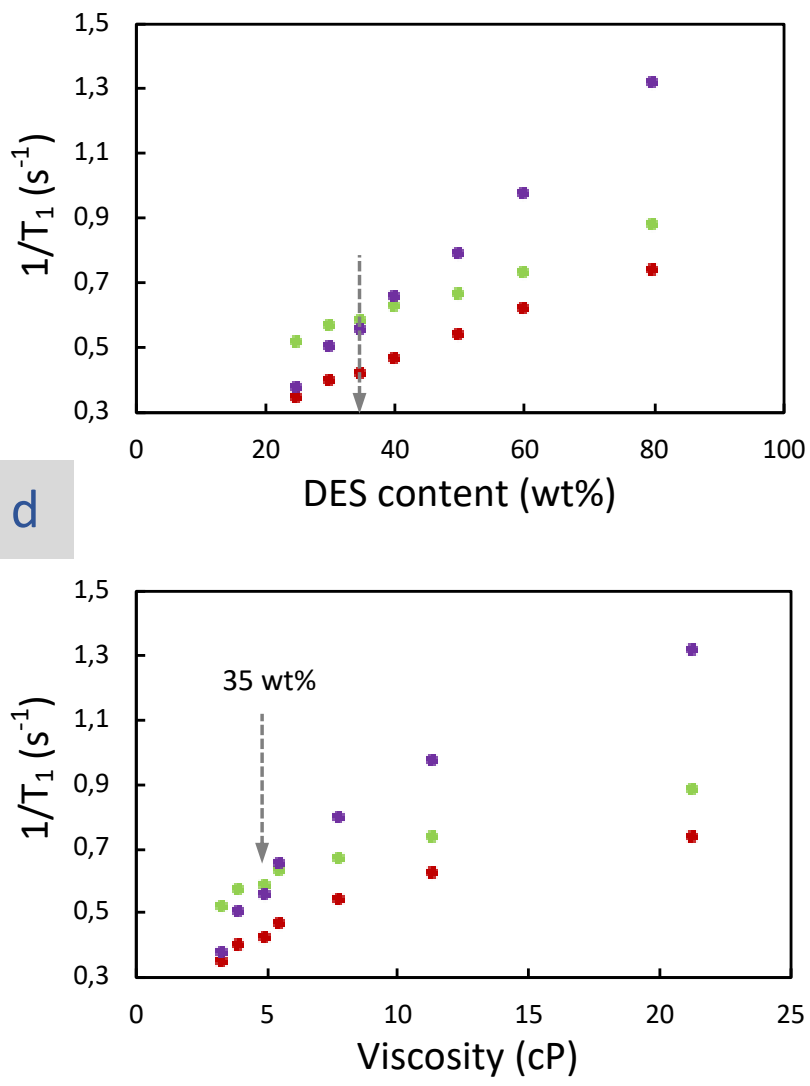
Figure 4: (a) MD simulation snapshot showing BA self-interactions, HB type between one BA molecule and two adjacent ones, and $\pi-\pi$ between one BA molecule and one adjacent one. Carbon atoms in blue, hydrogen atoms in white and oxygen atoms in red. Distances used in MD simulations were $x x$ for $H B$ and $y y$ for $\pi-\pi$. (b) MD simulation snapshot of the lineal HB network (in orange) formed in neat BA. Carbon atoms in blue and oxygen atoms in red. (c) Average number of HBs (red circles) and of $\pi$ - $\pi$ interactions (blue diamonds) per molecule of BA versus DES content (in wt \%). (d) Probability of finding molecules of $\mathrm{BA}$ forming $\mathrm{HBs}$ in RUChClOBA (red circles), $\mathrm{RUChCl5.4BA}$ (blue triangles), RUChCl11BA (green squares), and RUChCl21BA (purple diamonds), as obtained from MD simulation.
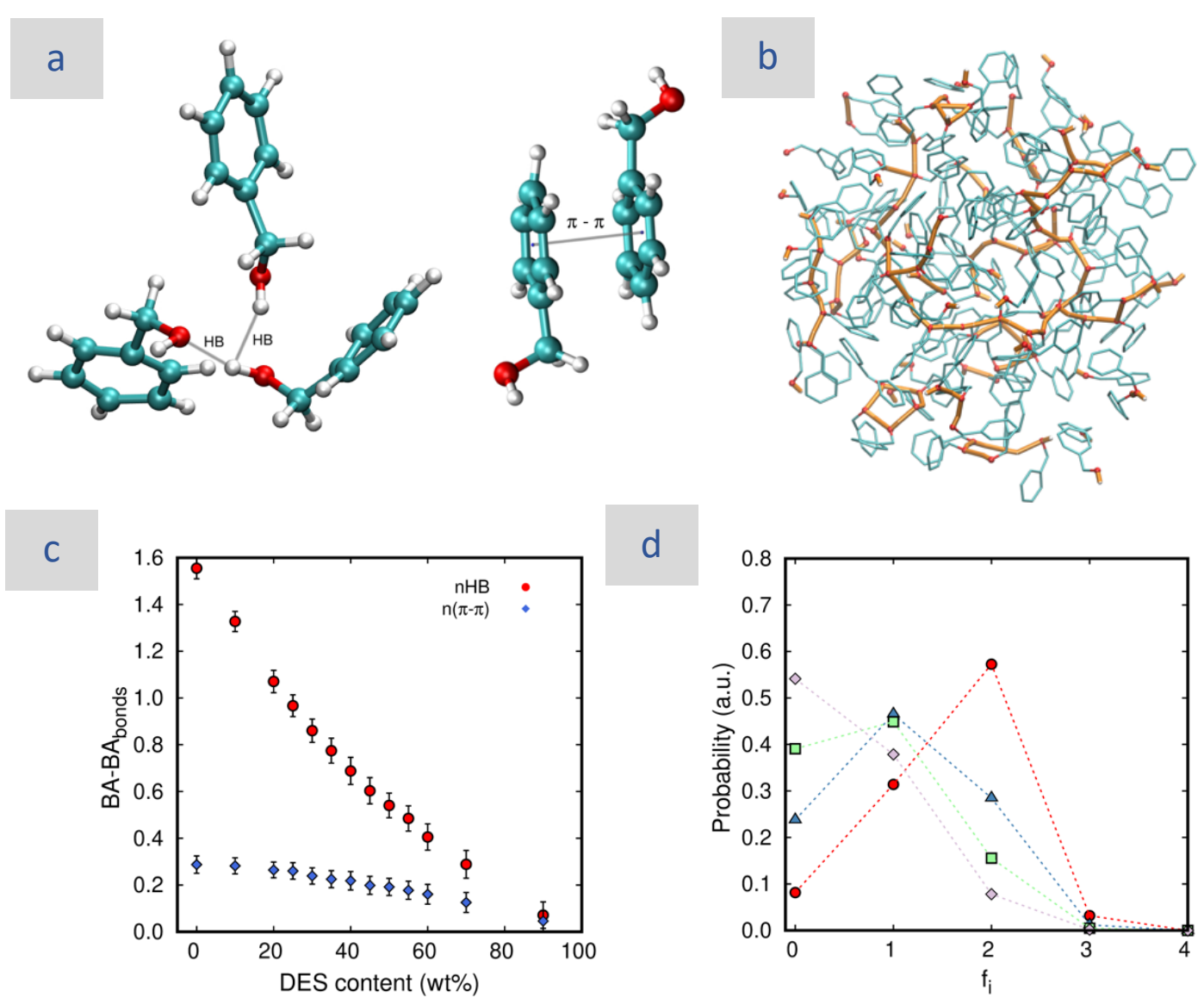

d

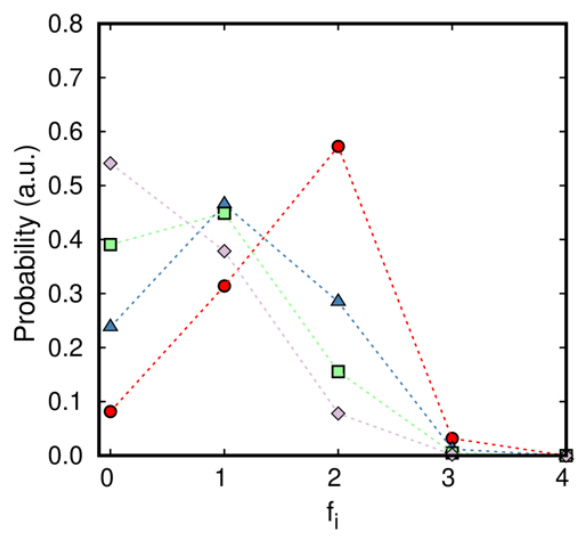


Figure 3: (a) Coordination numbers ( $N_{\text {coord }}$ ) for $\mathrm{HB}$ interactions established by $\mathrm{Cl}$ with $\mathrm{U}$ $(\mathrm{Cl}-\mathrm{Hu})$ and $\mathrm{Ch}(\mathrm{Cl}-\mathrm{HcO}), \mathrm{R}(\mathrm{Cl}-\mathrm{Hrp})$, and $\mathrm{BA}(\mathrm{Cl}-\mathrm{Hb})$ in RUChClOBA (red bars), RUChCl5.4BA (purple bars), RUChCl11BA (green bars), and RUChCl21BA (blue bars). (b) $N_{\text {coord }}$ for HB interactions established by either water (in RUChCl11W; orange bars) or $\mathrm{BA}$ (in RUChCl5.4BA and RUChCl11BA; purple and green bars, respectively) with $\mathrm{U}$ (OuHsolvent), Ch (Oc-Hsolvent), and R (Or-Hsolvent) playing the solvent the role of HBA, and with $\mathrm{R}$ (Osolvent-Hrp) playing the solvent the role of HBA. HB self-correlation interactions are also included (Osolvent-Hsolvent).

a

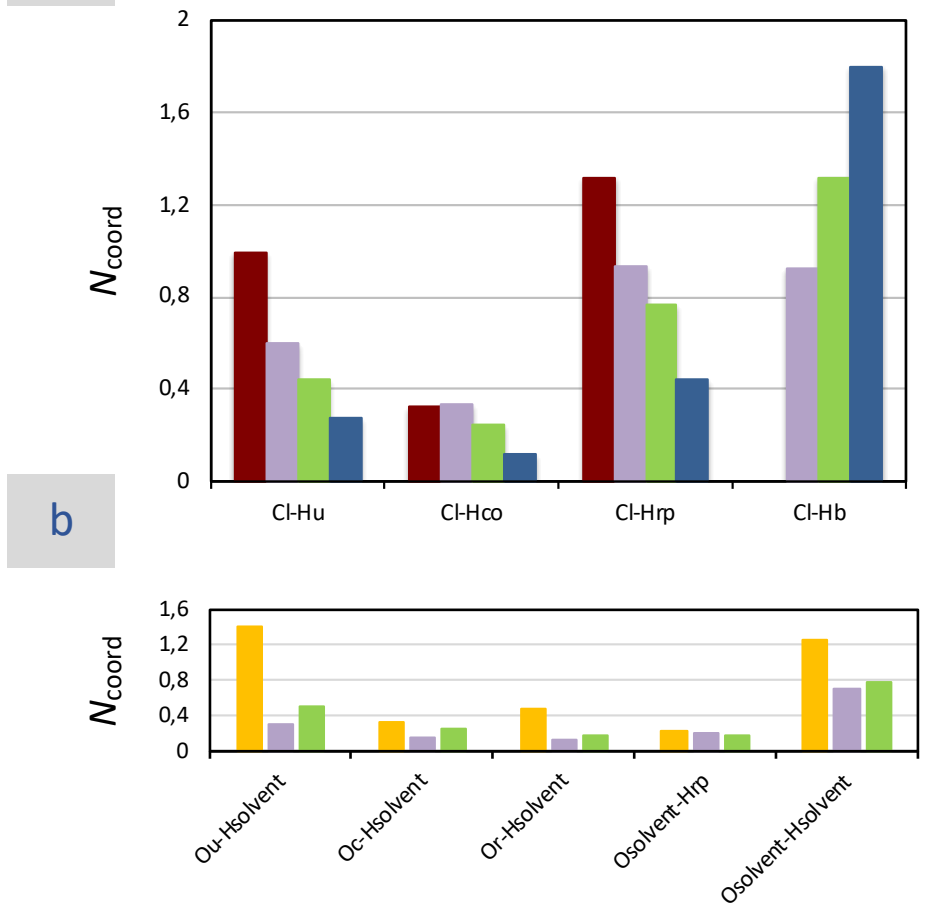


Figure 2: Partial $g(r)$ values for pair correlations between different exchangeable protons and the chloride anion as obtained from (a) EPSR analysis of neutron scattering experiments and (b) MD simulations, in RUChClOBA (red line), RUChCl5.4BA (yellow line), RUChCl11BA (blue line), and RUChCl21BA (green line) at $353 \mathrm{~K}$.
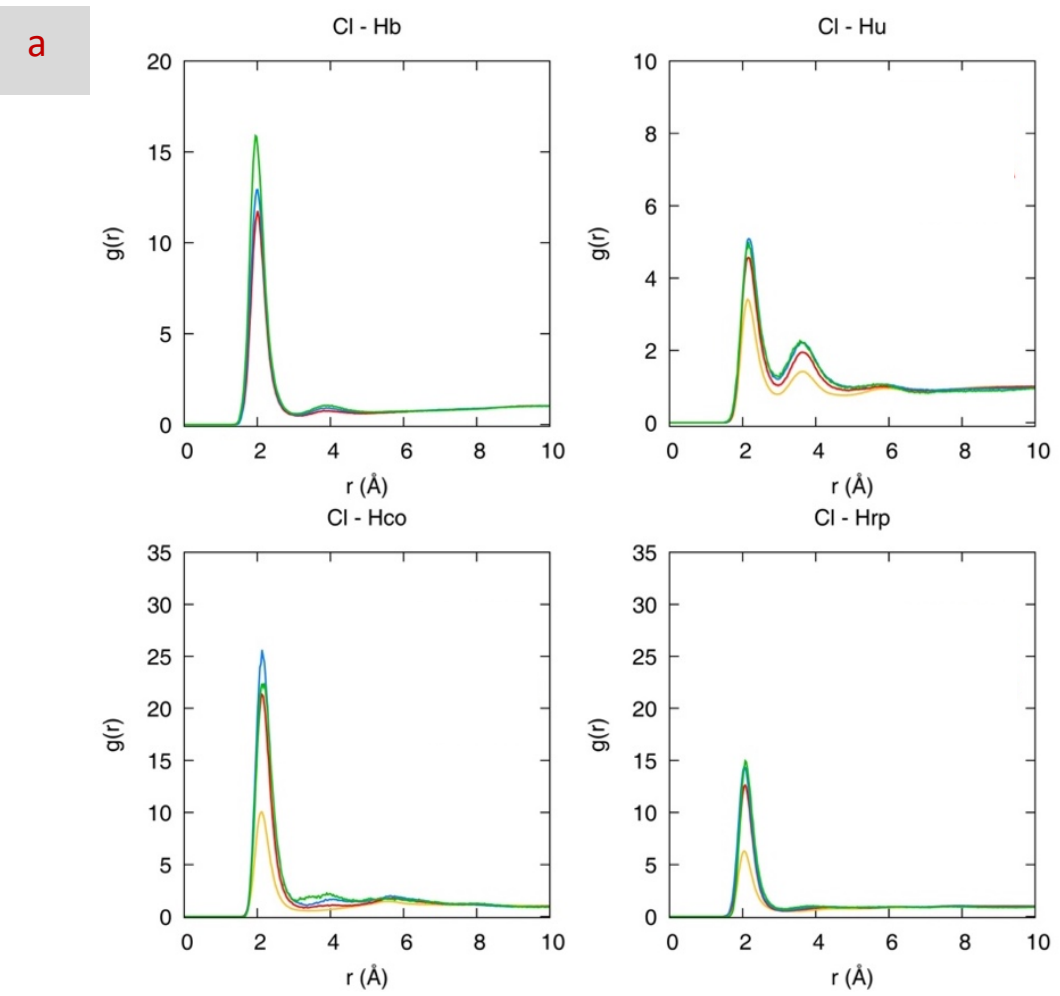

b
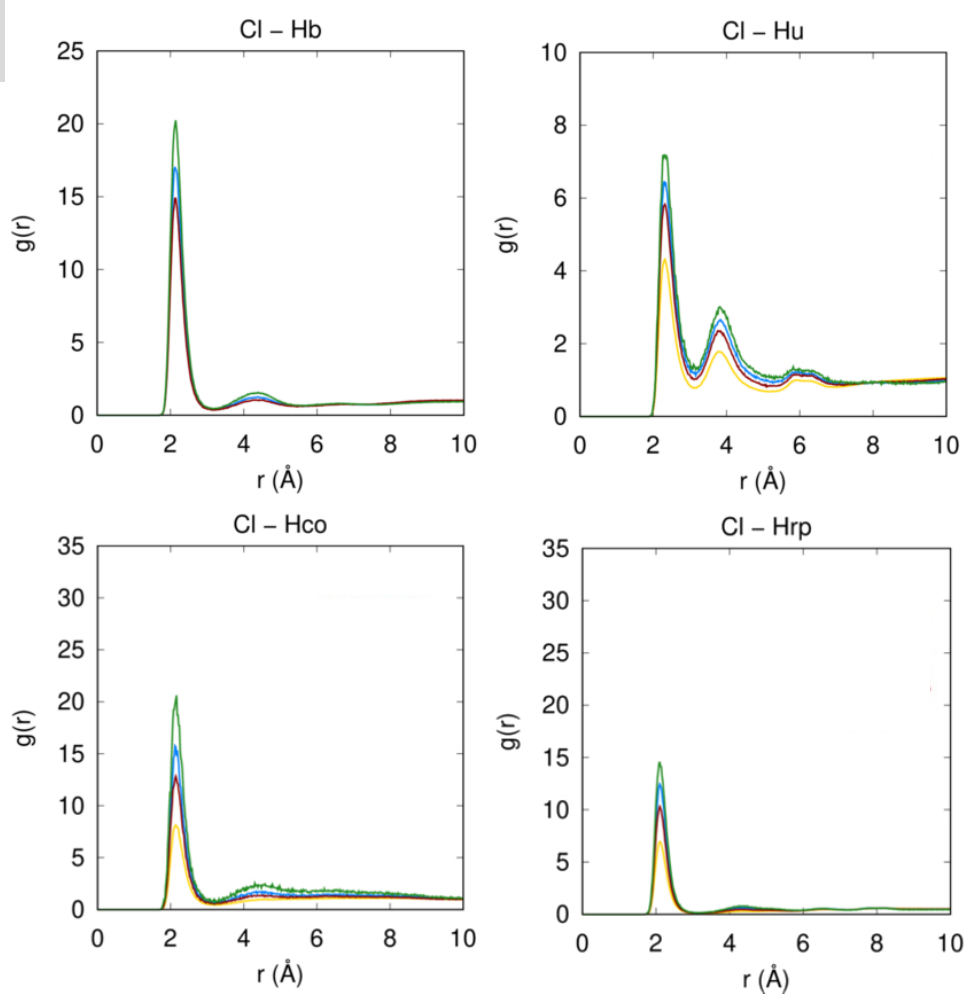
Figure 1: Molecules used to create the EPSR reference potential labelled with atom number and atom type, and the assigned interatomic bond length constraints alongside the permitted variance in bond length.

RESORCINOL

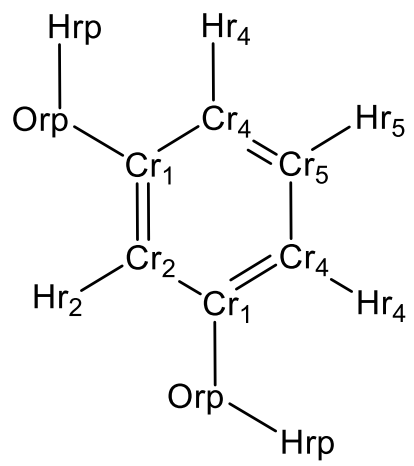

CHOLINE CHLORIDE

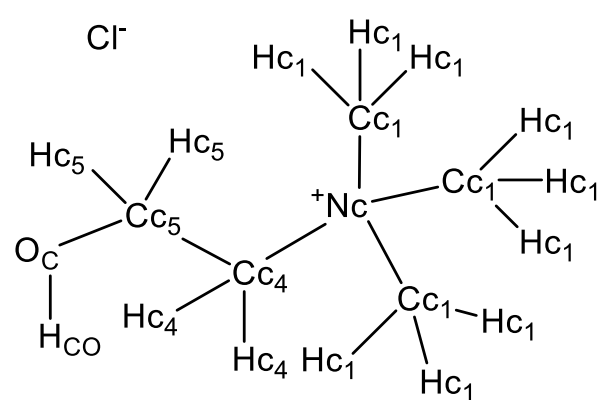

UREA<smiles>CN(C)C(=O)N(C)C</smiles>

BENZYL ALCOHOL

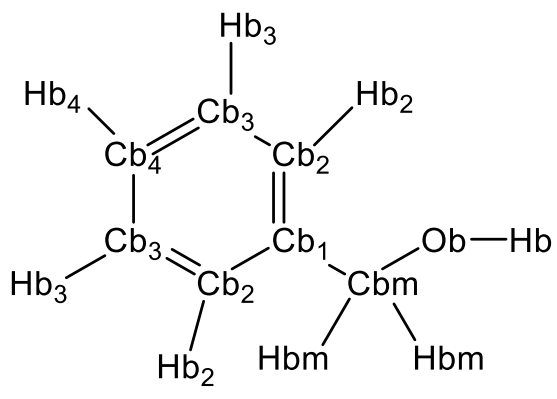


Table S1: Components contents (as molar ratios and wt\%) in the different samples. Samples studied by NDIS-EPSR are in red.

\begin{tabular}{ccccccc}
\hline $\begin{array}{c}\text { DES content } \\
(\mathbf{w t} \%)\end{array}$ & $\begin{array}{c}\text { BA content } \\
(\mathbf{w t} \%)\end{array}$ & $\begin{array}{c}\mathbf{R} \\
(\mathbf{m o l})\end{array}$ & $\begin{array}{c}\mathbf{U} \\
(\mathbf{m o l})\end{array}$ & $\begin{array}{c}\text { ChCl } \\
(\mathbf{m o l})\end{array}$ & $\begin{array}{c}\text { BA } \\
(\mathbf{m o l})\end{array}$ & Sample \\
\hline 100 & 0 & 3 & 2 & 1 & 0 & RUChCl0BA \\
80 & 20 & 3 & 2 & 1 & 1.4 & RUChCl1.4BA \\
60 & 40 & 3 & 2 & 1 & 3.6 & RUChCl3.6BA \\
55 & 45 & 3 & 2 & 1 & 4.5 & RUChCl4.5BA \\
50 & 50 & 3 & 2 & 1 & 5.4 & RUChCl5.4BA \\
45 & 55 & 3 & 2 & 1 & 6.7 & RUChCl7BA \\
40 & 60 & 3 & 2 & 1 & 8.2 & RUChCl8BA \\
35 & 65 & 3 & 2 & 1 & 10.1 & RUChCl10BA \\
33 & 67 & 3 & 2 & 1 & 11 & RUChCl11BA \\
30 & 70 & 3 & 2 & 1 & 12.7 & RUChCl13BA \\
25 & 75 & 3 & 2 & 1 & 16.3 & RUChCl16A \\
20 & 80 & 3 & 2 & 1 & 21.8 & RUChCl22BA \\
10 & 90 & 3 & 2 & 1 & 49.1 & RUChCl49BA \\
\hline
\end{tabular}

Table S2: Summary of the different isotopic substitution used in RUChCl22BA, RUChCl11BA and $\mathrm{RUChCl5.4BA}$ to carry out the neutron scattering experiments.

\begin{tabular}{|c|c|c|c|c|c|c|c|c|c|c|c|c|c|c|c|c|c|}
\hline \multicolumn{6}{|c|}{ RUChCl22BA } & \multicolumn{6}{|c|}{ RUChCl11BA } & \multicolumn{6}{|c|}{ RUChCl5.4BA } \\
\hline \multirow{2}{*}{ ID } & \multicolumn{4}{|c|}{ Composition } & \multirow{2}{*}{$\begin{array}{c}\text { DSC } \\
\text { Level }\end{array}$} & & & & & & \multirow{2}{*}{ DSC Level } & & & & & & \multirow{2}{*}{ DSC Level } \\
\hline & $\mathrm{R}$ & $U$ & $\mathrm{C}$ & BA & & & $\mathrm{R}$ & $U$ & C & BA & & & $\mathrm{R}$ & $U$ & C & BA & \\
\hline 11 & D & $\mathrm{D}$ & D & $\mathrm{D}$ & $20 \% a$ & 21 & $\mathrm{D}$ & $\mathrm{D}$ & $\mathrm{D}$ & $\mathrm{D}$ & OK & 31 & D & $\mathrm{D}$ & D & $\mathrm{D}$ & OK \\
\hline 12 & $\mathrm{H}$ & D & $D$ & D & OK & 22 & $\mathrm{H}$ & D & D & D & OK & 32 & $\mathrm{H}$ & D & $D$ & $D$ & OK \\
\hline 13 & $D$ & $\mathrm{H}$ & $\mathrm{D}$ & $D$ & OK & 23 & $\mathrm{D}$ & $\mathrm{H}$ & $\mathrm{D}$ & $\mathrm{D}$ & OK & 33 & $\mathrm{D}$ & $\mathrm{H}$ & $D$ & $D$ & OK \\
\hline 14 & $\mathrm{D}$ & $\mathrm{D}$ & $\mathrm{H}$ & $\mathrm{D}$ & $\mathrm{OK}$ & 24 & $\mathrm{D}$ & $\mathrm{D}$ & $\mathrm{H}$ & $\mathrm{D}$ & $\mathrm{OK}$ & 34 & $\mathrm{D}$ & $\mathrm{D}$ & $\mathrm{H}$ & $\mathrm{D}$ & $\mathrm{OK}$ \\
\hline 15 & $\mathrm{D}$ & $\mathrm{D}$ & $\mathrm{D}$ & $\mathrm{H}$ & OK & 25 & $\mathrm{D}$ & $\mathrm{D}$ & $\mathrm{D}$ & $\mathrm{H}$ & OK & 35 & $\mathrm{D}$ & $\mathrm{D}$ & $\mathrm{D}$ & $\mathrm{H}$ & OK \\
\hline 16 & $\mathrm{H}$ & $\mathrm{H}$ & $\mathrm{H}$ & $\mathrm{H}$ & OK & 26 & $\mathrm{H}$ & $\mathrm{H}$ & $\mathrm{H}$ & $\mathrm{H}$ & $\mathrm{OK}$ & 36 & $\mathrm{H}$ & $\mathrm{H}$ & $\mathrm{H}$ & $\mathrm{H}$ & OK \\
\hline 17 & $\mathrm{DH}$ & $\mathrm{DH}$ & $\mathrm{DH}$ & $\mathrm{DH}$ & OK & 27 & $\mathrm{DH}$ & $\mathrm{DH}$ & $\mathrm{DH}$ & $\mathrm{DH}$ & OK & 37 & $\mathrm{DH}$ & $\mathrm{DH}$ & $\mathrm{DH}$ & $\mathrm{DH}$ & OK \\
\hline 18 & $\mathrm{DH}$ & $\mathrm{D}$ & $\mathrm{D}$ & $\mathrm{D}$ & OK & 28 & $\mathrm{DH}$ & $\mathrm{D}$ & $\mathrm{D}$ & $\mathrm{D}$ & OK & 38 & $\mathrm{DH}$ & $\mathrm{D}$ & $\mathrm{D}$ & $\mathrm{D}$ & OK \\
\hline 19 & $\mathrm{D}$ & $\mathrm{DH}$ & $\mathrm{D}$ & $\mathrm{D}$ & OK & 29 & $\mathrm{D}$ & $\mathrm{DH}$ & $\mathrm{D}$ & $\mathrm{D}$ & OK & 39 & $\mathrm{D}$ & $\mathrm{DH}$ & $\mathrm{D}$ & $\mathrm{D}$ & OK \\
\hline 110 & $D$ & $\mathrm{D}$ & $\mathrm{DH}$ & $\mathrm{D}$ & OK & 210 & $D$ & $\mathrm{D}$ & $\mathrm{DH}$ & $\mathrm{D}$ & NM & 310 & $\mathrm{D}$ & $\mathrm{D}$ & $\mathrm{DH}$ & $\mathrm{D}$ & OK \\
\hline 111 & $\mathrm{D}$ & $\mathrm{D}$ & $D$ & $\mathrm{DH}$ & OK & 211 & $\mathrm{D}$ & $\mathrm{D}$ & $\mathrm{D}$ & $\mathrm{DH}$ & OK & 311 & $\mathrm{D}$ & $\mathrm{D}$ & $\mathrm{D}$ & $\mathrm{DH}$ & OK \\
\hline
\end{tabular}

* a: above, b: bellow, OK: Sample and Gudrun DSC levels coincides, NM: Not measured 
Table S3: Lennard-Jones parameters, masses, and point charges used in the reference potential to simulate RUChCl DES components and BA. Atom types are depicted in Figure 1 of the manuscript.

\begin{tabular}{|c|c|c|c|c|c|}
\hline & Atom type & $\varepsilon(\mathrm{kJ} / \mathrm{mol})$ & $\sigma(\AA)$ & mass (amu) & $q(e)$ \\
\hline \multirow{9}{*}{ Resorcinol } & $\mathrm{Cr} 5$ & 0.293 & 3.550 & 12.011 & 0.098 \\
\hline & $\mathrm{Cr} 4$ & 0.293 & 3.550 & 12.011 & -0.589 \\
\hline & $\mathrm{Hr} 5$ & 0.126 & 2.420 & 2.000 & 0.133 \\
\hline & $\mathrm{Cr} 1$ & 0.293 & 3.550 & 12.011 & 0.601 \\
\hline & $\mathrm{Hr} 4$ & 0.126 & 2.420 & 2.000 & 0.198 \\
\hline & $\mathrm{Cr} 2$ & 0.293 & 3.550 & 12.011 & -0.585 \\
\hline & Or & 0.711 & 3.070 & 15.999 & -0.622 \\
\hline & $\mathrm{Hr} 2$ & 0.126 & 2.420 & 2.000 & 0.266 \\
\hline & Hrp & 0.000 & 0.000 & 2.000 & 0.456 \\
\hline \multirow{4}{*}{ Urea } & $\mathrm{Cu}$ & 0.439 & 3.750 & 12.011 & 0.152 \\
\hline & $\mathrm{Ou}$ & 0.878 & 2.960 & 15.999 & -0.390 \\
\hline & $\mathrm{Nu}$ & 0.711 & 3.250 & 14.007 & -0.541 \\
\hline & $\mathrm{Hu}$ & 0.000 & 0.000 & 2.000 & 0.330 \\
\hline \multirow{9}{*}{ Choline } & $\mathrm{Nc}$ & 0.700 & 3.200 & 14.007 & 1.000 \\
\hline & Cc4 & 0.800 & 3.700 & 12.011 & -0.120 \\
\hline & Cc1 & 0.800 & 3.700 & 12.011 & -0.180 \\
\hline & Cc5 & 0.800 & 3.700 & 12.011 & 0.145 \\
\hline & Hc4 & 0.200 & 2.580 & 2.000 & 0.060 \\
\hline & Hc1 & 0.200 & 2.580 & 2.000 & 0.060 \\
\hline & Oc & 0.650 & 3.100 & 15.999 & -0.683 \\
\hline & Hc5 & 0.200 & 2.580 & 2.000 & 0.060 \\
\hline & Hco & 0.000 & 0.000 & 2.000 & 0.418 \\
\hline Chloride & $\mathrm{Cl}$ & 0.566 & 4.191 & 35.453 & -1.000 \\
\hline \multirow{11}{*}{$\begin{array}{l}\text { Benzyl } \\
\text { alcohol }\end{array}$} & Cb1 & 0.28 & 3.50 & 12.01 & -0.06 \\
\hline & $\mathrm{Cb} 2$ & 0.29 & 3.55 & 12.01 & -0.12 \\
\hline & $\mathrm{Cbm}$ & 0.28 & 3.50 & 12.01 & 0.15 \\
\hline & Cb3 & 0.29 & 3.55 & 12.01 & -0.12 \\
\hline & $\mathrm{Hb} 2$ & 0.13 & 2.42 & 2.00 & 0.12 \\
\hline & $\mathrm{Hbm}$ & 0.13 & 2.50 & 2.00 & 0.04 \\
\hline & $\mathrm{Ob}$ & 0.71 & 3.12 & 16.00 & -0.68 \\
\hline & $\mathrm{Cb} 4$ & 0.29 & 3.55 & 12.01 & -0.12 \\
\hline & Hb3 & 0.13 & 2.42 & 2.00 & 0.12 \\
\hline & $\mathrm{Hb}$ & 0.00 & 0.00 & 2.00 & 0.52 \\
\hline & $\mathrm{Hb} 4$ & 0.13 & 2.42 & 2.00 & 0.12 \\
\hline
\end{tabular}


Figure S2: Densities obtained experimentally (blue triangles) and by MD simulations (red circles) (a) and viscosities obtained experimentally (b) of $\mathrm{RUChCl}$ and $\mathrm{BA}$ dilutions thereof.

a

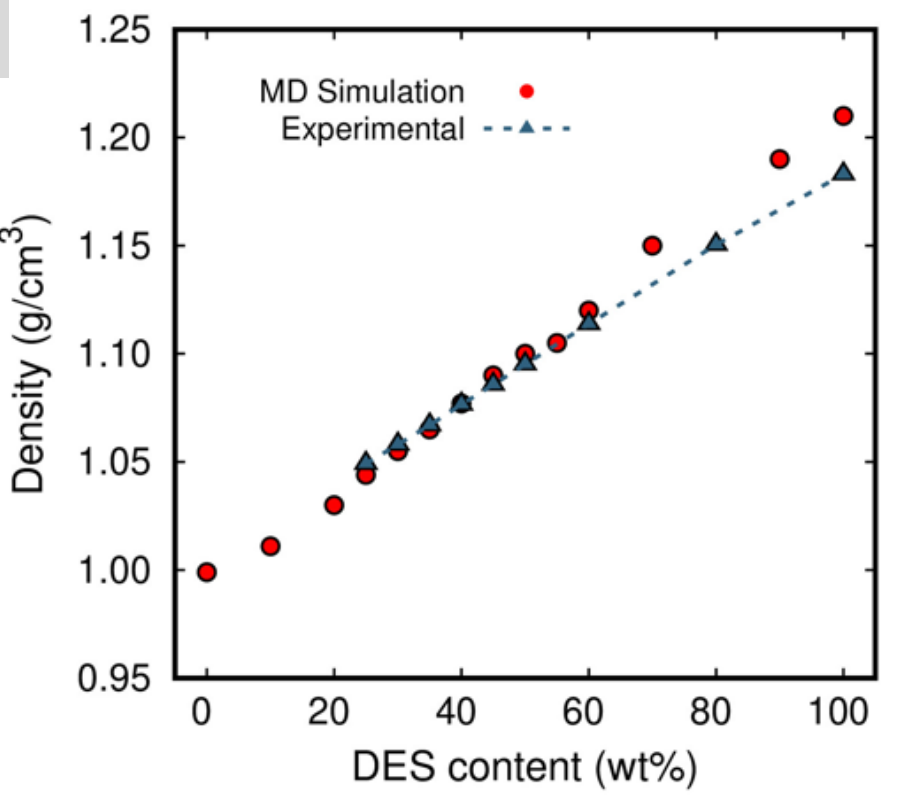

b

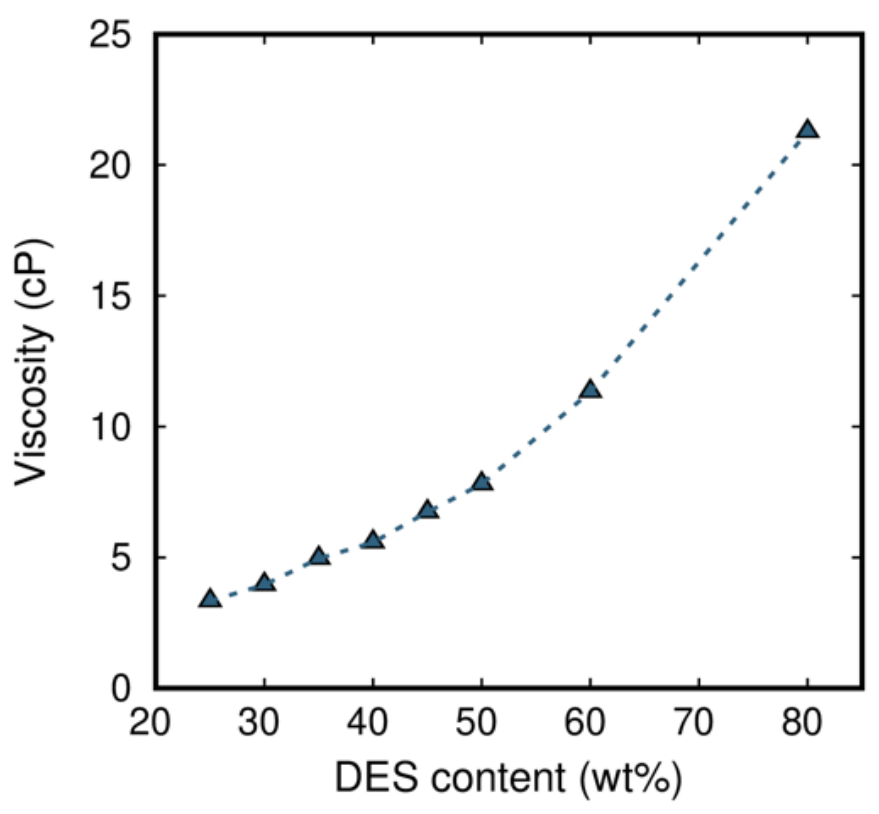


Figure S2: EPSR fits of the total diffraction data shown as a function of (left) $Q$ and (right) $r$ space of RUCBA samples (please note that levels have been shifted in the Y-axes for clarity).

RUChClOBA

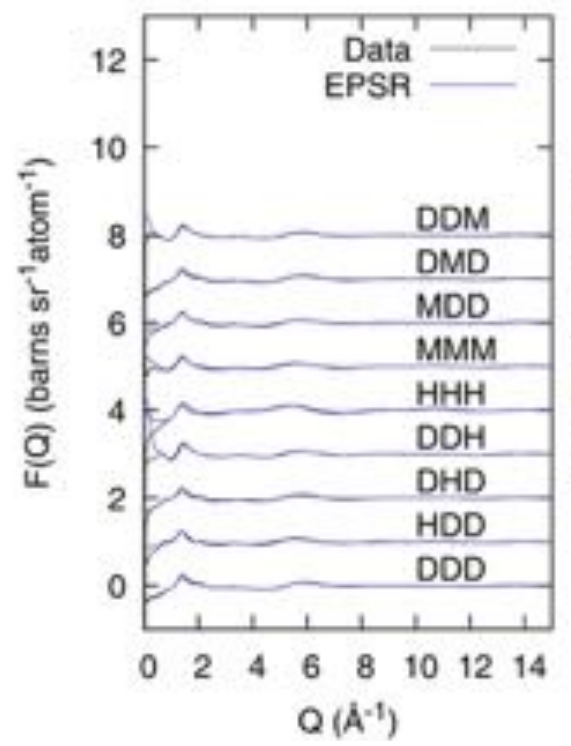

RUChCl11BA

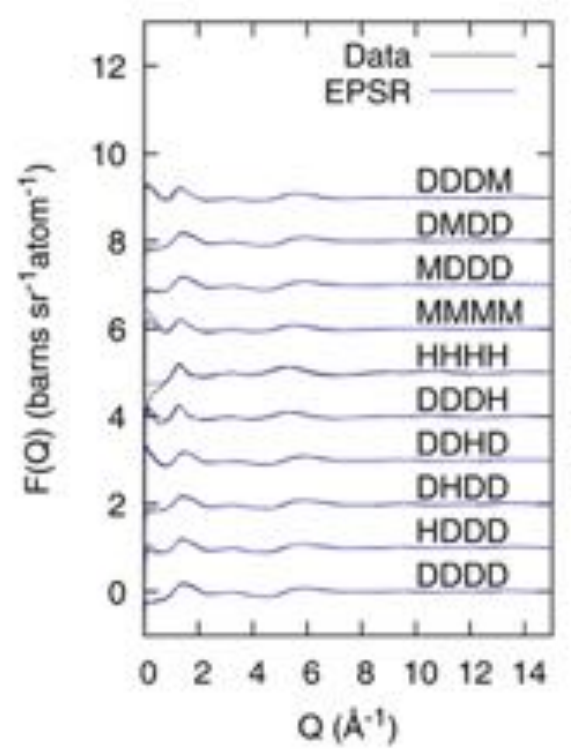

RUChCl5.4BA

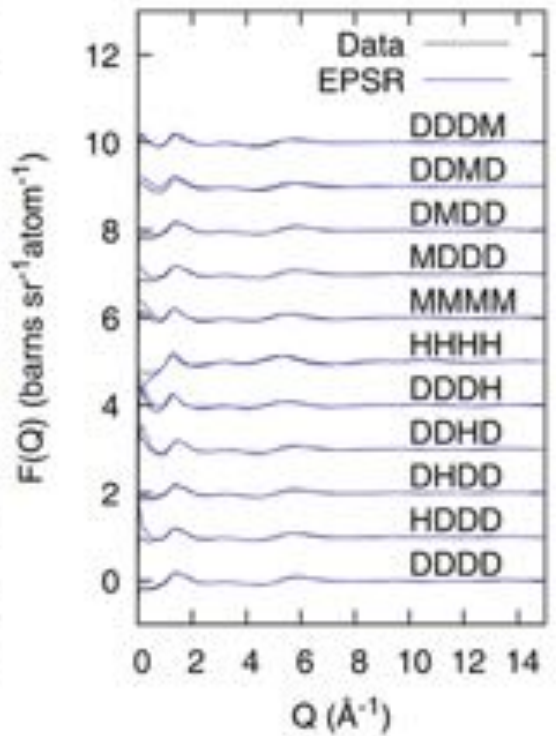

RUChCl22BA

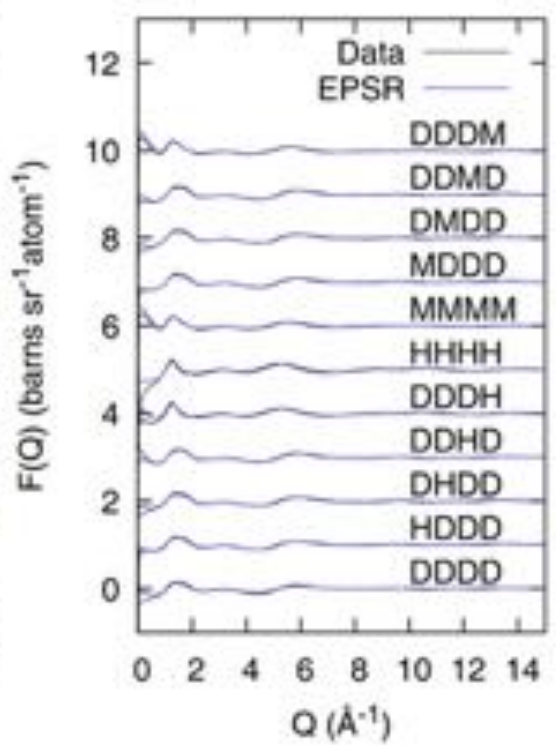

\footnotetext{
* The different contrasts are labeled acording to RUChClnBA isotopes. Note that $\mathrm{H}$ stands for the fully protonated isotope of a given molecule, $\mathrm{D}$ for the deuterated one whereas $M$ stands for a 50 wt\% mixture of $H$ and $D$ compounds (e.g., DDDM stands for fully deuterated $\mathrm{R}, \mathrm{U}$ and $\mathrm{Ch}$ mixed with a $50 \mathrm{wt} \%$ mixture of $D / H$ isotopes of $B A$ ).
} 
Figure S3: Total diffraction shown as a function of $Q$ of the different samples.

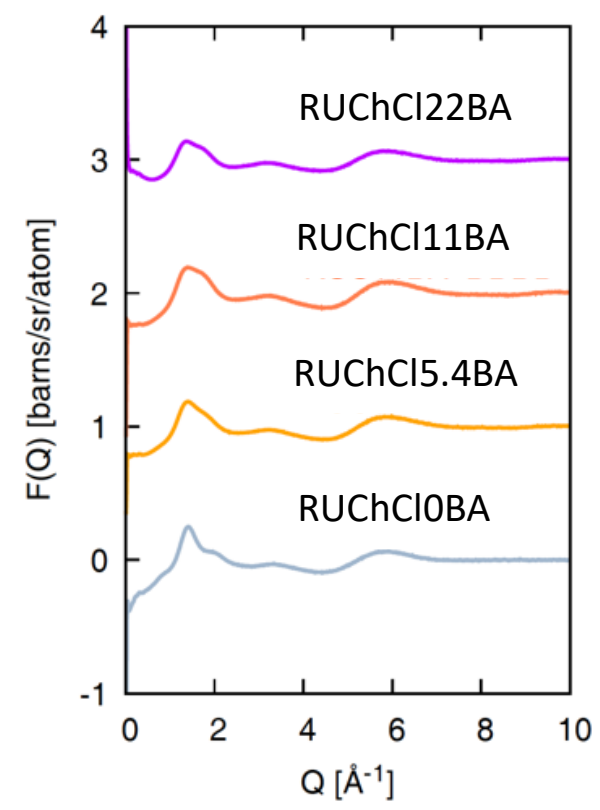

Figure S4: EPSR-derived RDFs for pair correlations between urea and choline, urea and chloride and urea self-correlation, and between choline and chloride, and choline self-correlation in RUChCIOBA (red line), RUChCl5.4BA (green line), RUChCl11BA (blue line), and RUChCl22BA (yellow line) at 353 K.
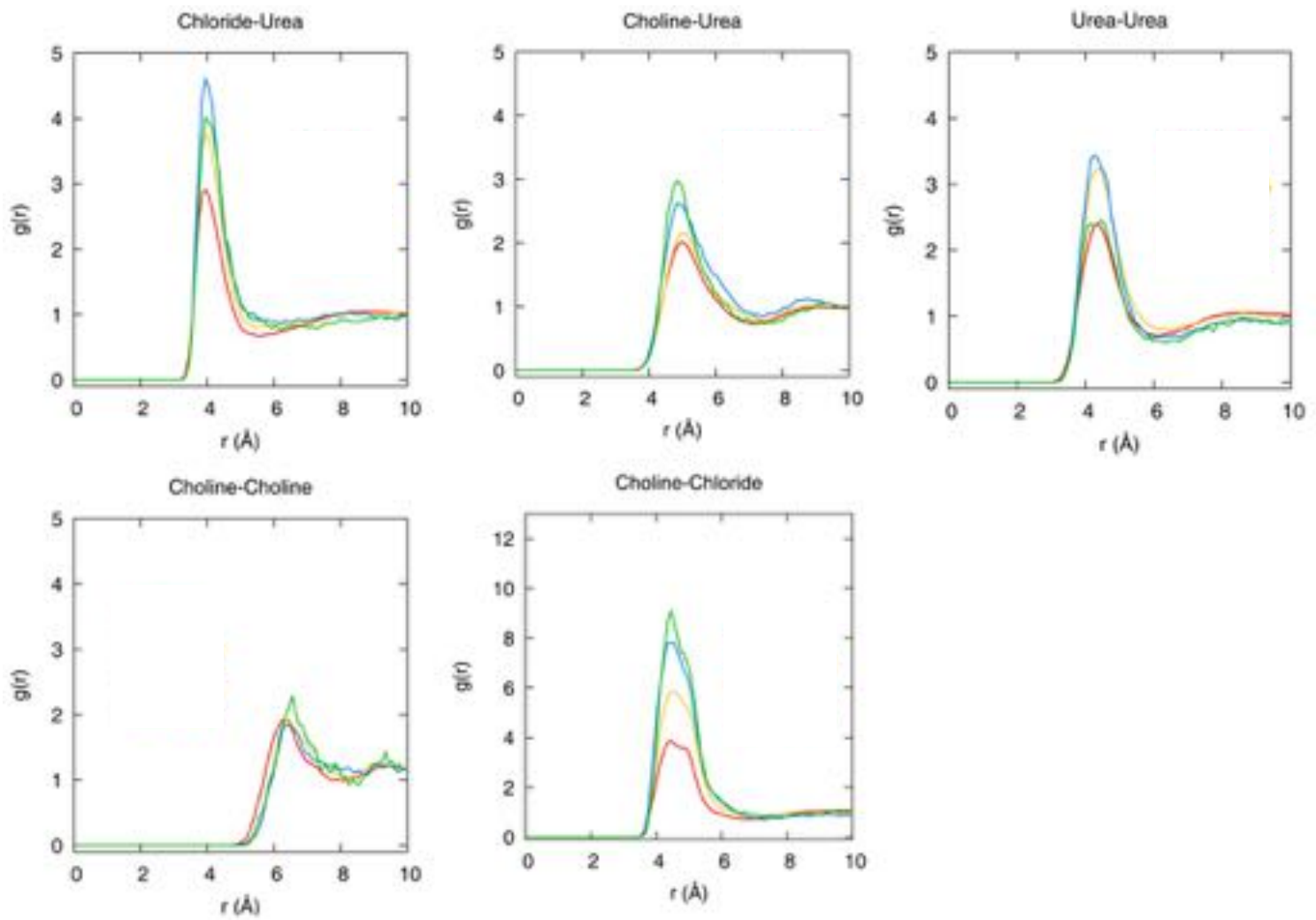
Figure S5: EPSR-derived RDFs for pair correlations between resorcinol and all other DES components, including resorcinol self-correlation, in RUChClOBA (red line), RUChCl5.4BA (green line), RUChCl11BA (blue line), and RUChCl22BA (yellow line) at $353 \mathrm{~K}$.
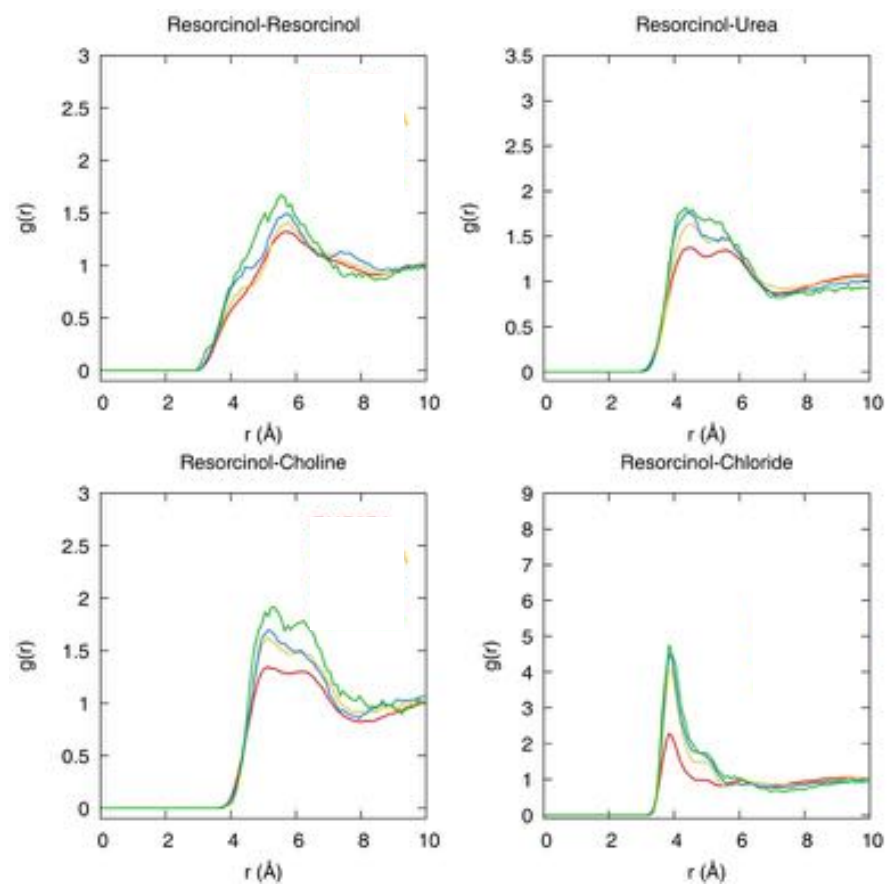

Figure S6: EPSR-derived RDFs for pair correlations between BA and all other DES components, including BA self-correlation, in RUChCl5.4BA (green line), $\mathrm{RUChCl11BA}$ (blue line), and RUChCl22BA (yellow line) at $353 \mathrm{~K}$.
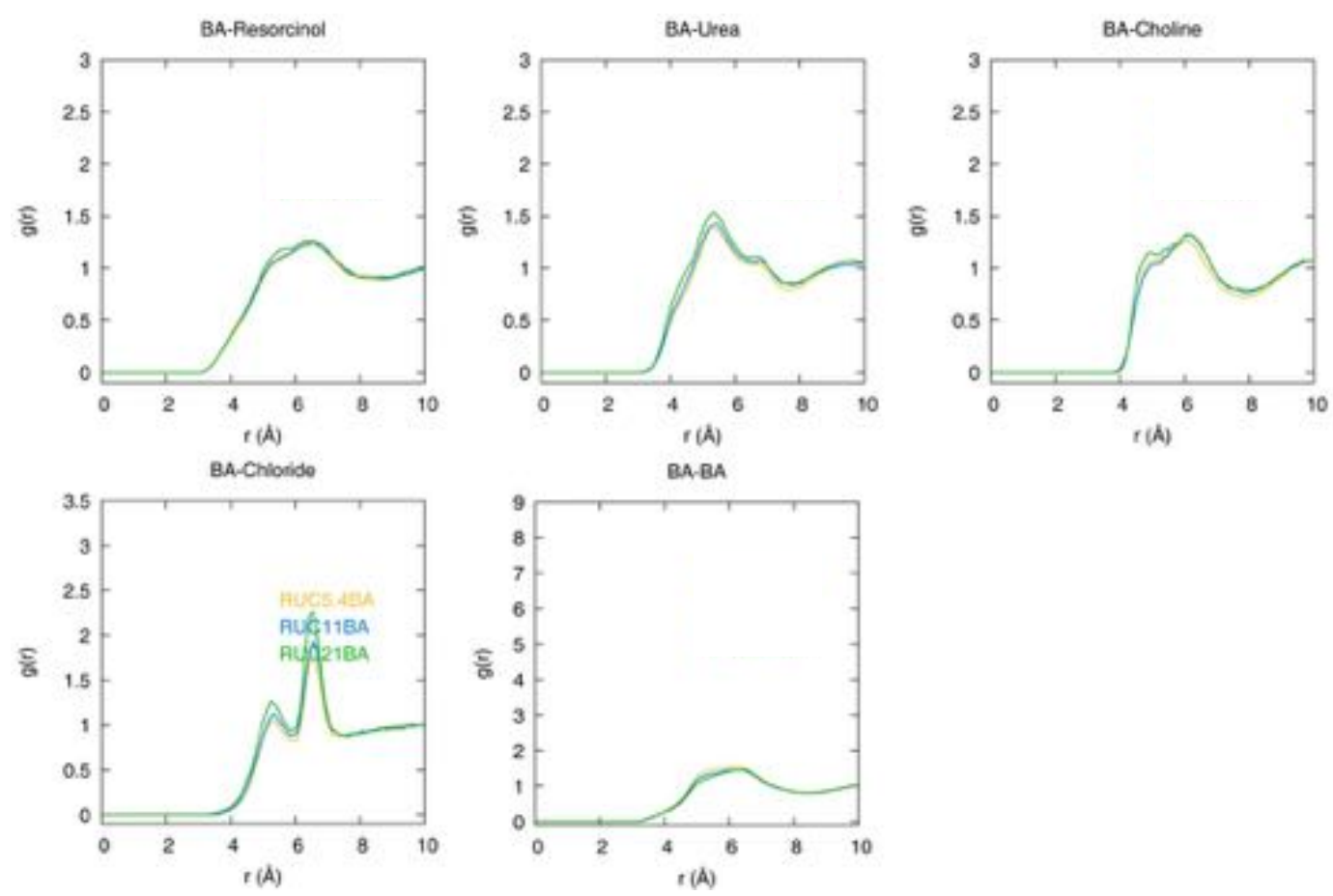
Figure S7: EPSR-derived partial RDFs for atom-atom pair correlations (e.g., between urea and chloride atoms) at $353 \mathrm{~K}$ in RUChClOBA, RUChCl5.4BA, RUChCl11BA, and RUChCl22BA.
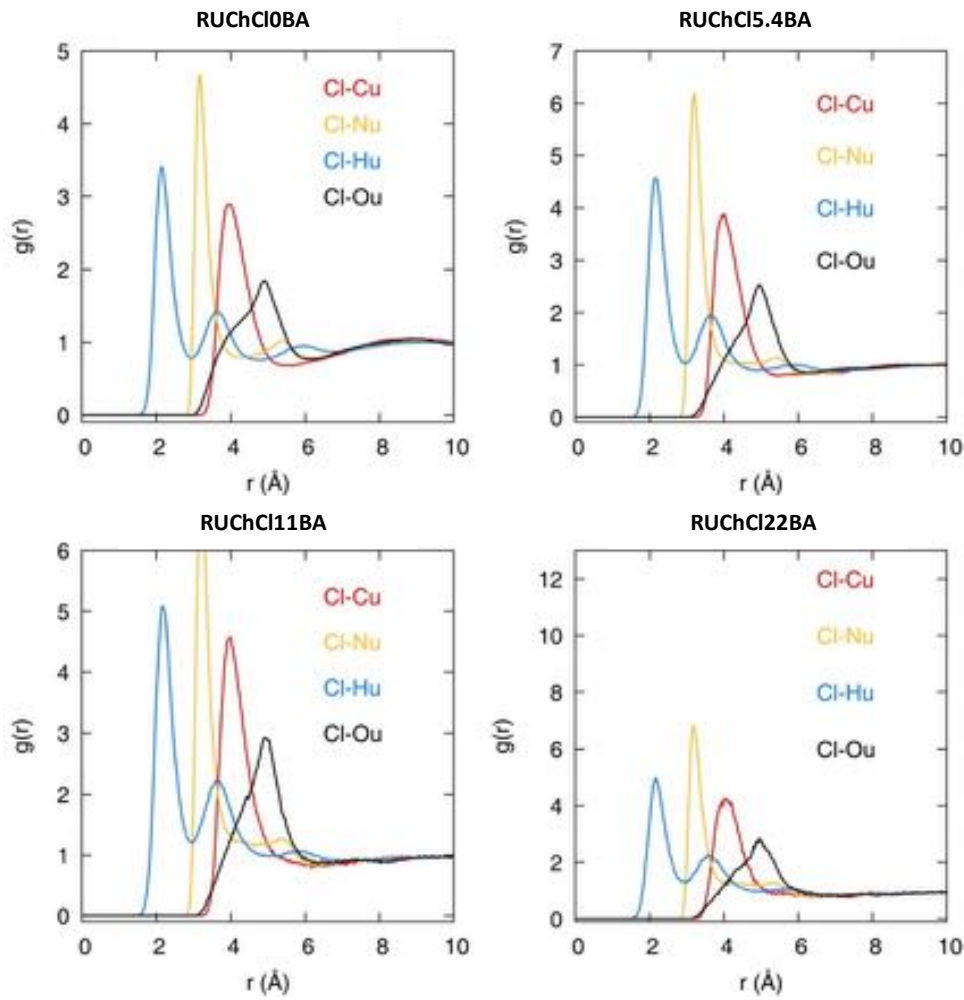

Figure S8: EPSR-derived partial RDFs for atom-atom pair correlations (e.g., urea self-correlation) at $353 \mathrm{~K}$ in RUChCl0BA, RUChCl5.4BA, RUChCl11BA, and RUChCl22BA.
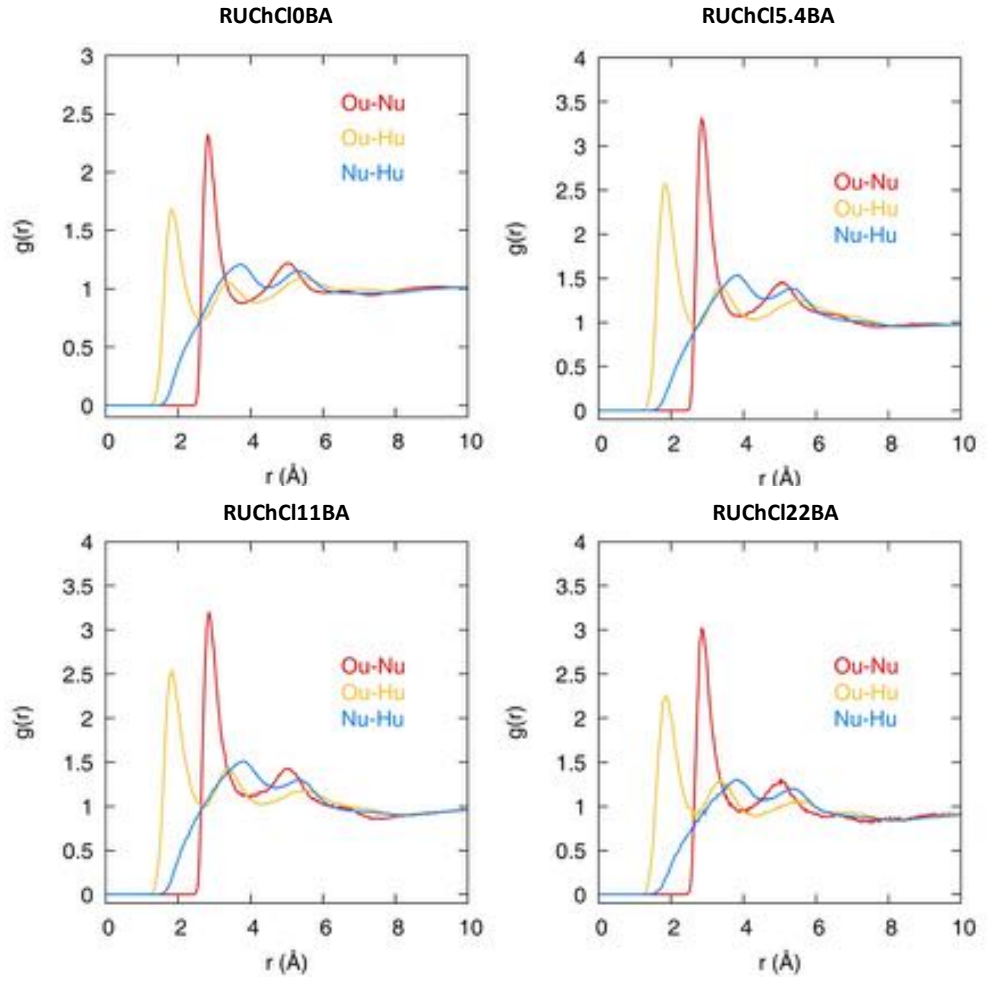
Figure S9: EPSR-derived partial RDFs for atom-atom pair correlations (e.g., between urea and choline atoms) at $353 \mathrm{~K}$ in RUChCl0BA, RUChCl5.4BA, RUChCl11BA, and RUChCl22BA.
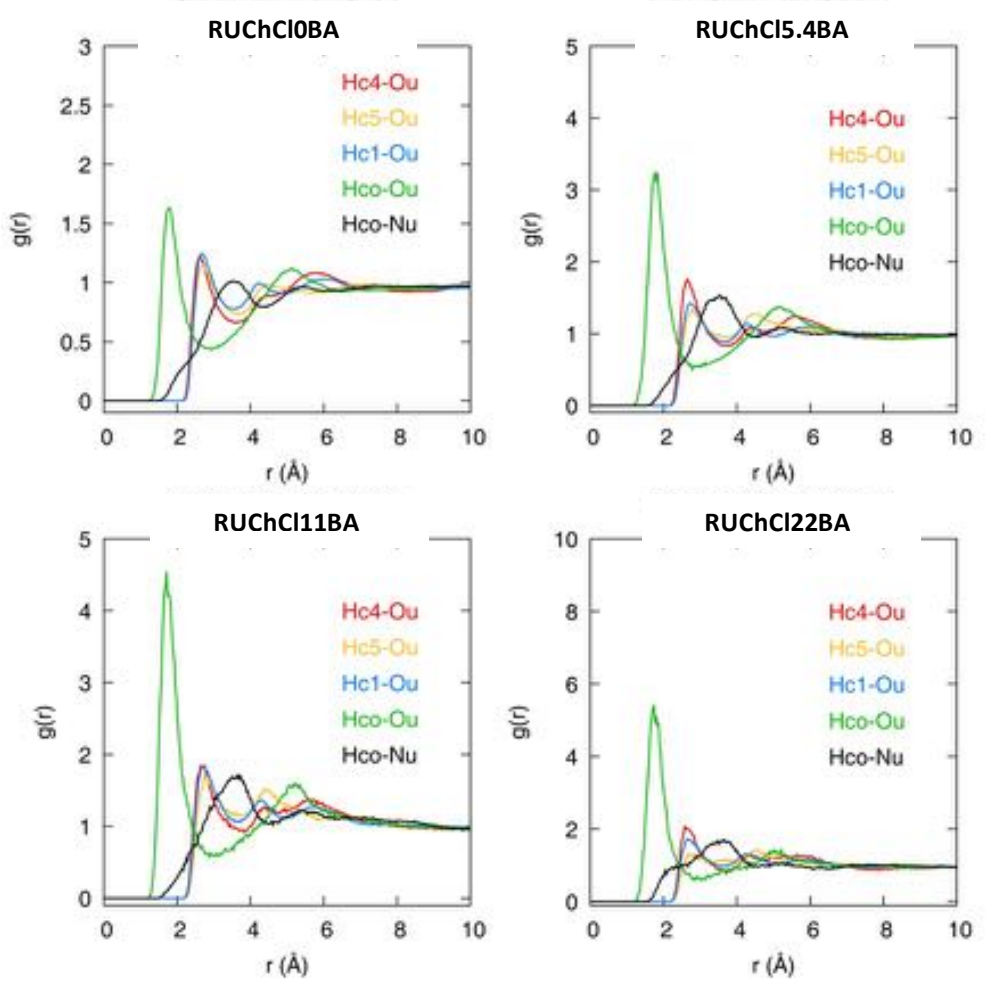

Figure S10: EPSR-derived partial RDFs for atom-atom pair correlations (e.g., between choline and chloride atoms) at $353 \mathrm{~K}$ in RUChCl0BA, RUChCl5.4BA, RUChCl11BA, and RUChCl22BA.
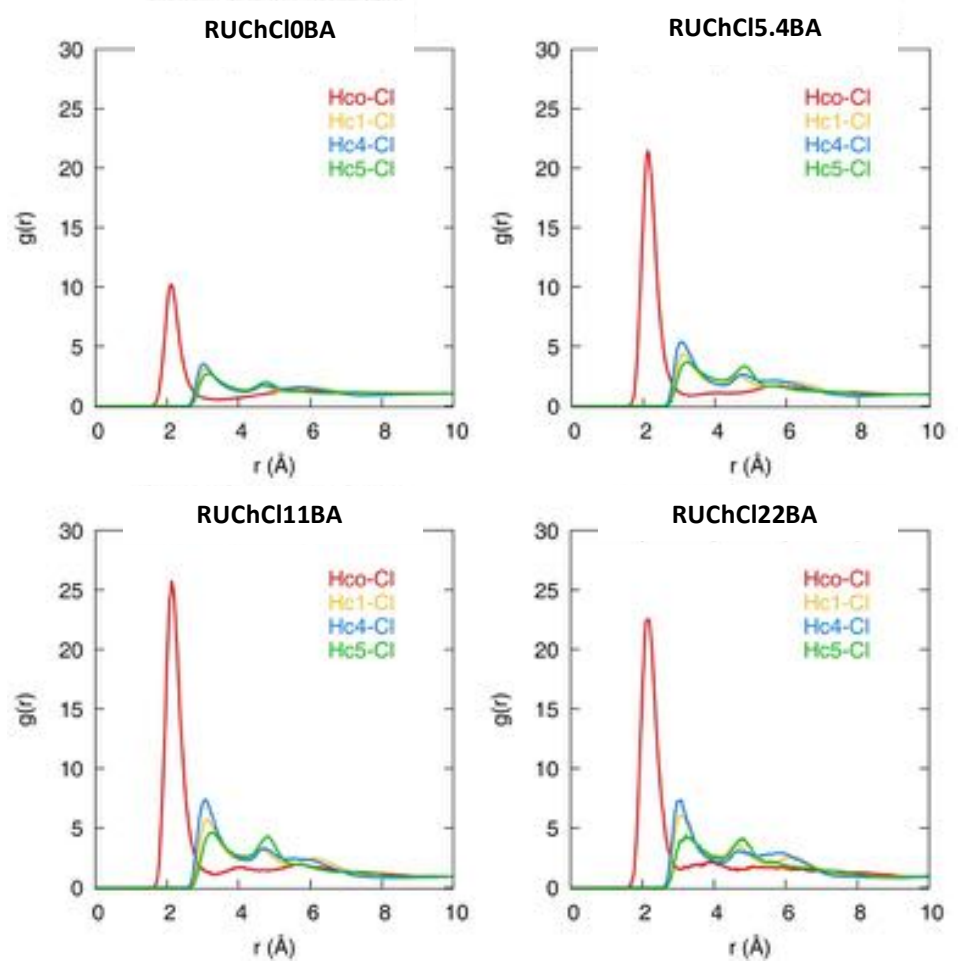
Figure S11: EPSR-derived partial RDFs for atom-atom pair correlations (e.g., choline self-correlation) at $353 \mathrm{~K}$ in RUChClOBA, RUChCl5.4BA, RUChCl11BA, and RUChCl22BA.
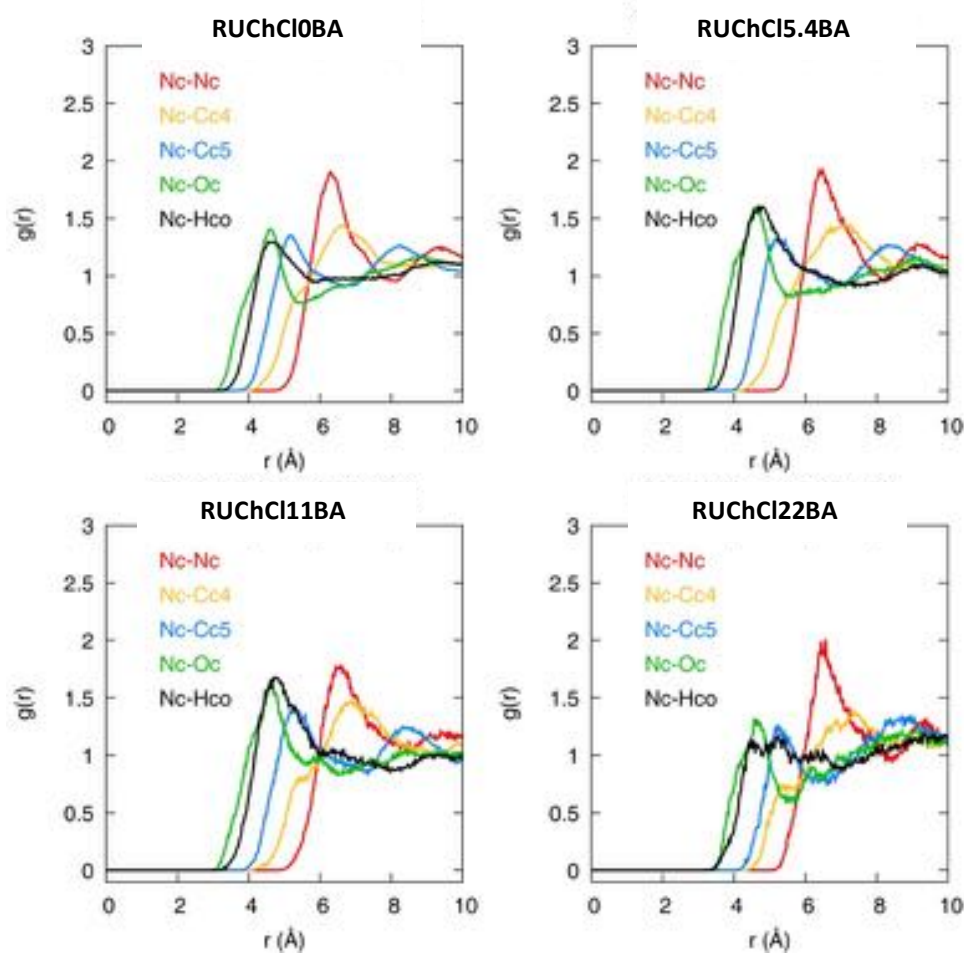

Figure S12: EPSR-derived partial RDFs for atom-atom pair correlations between resorcinol and all other DES components, including resorcinol self-correlation, in RUChClOBA (red line), RUChCl5.4BA (green line), RUChCl11BA (blue line), and RUChCl22BA (yellow line) at $353 \mathrm{~K}$.
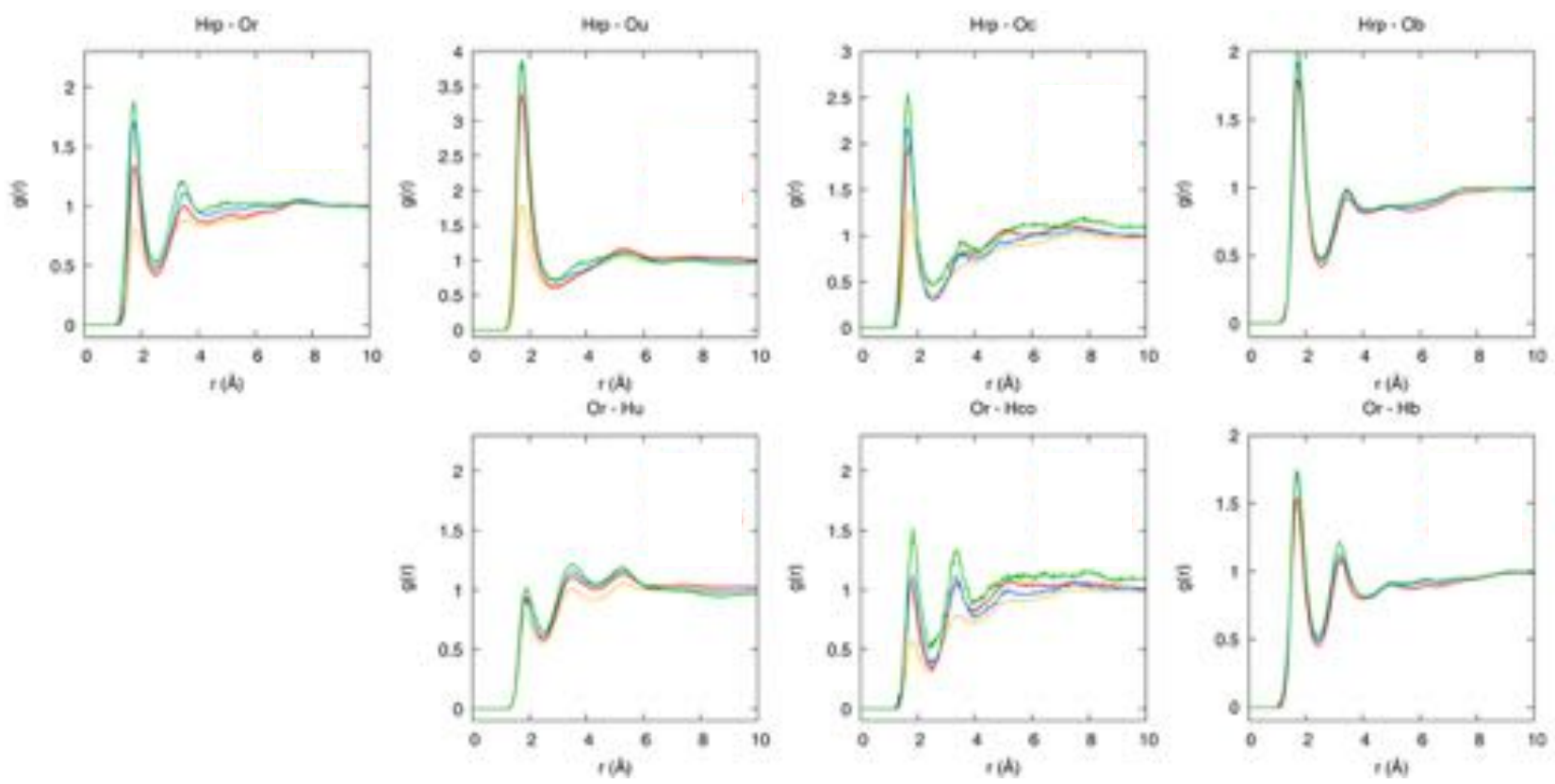
Figure S13: EPSR-derived partial RDFs for atom-atom pair correlations between BA and all other DES components, including BA self-correlation, in $\mathrm{RUChCl5.4BA}$ (red line), $\mathrm{RUChCl11BA}$ (blue line), and RUChCl22BA (green line) at $353 \mathrm{~K}$.
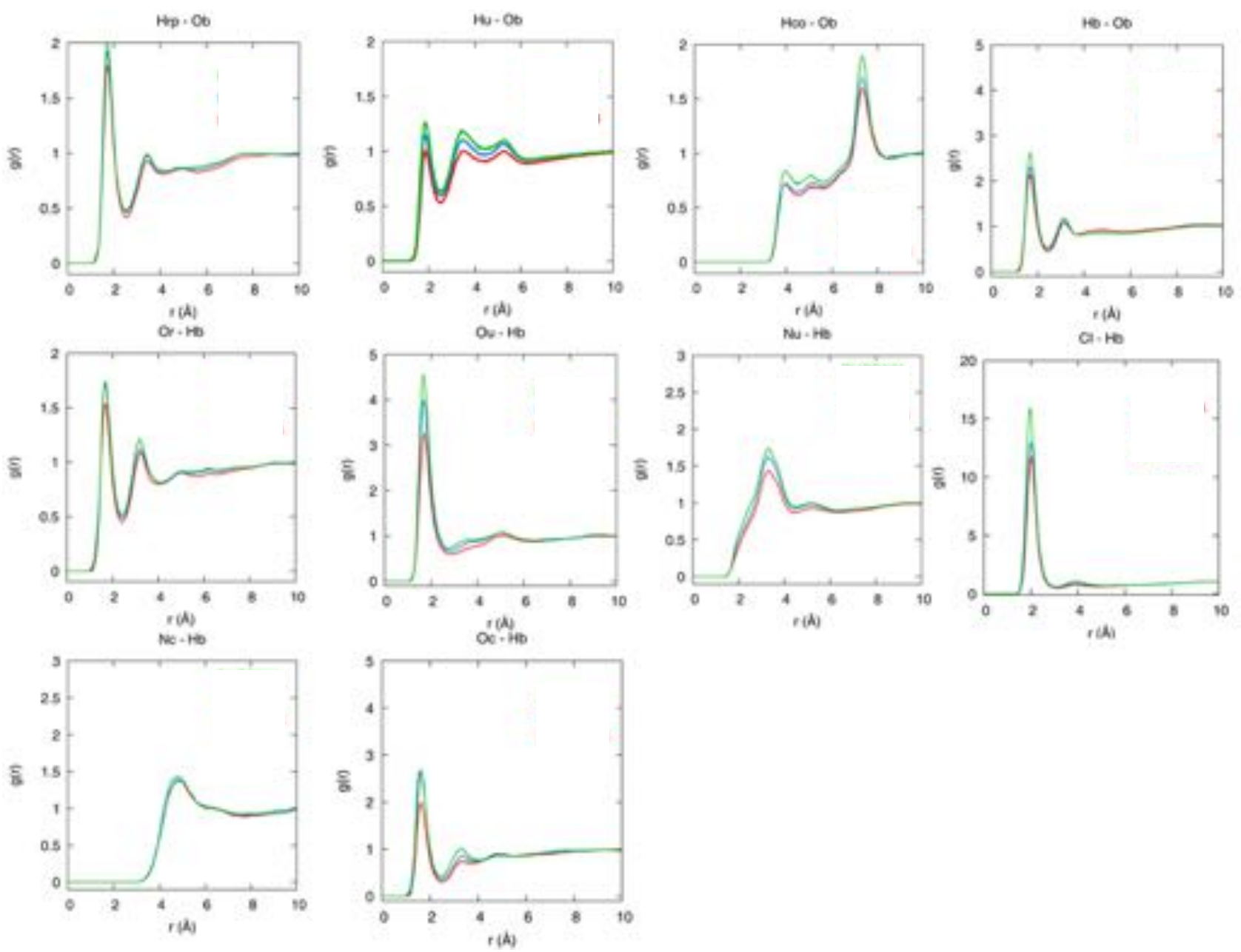
Figure S14: EPSR SDF reconstructions of the $g(r)$ data for atom-atom correlations between resorcinol and all the other DES components, including BA in DES dilutions ( $R$ in dark blue, $U$ in yellow, $\mathrm{Ch}$ in light blue, $\mathrm{Cl}$ in light purple, and $\mathrm{BA}$ in green).

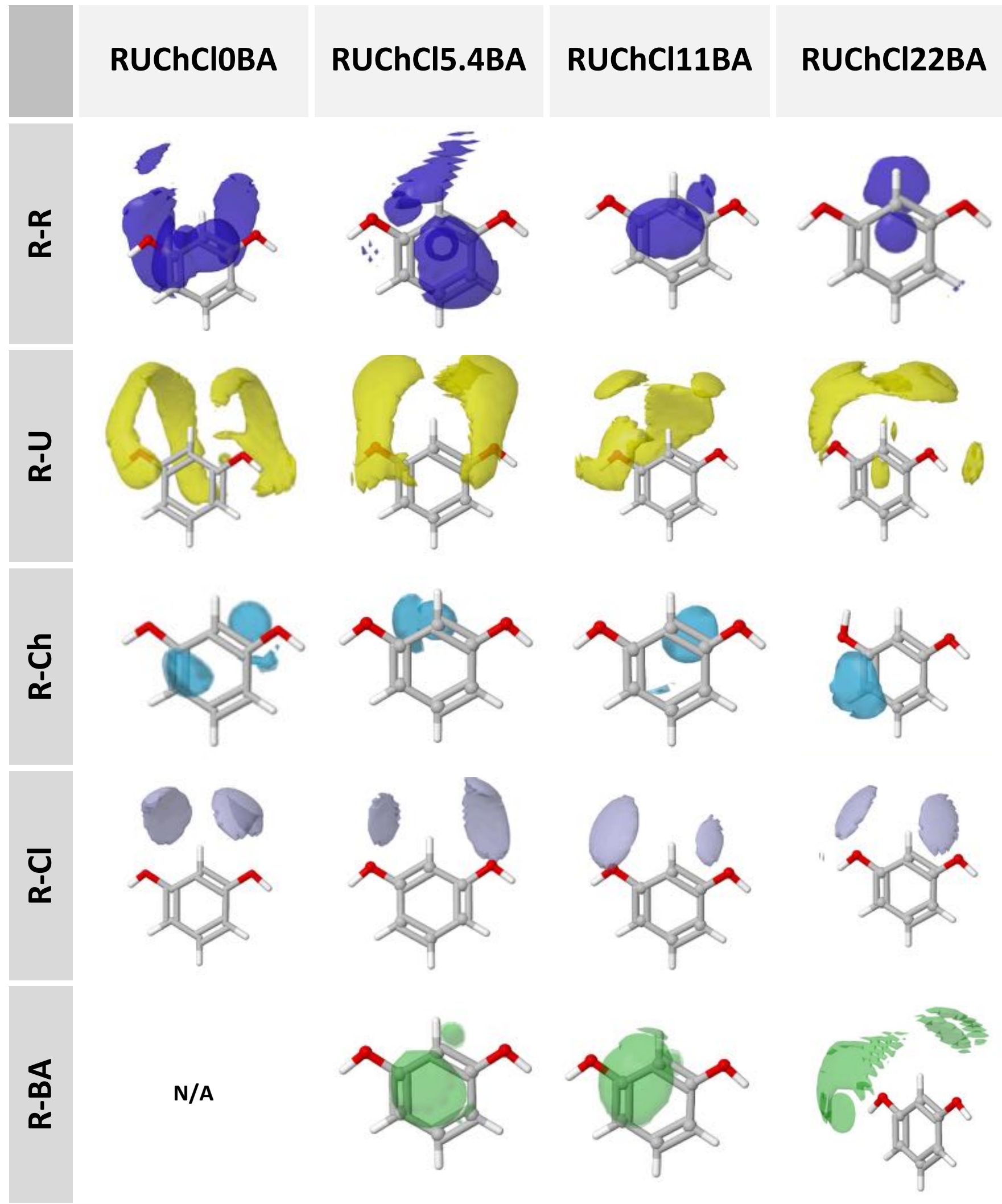


Figure S15: EPSR SDF reconstructions of the $g(r)$ data for atom-atom correlations between urea and all the other DES components, including BA in DES dilutions ( $R$ in dark blue, $U$ in yellow, $C h$ in light blue, $\mathrm{Cl}$ in light purple, and $\mathrm{BA}$ in green).

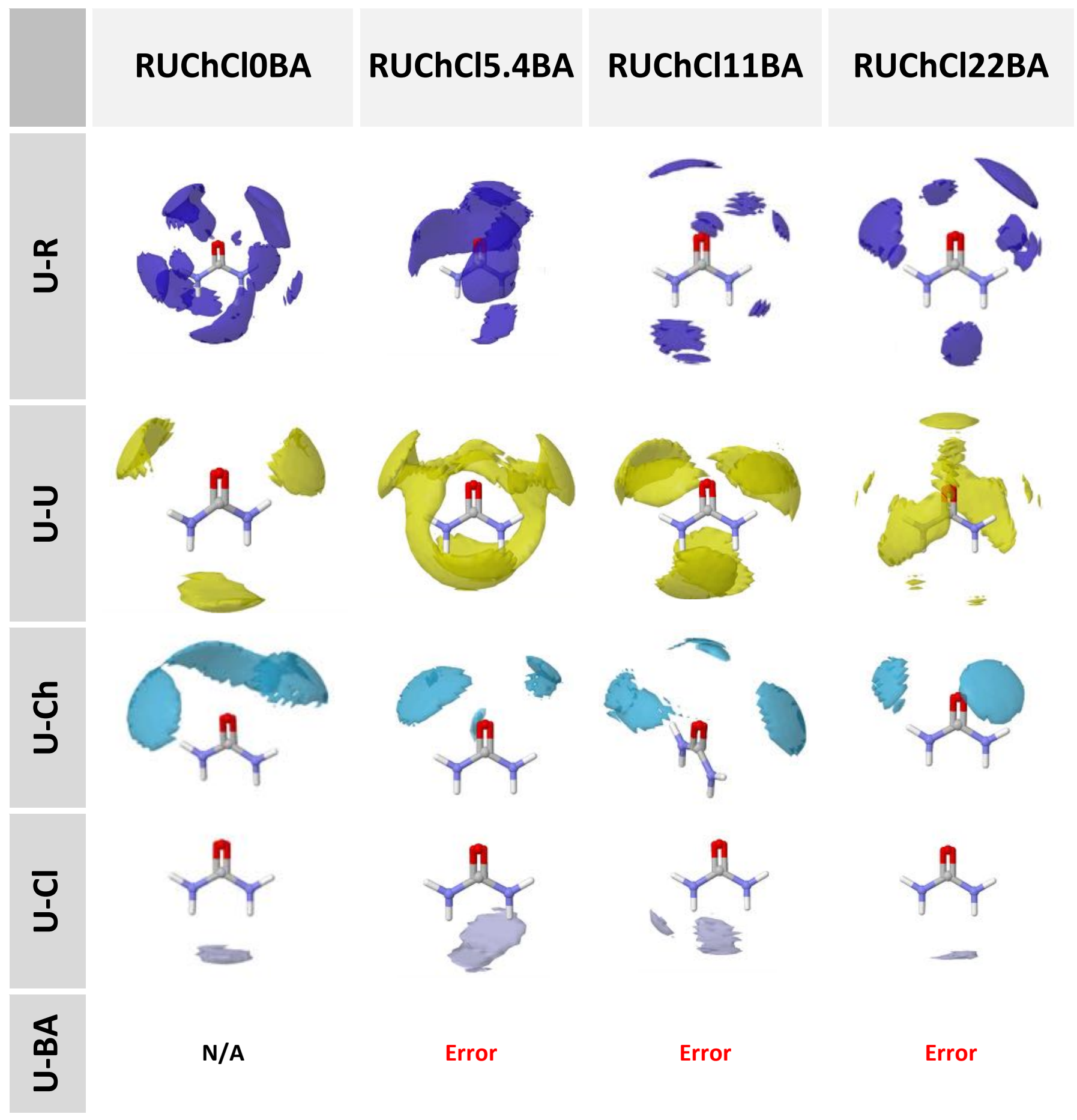


Figure S16: EPSR SDF reconstructions of the $g(r)$ data for atom-atom correlations between chloride and all the other DES components, including BA in DES dilutions ( $R$ in dark blue, $U$ in yellow, $C h$ in light blue, $\mathrm{Cl}$ in light purple, and $\mathrm{BA}$ in green).

\section{\begin{tabular}{l|l|l} 
RUChClOBA & RUChCl5.4BA & RUChCl11BA \\
\end{tabular}}

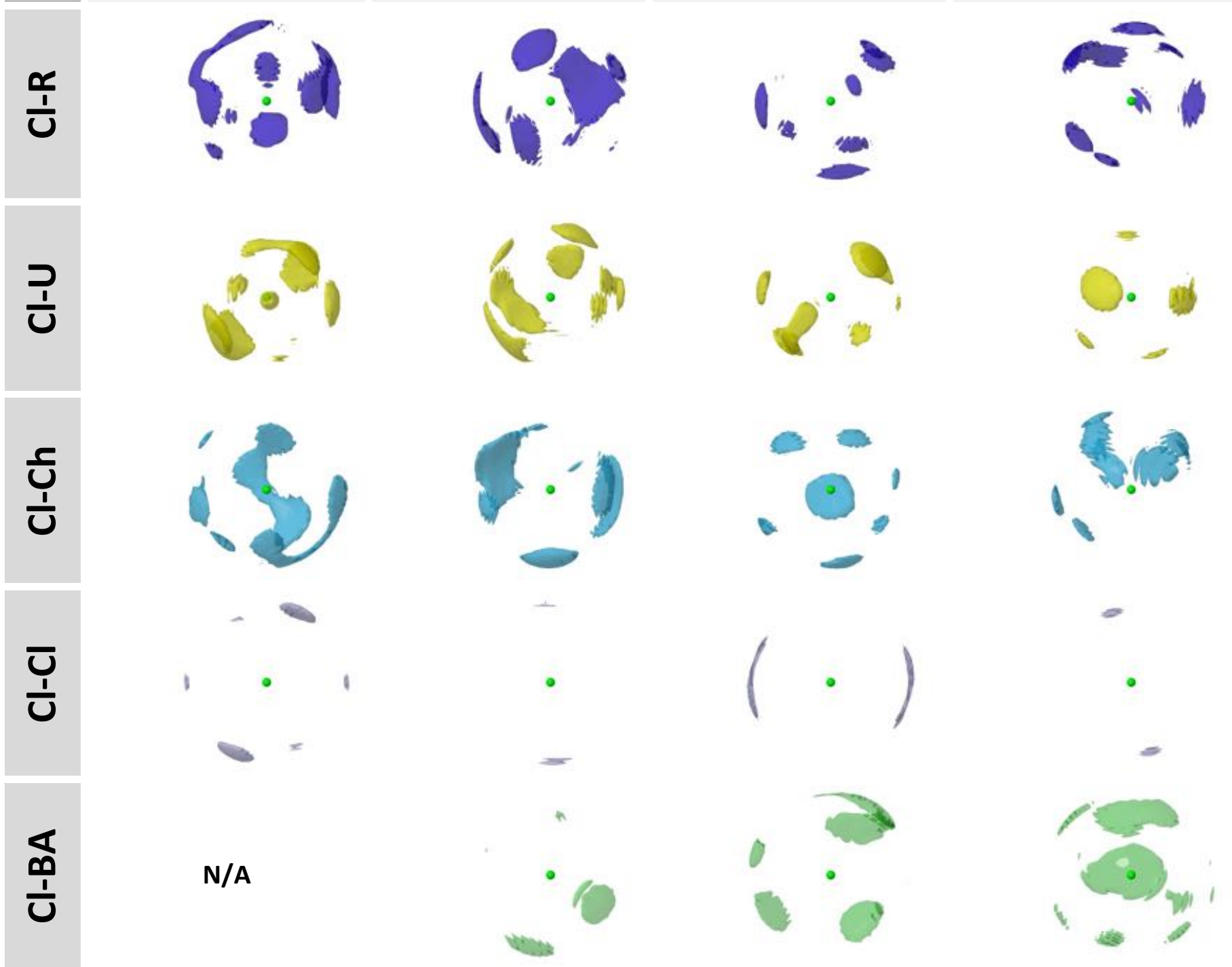


Figure S17: EPSR SDF reconstructions of the $g(r)$ data for atom-atom correlations between benzyl alcohol and all the other DES components, including BA in DES dilutions ( $R$ in dark blue, $U$ in yellow, $\mathrm{Ch}$ in light blue, $\mathrm{Cl}$ in light purple, and $\mathrm{BA}$ in green).

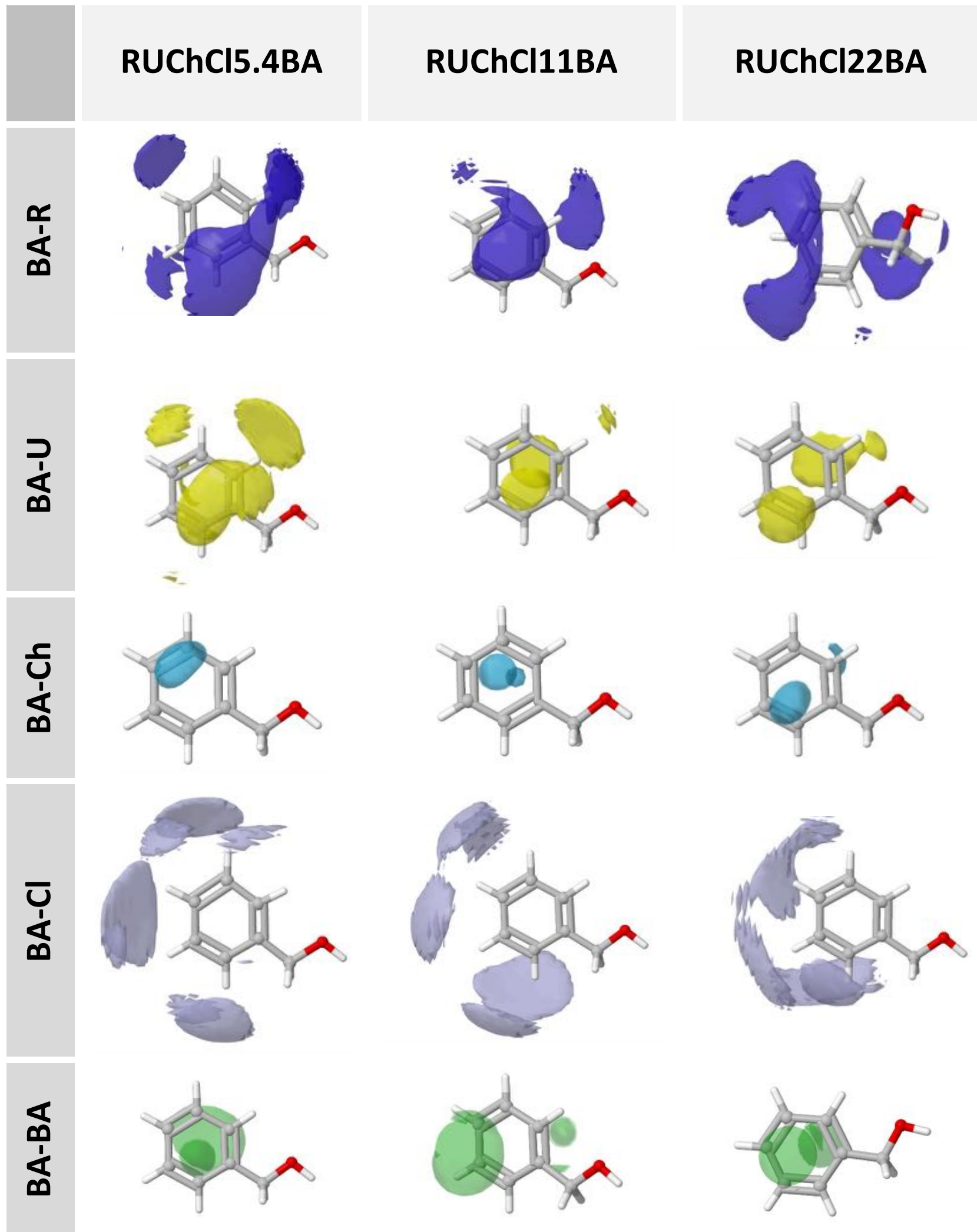


Table S4: Coordination numbers $\left(N_{\text {coord }}\right)$ around electronegative centers as obtained from EPSR analysis of neutron scattering experiments.

\begin{tabular}{|c|c|c|c|c|c|c|c|c|c|c|c|c|c|c|c|c|c|}
\hline & \multicolumn{2}{|c|}{ Atom } & \multirow{2}{*}{\multicolumn{3}{|c|}{$\frac{r_{\text {coord }}}{(\AA)}$}} & \multicolumn{12}{|c|}{$N_{\text {coord }}$} \\
\hline RDF & A & $B$ & & & & & Cho & & RU & h5 & 4BA & $\mathbf{R U}$ & h1 & $B A$ & RU & h21 & BA \\
\hline R-R & Or & $\mathrm{Hrp}$ & 1.0 & & 2.5 & 0.68 & \pm & 0.65 & 0.65 & \pm & 0.62 & 0.61 & \pm & 0.60 & 0.59 & \pm & 0.59 \\
\hline U-R & Or & $\mathrm{Hu}$ & 1.0 & & 2.5 & 0.29 & \pm & 0.52 & 0.15 & \pm & 0.38 & 0.10 & \pm & 0.32 & 0.07 & \pm & 0. \\
\hline Ch-R & Or & $\mathrm{HcO}$ & 1.0 & & 2. & 0.03 & \pm & 0.18 & 0.01 & \pm & 0.1 & 0.02 & \pm & 3 & .01 & \pm & \\
\hline BA-R & Or & $\mathrm{Hb}$ & 1.0 & & 2.5 & & - & & 0.12 & \pm & 0.33 & 0.17 & \pm & 0.38 & .22 & \pm & 0.42 \\
\hline R-U & $\mathrm{Ou}$ & $\mathrm{Hrp}$ & 1.0 & & 2.9 & 0.61 & \pm & 0.73 & 0.34 & \pm & 0.55 & 0.27 & \pm & 0.48 & 0.13 & \pm & 0.33 \\
\hline U-U & Ou & $\mathrm{Hu}$ & 1.0 & & 2.9 & 2.84 & \pm & 1.21 & 2.34 & \pm & 1.05 & 2.30 & \pm & 1.0 & 2.21 & \pm & 0.98 \\
\hline Ch-U & $\mathrm{Ou}$ & $\mathrm{HcO}$ & 1.0 & - & 2.9 & 0.09 & \pm & 0.29 & 0.08 & \pm & 0.27 & 0.05 & \pm & 0.21 & 0.02 & \pm & 0.1 \\
\hline BA-U & $\mathrm{Ou}$ & $\mathrm{Hb}$ & 1.0 & - & 2.9 & & - & & .31 & \pm & 0.5 & 0.50 & \pm & 0.6 & 0.66 & \pm & 0. \\
\hline $\mathrm{R}-\mathrm{Cl}$ & $\mathrm{Cl}$ & $\mathrm{Hrp}$ & 1.3 & - & 2.6 & & \pm & 0.88 & 0.93 & \pm & 0.86 & 0.77 & \pm & 0.79 & 0.44 & \pm & 0.71 \\
\hline U-Cl & $\mathrm{Cl}$ & $\mathrm{Hu}$ & 1.3 & - & 2.6 & 0.99 & \pm & 1.00 & 0.60 & \pm & 0.81 & 0.44 & \pm & 0.70 & 0.28 & \pm & 0.58 \\
\hline Ch-Cl & $\mathrm{Cl}$ & $\mathrm{HcO}$ & 1.3 & - & 2.6 & 0.32 & \pm & 0.54 & 0.33 & \pm & 0.51 & 0.25 & \pm & 0.47 & 0.12 & \pm & 0.32 \\
\hline $\mathrm{BA}-\mathrm{Cl}$ & $\mathrm{Cl}$ & $\mathrm{Hb}$ & 1.3 & - & 2.6 & & - & & 0.92 & \pm & 0.85 & 1.32 & \pm & 0.87 & 1.80 & \pm & 0.9 \\
\hline R-Ch & Oc & Hrp & 1.0 & - & 2.5 & & \pm & 0.45 & 0.19 & \pm & 0.40 & 0.09 & \pm & 0.28 & 0.08 & \pm & 0.28 \\
\hline U-Ch & Oc & $\mathrm{Hu}$ & 1.0 & - & 2.5 & 0.30 & \pm & 0.50 & 0.16 & \pm & 0.40 & 0.12 & \pm & 0.3 & 0.07 & \pm & 0.28 \\
\hline Ch-Ch & Oc & $\mathrm{HcO}$ & 1.0 & - & 2. & 0.54 & \pm & 0.56 & 0.57 & \pm & 0.53 & 0.52 & \pm & 0.52 & 0.49 & \pm & 0.50 \\
\hline BA-Ch & Oc & $\mathrm{Hb}$ & 1.0 & - & 2.5 & & - & & 0.15 & \pm & 0.37 & 0.26 & \pm & 0.45 & 0.31 & \pm & 0.46 \\
\hline R-BA & $\mathrm{Ob}$ & Hrp & 1.0 & & 2.5 & & - & & 0.21 & 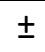 & 0.44 & 0.19 & \pm & 0.43 & 0.17 & \pm & 0.4 \\
\hline U-BA & $\mathrm{Ob}$ & $\mathrm{Hu}$ & 1.0 & - & 2.5 & & - & & 0.21 & \pm & 0.45 & 0.19 & \pm & 0.4 & 0.17 & \pm & $0<2$ \\
\hline BA-BA & $\mathrm{Ob}$ & $\mathrm{Hb}$ & 1.0 & - & 2.5 & & - & & 0.71 & \pm & 0.62 & 0.79 & \pm & 0.67 & 0.87 & \pm & 0.71 \\
\hline Ch-BA & $\mathrm{Ob}$ & $\mathrm{HcO}$ & 1.0 & - & 2.5 & & - & & 0.09 & \pm & 0.32 & 0.10 & \pm & 0.35 & 0.12 & \pm & 0.39 \\
\hline R-U & $\mathrm{Nu}$ & Hrp & 1.3 & - & 4. & & \pm & 1.3 & 1.05 & \pm & 1.01 & 0.77 & \pm & 0.85 & 0.48 & \pm & 0.70 \\
\hline U-U & $\mathrm{Nu}$ & $\mathrm{Hu}$ & 1.3 & & 4. & & \pm & 2.56 & 3.74 & \pm & 1.89 & 3.07 & \pm & 1.49 & 2.69 & \pm & 1.28 \\
\hline Ch-U & $\mathrm{Nu}$ & Hco & 1.3 & - & 4.4 & 0.34 & \pm & 0.55 & 0.19 & \pm & 0.42 & 0.13 & \pm & 0.36 & 0.06 & \pm & 0.28 \\
\hline U-BA & $\mathrm{Nu}$ & $\mathrm{Hb}$ & 1.3 & - & 4.4 & & - & & 0.93 & \pm & 0.90 & 1.40 & \pm & 1.07 & 1.82 & \pm & 1.21 \\
\hline
\end{tabular}


Figure S18: (a) BA clusters size probability as obtained from MD simulations for BA (red line), RUChCl22BA (blue line), RUChCl11BA (green line), and RUChCl5.4BA (purple line). (b) MD simulation snapshots of (from left to right) RUChCl22BA, RUChCl11BA and $\mathrm{RUChCl5.4BA}$, representing DES components ( $\mathrm{R}$ in red, $\mathrm{U}$ in yellow, $\mathrm{Ch}$ in green and $\mathrm{Cl}$ in purple) and $\mathrm{BA}$ (in light blue).

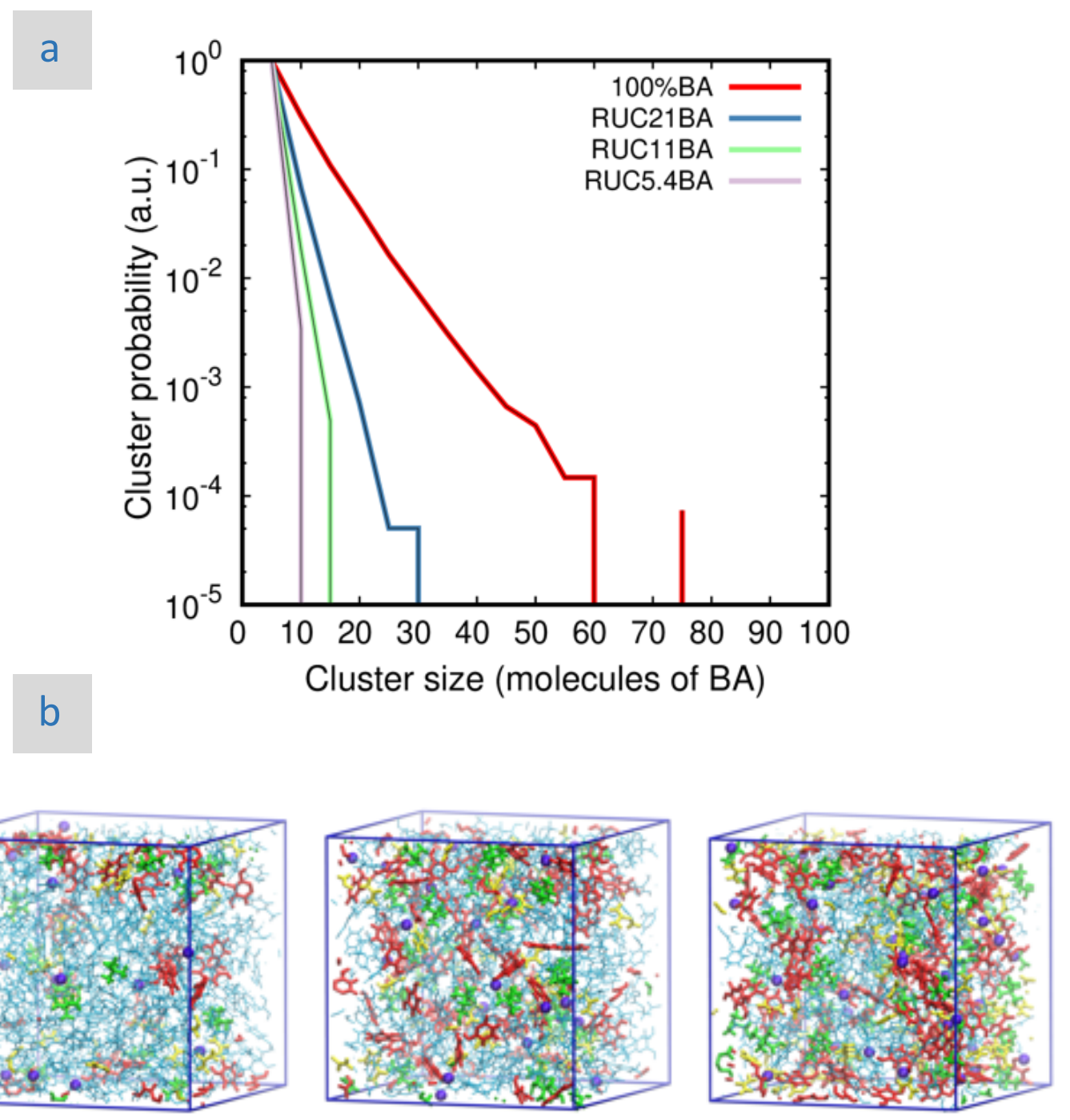


Figure S19: DSC scans of RUChCl (black line) and BA dilutions thereof with DES contents of 80 wt\% (red line), 60 wt\% (blue line), 50 wt\% (pink line), 45 wt\% (green line), 40 wt\% (dark blue line), 35 wt\% (violet line), $30 \mathrm{wt} \%$ (orange), and $25 \mathrm{wt} \%$ (brown line). The DSC scan of neat BA is also included (yellow line).

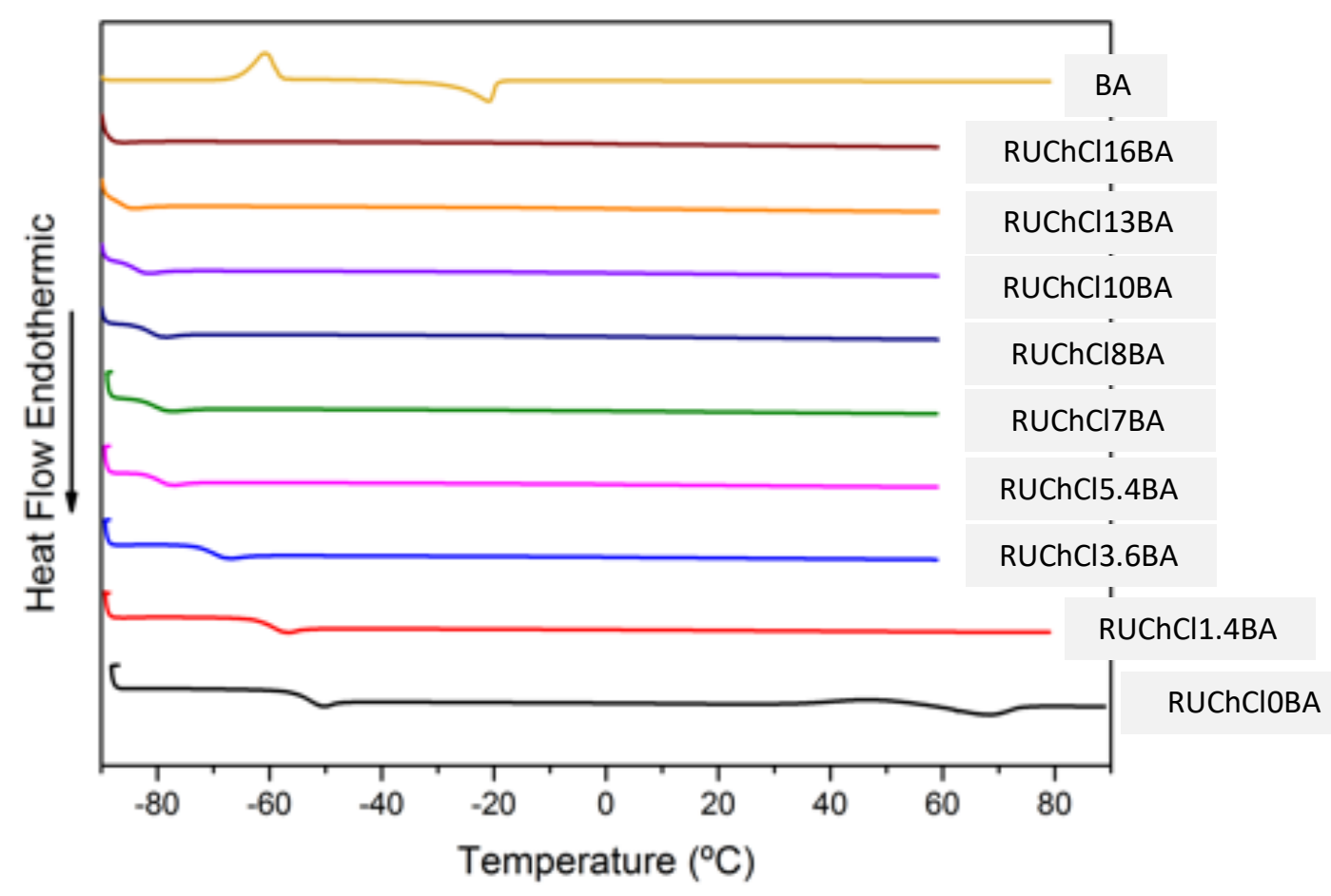


Figure S20: ${ }^{1} \mathrm{H}$ NMR spectra of RUChCl and BA dilutions thereof, with DES contents of (a) 100 wt\%, (b) 80 wt\%, (c) 60 wt\%, (d) 50 wt\%, (e) 40 wt\%, (f) 35 wt\%, (g) $30 w t \%$, (h) 25 wt\%, (i) 20 wt\%, and (j) $10 \mathrm{wt} \%$.

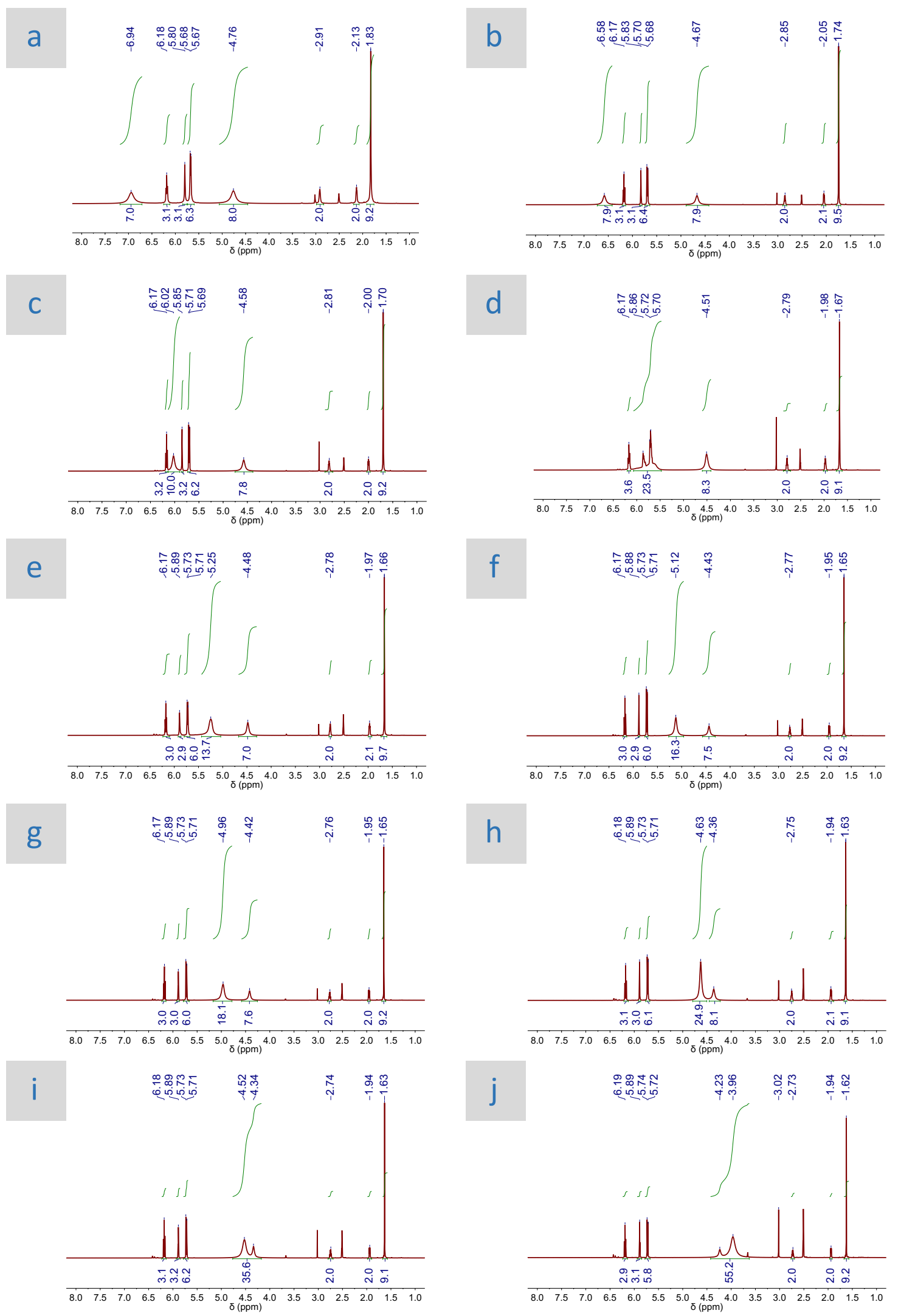


Table S5: Chemical shifts obtained in the ${ }^{1} \mathrm{H}$ NMR spectra of $\mathrm{RUChCl}$ and $\mathrm{BA}$ dilutions thereof, with different DES contents.

\begin{tabular}{|c|c|c|c|c|c|c|c|c|}
\hline \multirow{3}{*}{$\begin{array}{c}\text { DES } \\
\text { content } \\
\text { (wt\%) }\end{array}$} & \multicolumn{8}{|c|}{ Chemical Shifts (ppm) } \\
\hline & & \multicolumn{3}{|c|}{ Resorcinol } & Urea & \multicolumn{3}{|c|}{ Choline Chloride } \\
\hline & $\begin{array}{l}\text { Exchangeable protons } \\
\text { from } \mathrm{R}, \mathrm{ChCl} \text { and } \mathrm{BA} *\end{array}$ & $\begin{array}{l}\mathrm{H} \\
\text { at } \mathrm{C5}\end{array}$ & $\begin{array}{c}\mathrm{H} \\
\text { at } \mathrm{C2}\end{array}$ & $\begin{array}{l}\mathrm{H} \text { at } \\
\mathrm{C} 4 \& \mathrm{C} 6\end{array}$ & $\frac{\left(\mathrm{N}_{2}\right)_{2}-}{\mathrm{CO}}$ & $\begin{array}{l}-\mathrm{CH}_{2}- \\
\mathrm{HO}\end{array}$ & $-\underline{\mathrm{CH}}_{2}-$ & $\frac{\left(\mathrm{C}_{\mathrm{H}_{3}}\right)_{3^{-}}}{\mathrm{N}^{+}}$ \\
\hline 100 & $\begin{array}{c}6.94 \\
\left(6 \mathrm{H}_{\mathrm{R}}+1 \mathrm{H}_{\mathrm{ChCl}}\right)\end{array}$ & $\begin{array}{l}6.18 \\
(3 \mathrm{H})\end{array}$ & $\begin{array}{l}5.80 \\
(3 \mathrm{H}) \\
\end{array}$ & $\begin{array}{l}5.68 \\
(6 \mathrm{H})\end{array}$ & $\begin{array}{l}4.76 \\
(8 \mathrm{H})\end{array}$ & $\begin{array}{l}2.91 \\
(2 \mathrm{H})\end{array}$ & $\begin{array}{l}2.13 \\
(2 \mathrm{H})\end{array}$ & $\begin{array}{l}1.83 \\
(9 \mathrm{H})\end{array}$ \\
\hline 80 & $\begin{array}{c}6.58 \\
\left(6 \mathrm{H}_{\mathrm{R}}+1 \mathrm{H}_{\mathrm{ChCl}}+1 \mathrm{H}_{\mathrm{BA}}\right)\end{array}$ & $\begin{array}{l}6.17 \\
(3 \mathrm{H})\end{array}$ & $\begin{array}{l}5.83 \\
(3 \mathrm{H})\end{array}$ & $\begin{array}{l}5.70 \\
(6 \mathrm{H})\end{array}$ & $\begin{array}{c}4.67 \\
(7.9 \mathrm{H})\end{array}$ & $\begin{array}{l}2.85 \\
(2 \mathrm{H})\end{array}$ & $\begin{array}{l}2.05 \\
(2 \mathrm{H})\end{array}$ & $\begin{array}{l}1.74 \\
(9 \mathrm{H})\end{array}$ \\
\hline 60 & $\begin{array}{c}6.02 \\
\left(6 \mathrm{H}_{\mathrm{R}}+1 \mathrm{H}_{\mathrm{ChCl}}+3.4 \mathrm{H}_{\mathrm{BA}}\right)\end{array}$ & $\begin{array}{l}6.17 \\
(3 \mathrm{H}) \\
\end{array}$ & $\begin{array}{l}5.85 \\
(3 \mathrm{H}) \\
\end{array}$ & $\begin{array}{l}5.70 \\
(6 \mathrm{H}) \\
\end{array}$ & $\begin{array}{c}4.58 \\
(7 ., 8 \mathrm{H})\end{array}$ & $\begin{array}{l}2.81 \\
(2 \mathrm{H}) \\
\end{array}$ & $\begin{array}{l}2.00 \\
(2 \mathrm{H}) \\
\end{array}$ & $\begin{array}{l}1.70 \\
(9 \mathrm{H}) \\
\end{array}$ \\
\hline 50 & $6.1-5.5$ & $\begin{array}{l}6.17 \\
(3 \mathrm{H})\end{array}$ & $\begin{array}{l}5.86 \\
(3 \mathrm{H})\end{array}$ & $\begin{array}{l}5.70 \\
(6 \mathrm{H})\end{array}$ & $\begin{array}{c}4.51 \\
(8.5 \mathrm{H})\end{array}$ & $\begin{array}{l}2.79 \\
(2 \mathrm{H})\end{array}$ & $\begin{array}{l}1.97 \\
(2 \mathrm{H})\end{array}$ & $\begin{array}{l}1.67 \\
(9 \mathrm{H})\end{array}$ \\
\hline 40 & $\begin{array}{c}5.25 \\
\left(6 \mathrm{H}_{\mathrm{R}}+1 \mathrm{H}_{\mathrm{ChCl}}+6.7 \mathrm{H}_{\mathrm{BA}}\right)\end{array}$ & $\begin{array}{c}6.17 \\
(2.9 \mathrm{H})\end{array}$ & $\begin{array}{c}5.89 \\
(2.7 \mathrm{H}) \\
\end{array}$ & $\begin{array}{c}5.73 \\
(5.8 \mathrm{H}) \\
\end{array}$ & $\begin{array}{c}4.48 \\
(6.7 \mathrm{H})\end{array}$ & $\begin{array}{l}2.78 \\
(2 \mathrm{H})\end{array}$ & $\begin{array}{l}1.97 \\
(2 \mathrm{H})\end{array}$ & $\begin{array}{l}1.66 \\
(9 H)\end{array}$ \\
\hline 35 & $\begin{array}{c}6.49 \\
\left(6 \mathrm{H}_{\mathrm{R}}+1 \mathrm{H}_{\mathrm{ChCl}}+9.3 \mathrm{H}_{\mathrm{BA}}\right)\end{array}$ & $\begin{array}{l}6.17 \\
(3 \mathrm{H})\end{array}$ & $\begin{array}{l}5.88 \\
(3 \mathrm{H})\end{array}$ & $\begin{array}{l}5.72 \\
(6 \mathrm{H})\end{array}$ & $\begin{array}{c}4.43 \\
(7.6 \mathrm{H})\end{array}$ & $\begin{array}{l}2.76 \\
(2 \mathrm{H})\end{array}$ & $\begin{array}{l}1.96 \\
(2 \mathrm{H})\end{array}$ & $\begin{array}{l}1.65 \\
(9 \mathrm{H})\end{array}$ \\
\hline 30 & $\begin{array}{c}6.31 \\
\left(6 \mathrm{H}_{\mathrm{R}}+1 \mathrm{H}_{\mathrm{ChCl}}+11 \mathrm{H}_{\mathrm{BA}}\right)\end{array}$ & $\begin{array}{l}6.17 \\
(3 \mathrm{H})\end{array}$ & $\begin{array}{l}5.89 \\
(3 \mathrm{H}) \\
\end{array}$ & $\begin{array}{l}5.72 \\
(6 \mathrm{H}) \\
\end{array}$ & $\begin{array}{c}4.42 \\
(7.6 \mathrm{H})\end{array}$ & $\begin{array}{l}2.77 \\
(2 \mathrm{H}) \\
\end{array}$ & $\begin{array}{l}1.96 \\
(2 \mathrm{H}) \\
\end{array}$ & $\begin{array}{l}1.65 \\
(9 H) \\
\end{array}$ \\
\hline 25 & $\begin{array}{c}4.63 \\
\left(6 \mathrm{H}_{\mathrm{R}}+1 \mathrm{H}_{\mathrm{ChCl}}+18 \mathrm{H}_{\mathrm{BA}}\right)\end{array}$ & $\begin{array}{l}6.18 \\
(3 \mathrm{H})\end{array}$ & $\begin{array}{l}5 . .89 \\
(3 \mathrm{H}) \\
\end{array}$ & $\begin{array}{l}5.72 \\
(6 \mathrm{H}) \\
\end{array}$ & $\begin{array}{c}4.36 \\
(7.9 \mathrm{H})\end{array}$ & $\begin{array}{l}2.75 \\
(2 \mathrm{H}) \\
\end{array}$ & $\begin{array}{l}1.94 \\
(2 \mathrm{H}) \\
\end{array}$ & $\begin{array}{l}1.63 \\
(9 H)\end{array}$ \\
\hline 20 & $\begin{array}{c}4.52 \\
\left(6 \mathrm{H}_{\mathrm{R}}+1 \mathrm{H}_{\mathrm{ChCl}}+20.6 \mathrm{H}_{\mathrm{BA}}\right)\end{array}$ & $\begin{array}{l}6.18 \\
(3 \mathrm{H})\end{array}$ & $\begin{array}{l}5.89 \\
(3 \mathrm{H})\end{array}$ & $\begin{array}{l}5.72 \\
(6 \mathrm{H})\end{array}$ & $\begin{array}{l}4.34 \\
(8 \mathrm{H})\end{array}$ & $\begin{array}{l}2.74 \\
(2 \mathrm{H})\end{array}$ & $\begin{array}{l}1.95 \\
(2 \mathrm{H})\end{array}$ & $\begin{array}{l}1.63 \\
(9 H)\end{array}$ \\
\hline 10 & $\begin{array}{c}3.96 \\
\left(6 \mathrm{H}_{\mathrm{R}}+1 \mathrm{H}_{\mathrm{ChCl}}+40 \mathrm{H}_{\mathrm{BA}}\right)\end{array}$ & $\begin{array}{l}6.19 \\
(3 \mathrm{H})\end{array}$ & $\begin{array}{l}5.89 \\
(3 \mathrm{H})\end{array}$ & $\begin{array}{l}5.73 \\
(6 \mathrm{H})\end{array}$ & $\begin{array}{l}4.23 \\
(8 \mathrm{H})\end{array}$ & $\begin{array}{l}2.73 \\
(2 \mathrm{H})\end{array}$ & $\begin{array}{l}1.95 \\
(2 \mathrm{H})\end{array}$ & $\begin{array}{l}1.62 \\
(9 H)\end{array}$ \\
\hline
\end{tabular}


Figure S21: Plot of self-diffusion coefficients of $R, U, C h$ and BA versus DES content (in wt\%), as obtained from NMR spectroscopy and from MD simulations at $353 \mathrm{~K}$. Check data, correct $\mathrm{x}$ axis label "DES content (wt\%)", anything else? 
Table S6: Reagents used for the preparation of $\mathrm{RUChCl}$ and $\mathrm{BA}$ dilutions thereof as well as the crosslinker used for polycondensation.

\begin{tabular}{|c|c|c|c|c|c|c|}
\hline Sample & $\begin{array}{c}\mathrm{R} \\
\text { (mg) }\end{array}$ & $\begin{array}{c}\mathrm{U} \\
(\mathrm{mg})\end{array}$ & $\begin{array}{l}\mathrm{ChCl} \\
\text { (mg }\end{array}$ & RUChCl & $\mathrm{BA}^{\mathrm{a}}$ & $\begin{array}{l}\mathrm{pPA} \\
\text { (mg) }\end{array}$ \\
\hline RUChClOBA & 930 & 338 & 394 & 1662 (100 wt\%) & -- & -- \\
\hline RUChCl3.6BA & 930 & 338 & 394 & $1662(60 w t \%)^{b}$ & $1108(40 \mathrm{wt} \%)^{b}$ & 804 \\
\hline RUChCl5.4BA & 930 & 338 & 394 & $1662(50 w t \%)^{b}$ & $1662(50 \text { wt } \%)^{b}$ & 804 \\
\hline RUChCl8BA & 930 & 338 & 394 & $1662(40 w t \%)^{b}$ & $2493(60 \text { wt\% } \%)^{b}$ & 804 \\
\hline RUChCl10BA & 930 & 338 & 394 & $1662(35 w t \%)^{b}$ & $3087\left(65\right.$ wt\%) ${ }^{b}$ & 804 \\
\hline RUChCl13BA & 930 & 338 & 394 & $1662(30 w t \%)^{b}$ & $3878(70 w t \%)^{b}$ & 804 \\
\hline RUChCl22BA & 930 & 338 & 394 & $1662(20 w t \%)^{b}$ & $6648(80 \text { wt } \%)^{b}$ & 804 \\
\hline
\end{tabular}

Table S7: Nitrogen contents found in $R_{R U C h C I n B A}$ samples and conversions in which $R_{R U C h C l n B A}$ become $\mathrm{C}_{\mathrm{RUChClnBA}}$ after carbonization.

\begin{tabular}{|c|c|c|c|}
\hline Sample & $\begin{array}{c}\text { Nitrogen } \\
\text { Content } \\
(w t \%)^{a}\end{array}$ & Sample & $\begin{array}{c}\text { Conversion } \\
\text { (wt\%) }\end{array}$ \\
\hline $\mathrm{R}_{\mathrm{RUChCl} 3.6 \mathrm{BA}}$ & 4.9 & $\mathrm{C}_{\mathrm{RUChCl} 3.6 \mathrm{BA}}$ & 76 \\
\hline $\mathrm{R}_{\mathrm{R} \cup \mathrm{ChCl} 5.4 \mathrm{BA}}$ & 4.4 & $\mathrm{C}_{\mathrm{RUChCl}} 5.4 \mathrm{BA}$ & 76 \\
\hline $\mathrm{R}_{\mathrm{RUChCl}} \mathrm{BBA}$ & 4.4 & $\mathrm{C}_{\text {RUChCl8BA }}$ & 62 \\
\hline $\mathrm{R}_{\mathrm{RUChCl10BA}}$ & 4.3 & $C_{\text {RUChCl10BA }}$ & 59 \\
\hline $\mathrm{R}_{\mathrm{RUChCl13BA}}$ & 4.0 & $\mathrm{C}_{\text {RUChCl13BA }}$ & 57 \\
\hline $\mathrm{R}_{\mathrm{RUChCl} 22 \mathrm{BA}}$ & 4.2 & $\mathrm{C}_{\mathrm{RUChCl} 22 \mathrm{BA}}$ & 60 \\
\hline
\end{tabular}


Figure S22: FTIR spectra of RUChCl3.6BA (a), RUChCl5.4BA (b), RUChCl8BA (c), RUChCl10BA (d), RUChCl13BA (e), and RUChCl22BA (f).

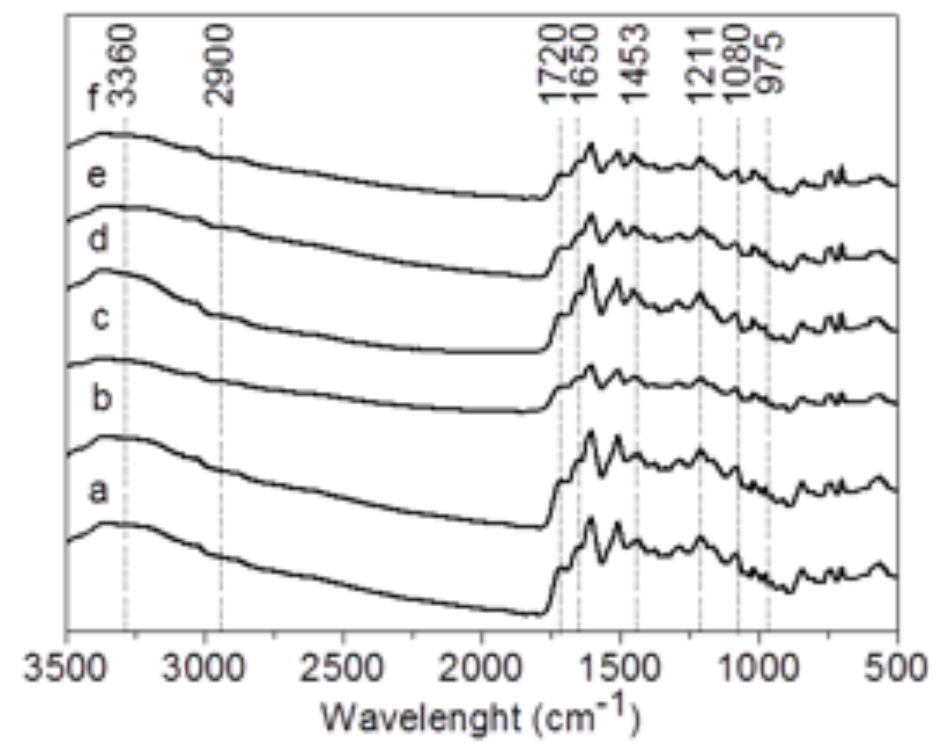


Figure S23: Solid-state ${ }^{13} \mathrm{C} C P M A S$ NMR spectra of RUChCl3.6BA (a), RUChCl5.4BA (b), RUChCl8BA (c), RUChCl10BA (d), RUChCl13BA (e), and RUChCl22BA (f).

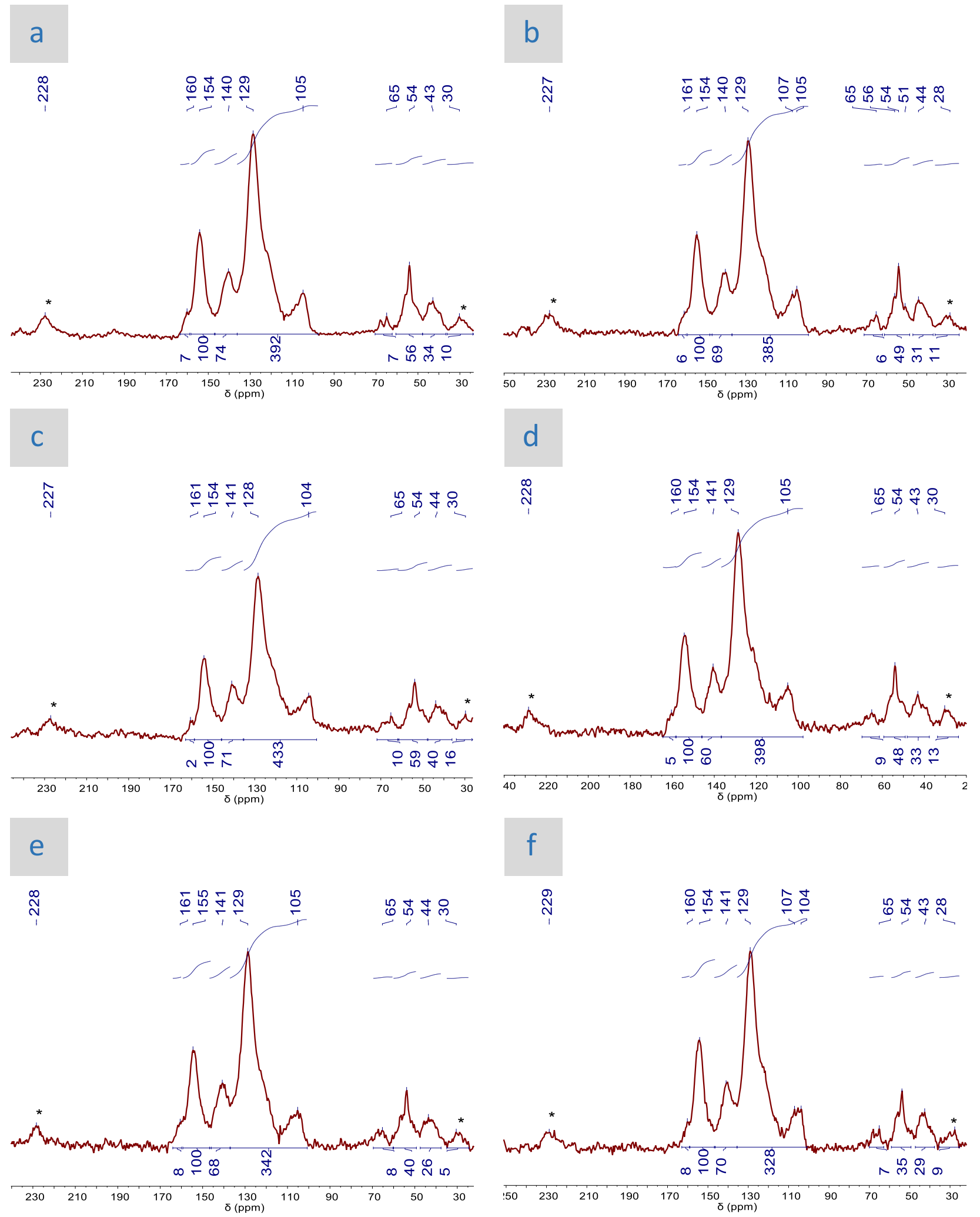


Figure S24: $\mathrm{N}_{2}$ adsorption isotherms obtained at $77 \mathrm{~K}$ for the different porous carbon materials prepared in this work.

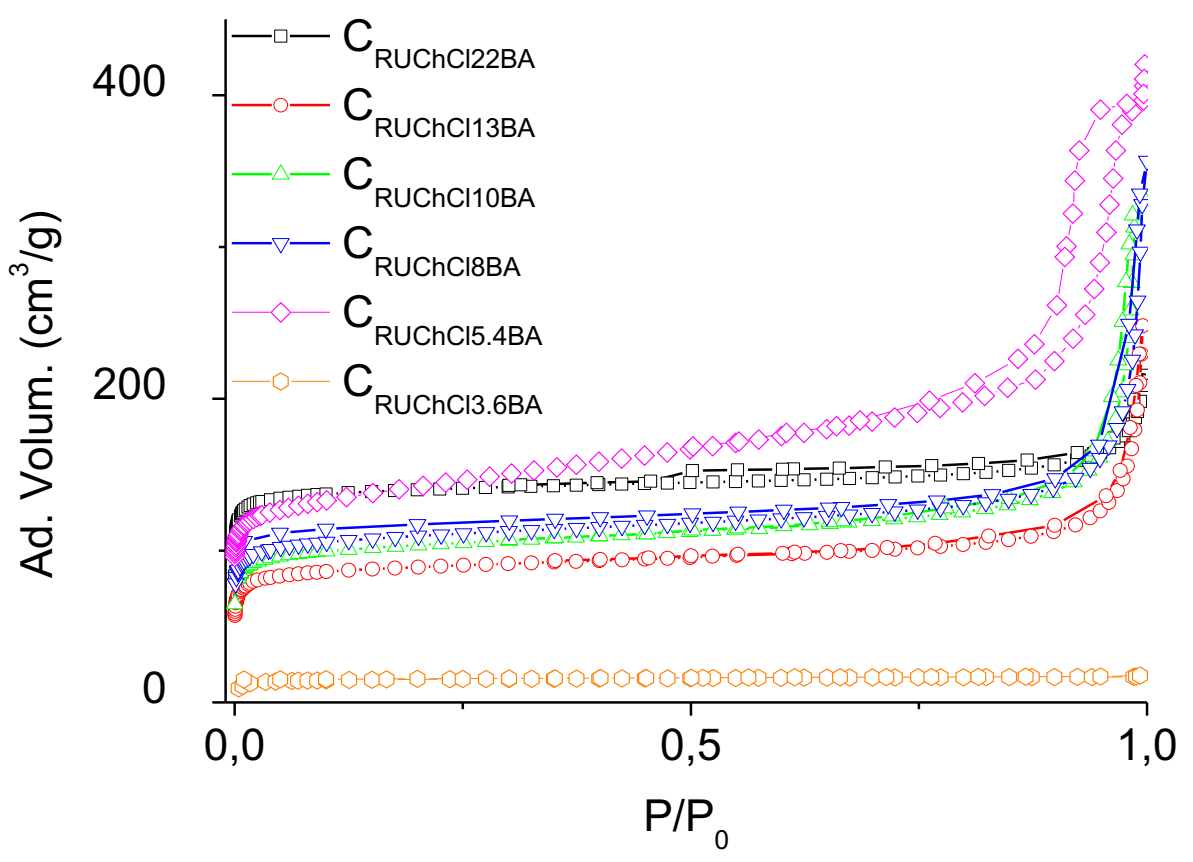


Figure S25: Pore size distribution obtained by $\mathrm{Hg}$ porosimetry of $\mathrm{C}_{\mathrm{RUChCl13BA}}(\mathrm{a}), \mathrm{C}_{\mathrm{RUChCl10BA}}$ (b) and $\mathrm{C}_{\mathrm{RUChCI5.4BA}}(\mathrm{C})$. Cumulative volume (black line and symbols, left axis); derivative volume (blue line and symbols, right axis).

a

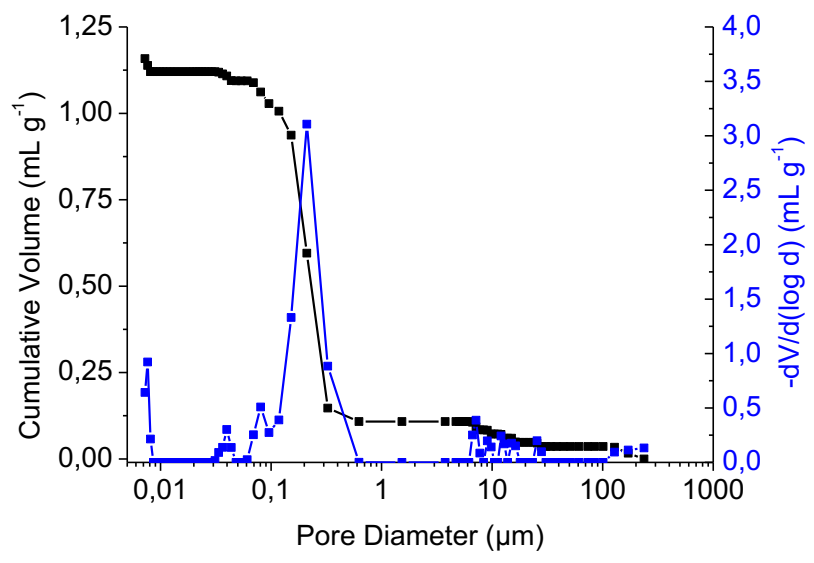

b

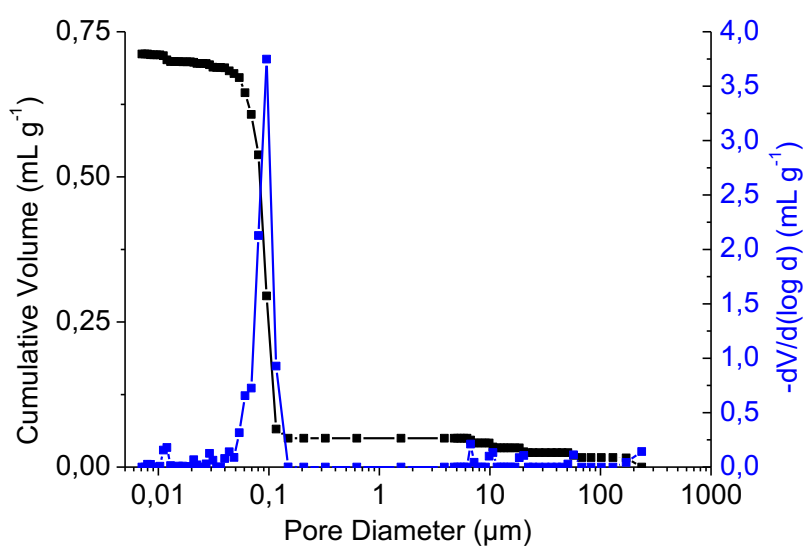

C

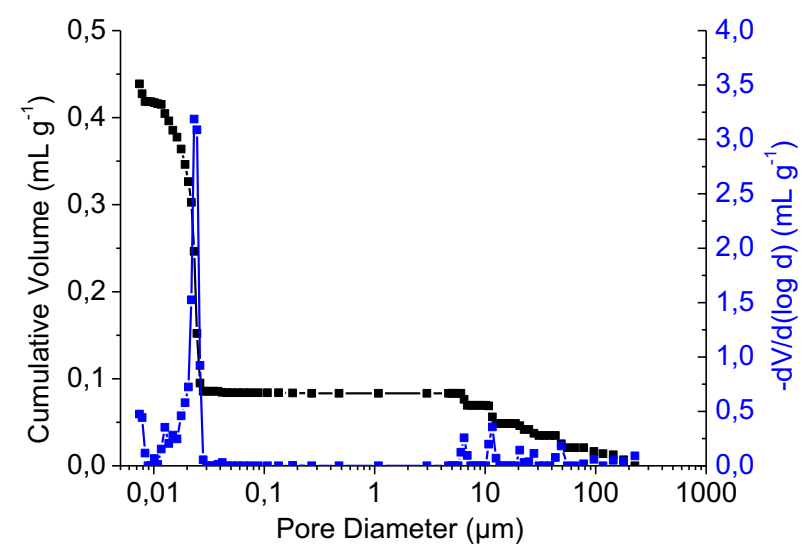


Figure S26: $\mathrm{CO}_{2}$ adsorption isotherms obtained at $273 \mathrm{~K} \mathrm{(a)}$ and at $298 \mathrm{~K}$ (b) for the different porous carbon materials prepared in this work.

a

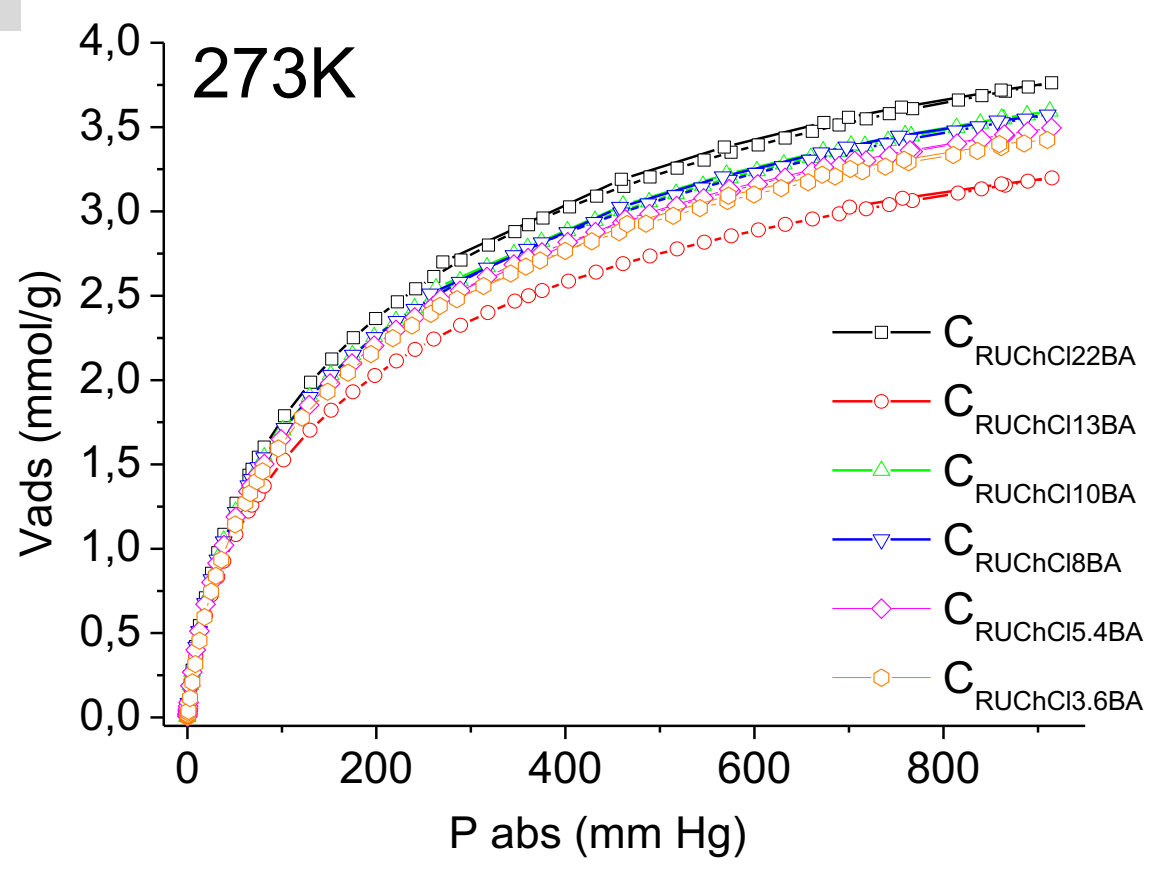

b

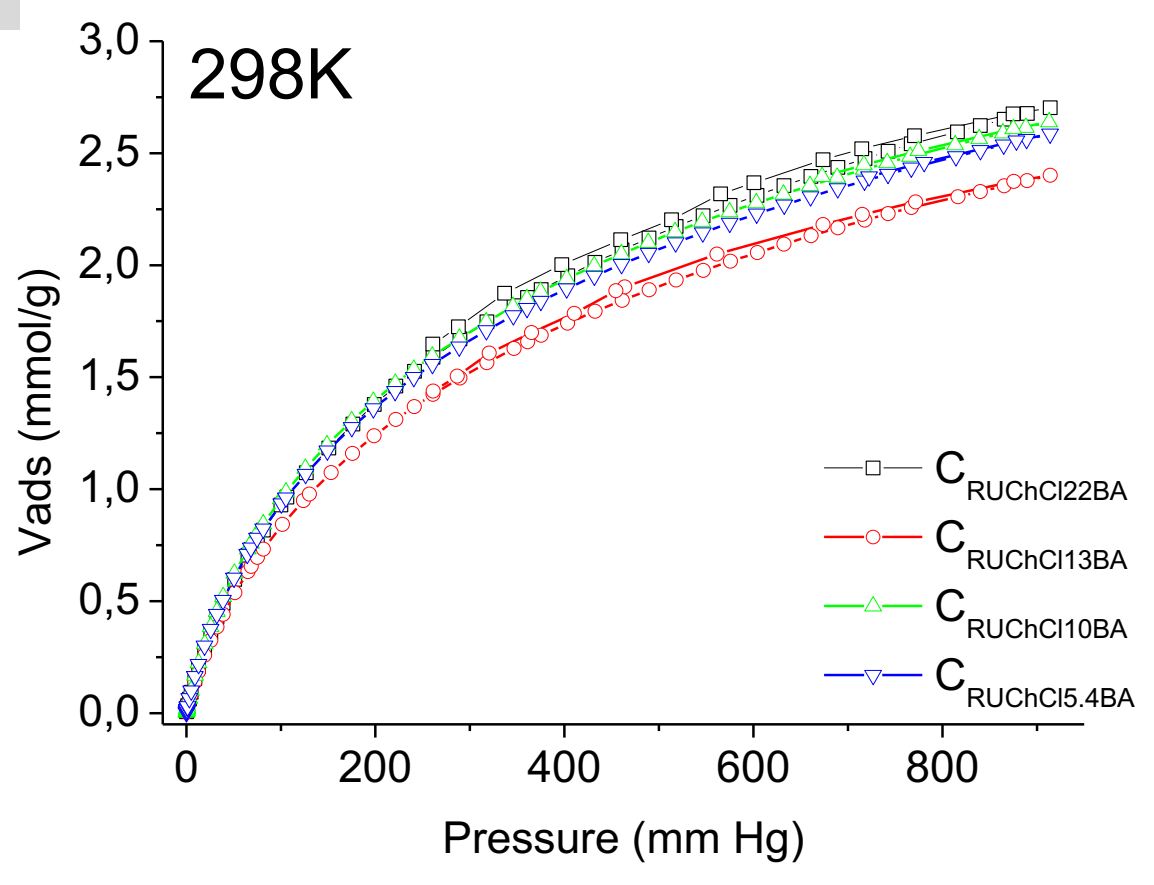


Table S8: Summary of data obtained for $\mathrm{C}_{\mathrm{RUChCInBA}}$ samples from $\mathrm{N}_{2}$ adsorption/desorption isotherms at $77 \mathrm{~K}$.

\begin{tabular}{|c|c|c|c|c|c|}
\hline Sample & $\begin{array}{c}\mathrm{S}_{\mathrm{BET}} \\
\left(\mathrm{m}^{2} / \mathrm{g}\right)^{\mathrm{a}}\end{array}$ & $\begin{array}{c}\text { Total } \\
\text { Volume } \\
\left(\mathrm{cm}^{3} / \mathrm{g}\right)^{b}\end{array}$ & $\begin{array}{l}\text { Mesopore } \\
\text { Volume } \\
\left(\mathrm{cm}^{3} / \mathrm{g}\right)^{\mathrm{c}}\end{array}$ & $\begin{array}{l}\text { Micropore } \\
\text { Volume } \\
\left(\mathrm{cm}^{3} / \mathrm{g}\right)^{\mathrm{c}}\end{array}$ & $\begin{array}{l}\text { Micropore } \\
\text { Volume } \\
\left(\mathrm{cm}^{3} / \mathrm{g}\right)^{\mathrm{d}}\end{array}$ \\
\hline $\mathrm{C}_{\mathrm{RUChCl} 3.6 \mathrm{BA}}$ & 48 & 0.03 & -- & -- & -- \\
\hline $\mathrm{C}_{\text {RUChCI5.4BA }}$ & 535 & 0.61 & 0.38 & 0.19 & 0.19 \\
\hline $\mathrm{C}_{\text {RUChCl8BA }}$ & 414 & 0.40 & 0.22 & 0.15 & 0.16 \\
\hline $\mathrm{C}_{\text {RUChCl10BA }}$ & 406 & 0.49 & 0.29 & 0.15 & 0.15 \\
\hline $\mathrm{C}_{\text {RUChCl13BA }}$ & 357 & 0.30 & 0.17 & 0.13 & 0.13 \\
\hline $\mathrm{C}_{\text {RUChCl22BA }}$ & 571 & 0.30 & 0.06 & 0.21 & 0.22 \\
\hline
\end{tabular}

Table S9: Summary of data obtained for $\mathrm{C}_{\mathrm{RUChClnBA}}$ samples from $\mathrm{CO}_{2}$ adsorption/desorption isotherms at $273 \mathrm{~K}$.

\begin{tabular}{|c|c|c|c|c|c|}
\hline Sample & $\begin{array}{c}S_{D R} \\
\left(\mathrm{~m}^{2} / \mathrm{g}\right)^{\mathrm{a}}\end{array}$ & $\begin{array}{c}S_{\text {micro }} \\
\left(\mathrm{m}^{2} / \mathrm{g}\right)^{\mathrm{a}}\end{array}$ & $\begin{array}{c}W_{\circ} \\
\left(\mathrm{cm}^{3} / \mathrm{g}\right)^{a}\end{array}$ & $\begin{array}{c}E_{o} \\
(k J / m o l)^{a}\end{array}$ & $\begin{array}{c}\mathrm{L} \\
(\mathrm{nm})^{\mathrm{a}}\end{array}$ \\
\hline $\mathrm{C}_{\mathrm{RUChCl} 3.6 \mathrm{BA}}$ & 583 & 886 & 0.26 & 30.1 & 0.58 \\
\hline $\mathrm{C}_{\text {RUChCl5.4BA }}$ & 578 & 910 & 0.25 & 30.7 & 0.56 \\
\hline $\mathrm{C}_{\mathrm{RUChCl}}$ BBA & 603 & 933 & 0.26 & 30.5 & 0.57 \\
\hline $\mathrm{C}_{\mathrm{RUChCl10BA}}$ & 611 & 944 & 0.27 & 30.4 & 0.57 \\
\hline $\mathrm{C}_{\mathrm{RUChCl13BA}}$ & 533 & 836 & 0.23 & 30.7 & 0.56 \\
\hline $\mathrm{C}_{\mathrm{RUChCl22BA}}$ & 624 & 977 & 0.27 & 30.6 & 0.56 \\
\hline
\end{tabular}

a Determined applying the DR method to the $\mathrm{CO}_{2}$ adsorption isotherms. 